\title{
Large Block Test Status Report
}

D. G. Wilder, W. Lin, S. C. Blair, T. Buscheck, R. C. Carlson (Woodward Clyde), K. Lee, A. Meike, A. L. Ramirez, J. L. Wagoner, and J. Wang (LBL)

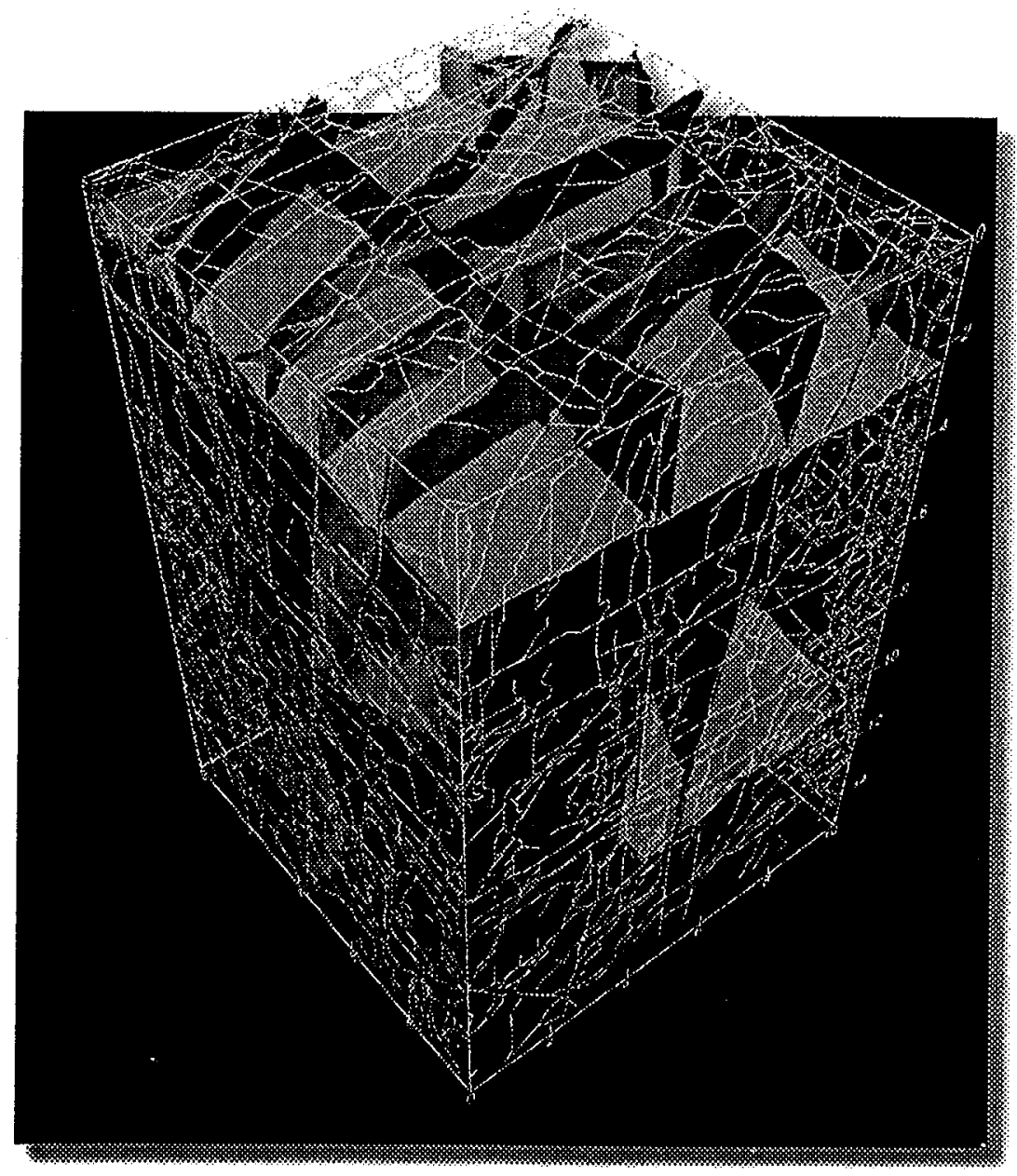

Lawrence Livermore National Laboratory Livermore, California 94551 


\section{DISCLAIMER}

This document was prepared as an account of work sponsored by an agency of the United States Government. Neither the United States Government nor the University of California nor any of their employees, makes any warranty, express or implied, or assumes any legal liability or responsibility for the accuracy, completeness, or usefulness of any information, apparatus, product, or process disclosed, or represents that its use would not infringe privately owned rights. Reference herein to any specific commercial product, process, or service by trade name, trademark, manufacturer, or otherwise, does not necessarily constitute or imply its endorsement, recommendation, or favoring by the United States Government or the University of California. The views and opinions of authors expressed herein do not necessarily state or reflect those of the United States Government or the University of California, and shall not be used for advertising or product endorsement purposes.

This report has been reproduced directly from the best available copy.

Available to DOE and DOE contractors from the Office of Scientific and Technical Information

P.O. Box 62, Oak Ridge, TN 37831

Prices available from (423) 576-8401

Available to the public from the .

National Technical Information Service

U.S. Department of Commerce 5285 Port Royal Rd.

Springfield, VA 22161

Work performed under the auspices of the U.S. Department of Energy by Lawrence Livermore National Laboratory under Contract W-7405-ENG-48. 


\section{Large Block Test Status Report}

D. G. Wilder, W. Lin, S. C. Blair, T. Buscheck, R. C. Carlson (Woodward Clyde), K. Lee, A. Meike, A. L. Ramirez, J. L. Wagoner, and J. Wang (LBL)

Lawrence Livermore National Laboratory Livermore, California 94551

Publication Date: August 26, 1997 


\section{Table of Contents}

\section{List of Figures}

Acronyms and Abbreviations

1.0 Introduction

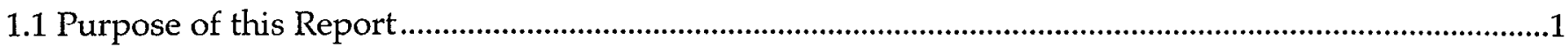

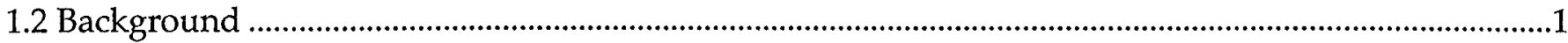

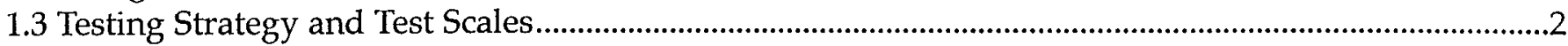

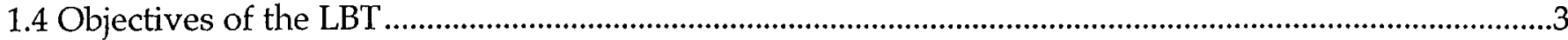

1.5 Quality Assurance (QA) Controls..................................................................................................................4

2.0 Block Preparation and Pretest Characterization …………………………..............................................

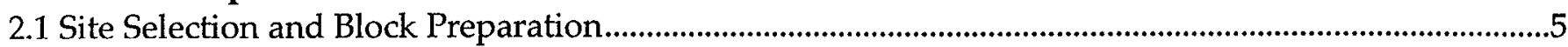

2.2 Block Characterization....................................................................................................................

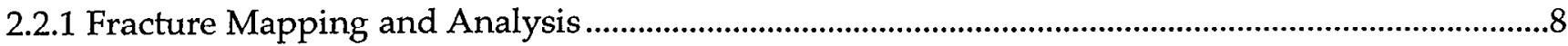

2.2.2 Permeability ...................................................................................................................................16

2.2.3 Neutron Logging and Moisture Conditions....................................................................................20

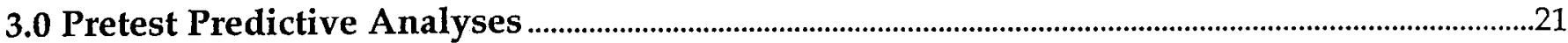

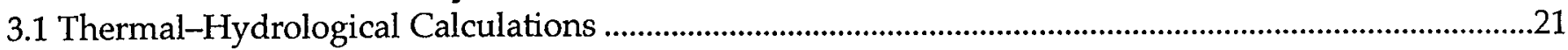

3.1.1 Homogeneous and Heterogeneous Cases ........................................................................................21

3.1.2 Thermal-Hydrologic Discrete Fracture Model ......................................................................................21

3.1.3 Three-Dimensional Thermal-Hydrologic Model ..............................................................................21

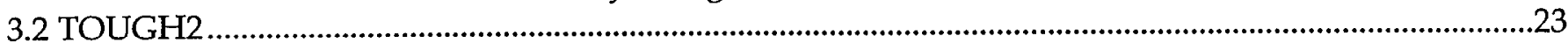

3.2.1 3D Tracer Injection Simulations in Layer Model ..............................................................................28

3.2.2 3D Tracer Injection Simulations with Vertical and Inclined Fracture Model .................................28

3.2.3 3D Thermal-Hydrological Evolution with Vertical and Inclined Fracture Model...........................29

3.3 Thermal-Mechanical Predictive Modeling …………....................................................................................29

4.0 Instrumentation and Monitoring ...............................................................................................................31

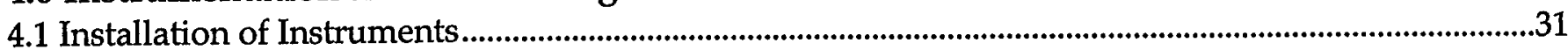

4.2 Location of Instruments .......................................................................................................................

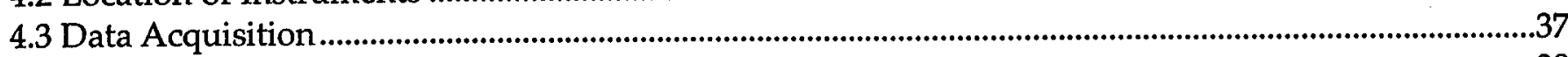

4.4 Microbial Studies ...................................................................................................................................38

4.4.1 Survival Test ..............................................................................................................................3

4.4.2 Migration Test ....................................................................................................................................39

4.5 Baseline Data Collection and Heater Turn-On .............................................................................................39

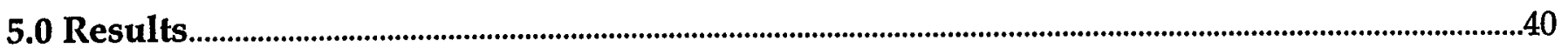

5.1 Air Injection Measurements........................................................................................................................40

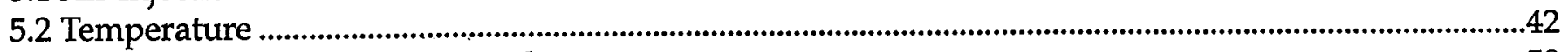

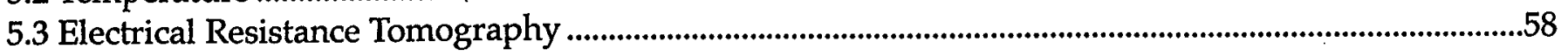




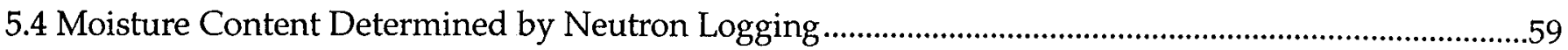

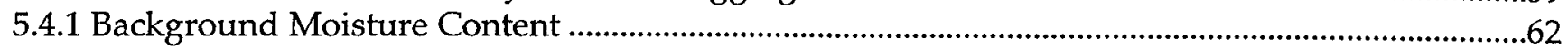

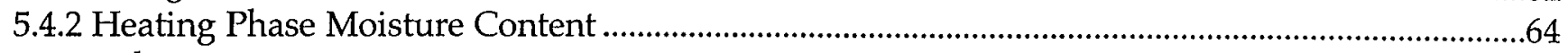

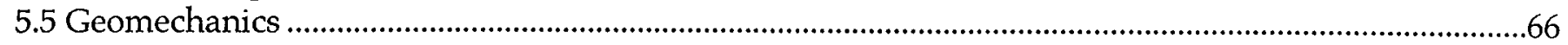

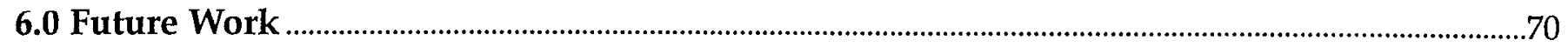

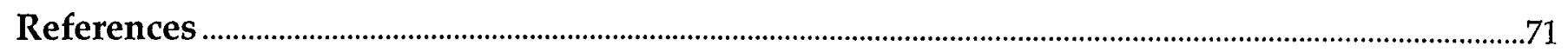




\section{List of Figures}

\section{Section 1}

Figure 1-1. Location of the Yucca Mountain site

\section{Section 2}

Figure 2-1.

Figure 2-2.

Figure 2-3.

Initial fracture mapping at Fran Ridge .5

Figure 2-4.

Drilling rig for horizontal instrumentation boreholes.........................................................6

Figure 2-5.

Excavation of level surface

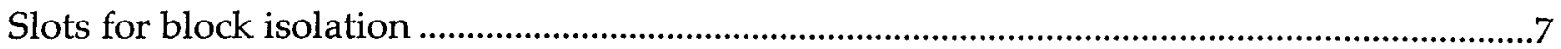

Figure 2-6.

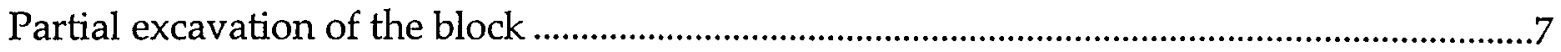

Figure 2-7.

Excavated large block at Fran Ridge ........................................................................................

Figure 2-8.

Map of surface fractures on the top face of the block

Map of surface fractures on the north face of the block...............................................................

Figure 2-9. Map of surface fractures on the east face of the block ..............................................................10

Figure 2-10. Map of surface fractures on the south face of the block............................................................11

Figure 2-11. Map of surface fractures on the west face of the block ............................................................12

Figure 2-12. 3D physical model of fractures within the block .......................................................................13

Figure 2-13. Analysis of mapped fractures displayed as stereonets ............................................................13

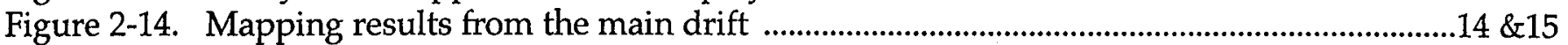

Figure 2-15. Mapping results on block surface before it was cut .....................................................................16

Figure 2-16. Fracture distribution in the main drift.............................................................................17

Figure 2-17. Air permeability from a single borehole (N1) as a function of depth.....................................17

Figure 2-18. Air permeability results for the LBT versus SHT ........................................................................17

Figure 2-19. Air permeability variations along five heater boreholes...............................................................18

Figure 2-20. Air permeability variations along three monitoring boreholes ...................................................19

Figure 2-21. Tracer breakthrough curves ........................................................................................................2

Figure 2-22. Water saturation as a function of depth........................................................................................2

\section{Section 3}

Figure 3-1. Case A rock temperatures along a vertical north-south plane ...................................................23

Figure 3-2. Case A liquid saturations along a vertical north-south plane ..................................................24

Figure 3-3. Case A vertical temperature and liquid saturation profile .........................................................25

Figure 3-4. Case A temperature and liquid saturation history at the heater level .......................................25

Figure 3-5. Case A temperature and liquid saturation history $90 \mathrm{~cm}$ above the heater level ...................26

Figure 3-6. Case A temperature and liquid saturation history $90 \mathrm{~cm}$ below the heater level...................26

Figure 3-7. Comparison of Case 1 through Case 6 temperature histories.....................................................27

Figure 3-8. Discrete fractures incorporated in the layer fracture model.........................................................28

\section{Section 4}

Figure 4-1. Location of instruments on the top surface of the large block...................................................31

Figure 4-2. Location of instruments on the north face of the large block....................................................32

Figure 4-3. Location of instruments on the east face of the large block .......................................................32

Figure 4-4. Location of instruments on the south face of the large block .....................................................33

Figure 4-5. Location of instruments on the west face of the large block ......................................................33 
Figure 4-6. Location of all boreholes in the large block.

Figure 4-7. Location of boreholes with extensometers and MPBX anchors...............................................38

\section{Section 5}

Figure 5-1. $\quad$ Air permeability profiles from 1993 and 1997 tests ...........................................................41

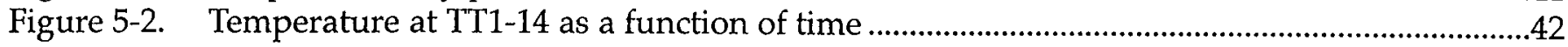

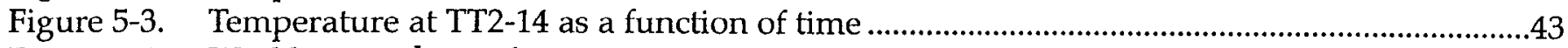

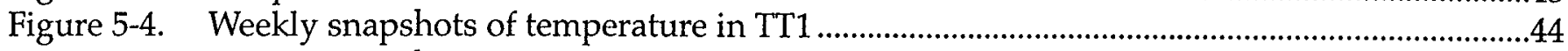

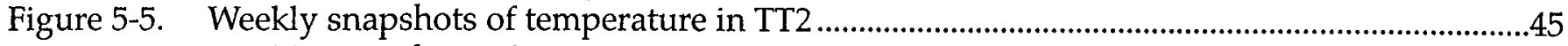

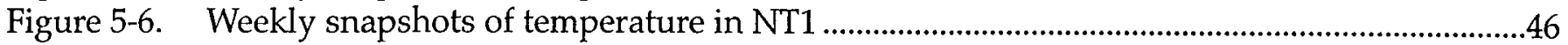

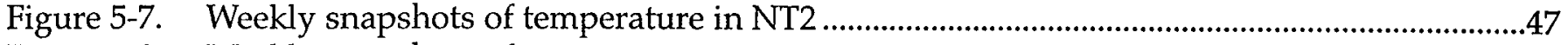

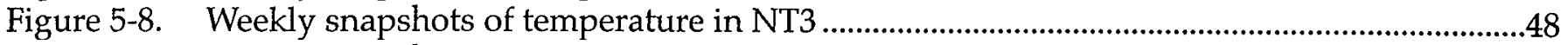

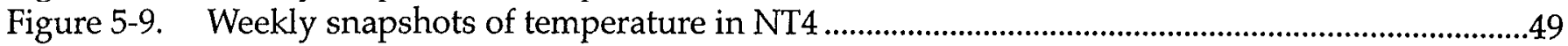

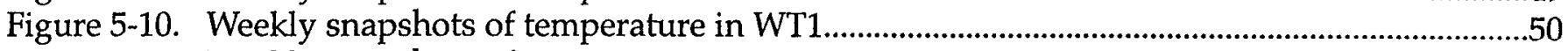

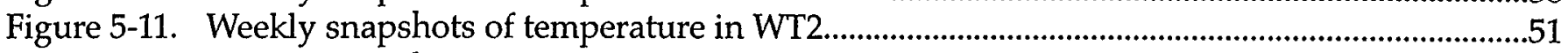

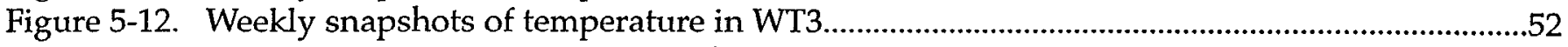

Figure 5-13. Temperature contours in a vertical cross section along TT1 ................................................53

Figure 5-14. Temperatures at TT1-8 to -13 as a function of heating time ................................................54

Figure 5-15. Temperatures at TT1-14 to -19 as a function of heating time ..................................................54

Figure 5-16. Temperatures at TT2-10 to -13 as a function of heating time ...................................................55

Figure 5-17. Temperatures at TT2-15 to -17 as a function of heating time ..............................................55

Figure 5-18. Temperatures at TT1-13 to -17 as a function of heating time ..................................................56

Figure 5-19. Temperatures at TT1-18 to -22 as a function of heating time ..................................................56

Figure 5-20. Temperatures at 'I"T2-13 to -17 as a function of heating time ................................................57

Figure 5-21. Temperatures at TT2-18 to -22 as a function of heating time ................................................57

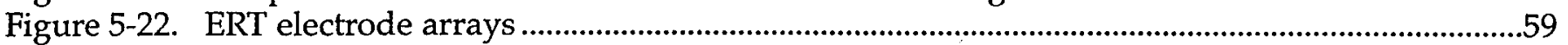

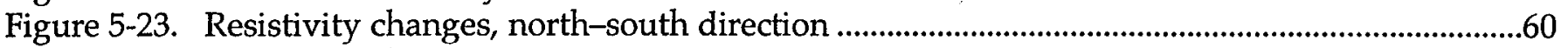

Figure 5-24. Resistivity changes, east-west direction ......................................................................................60

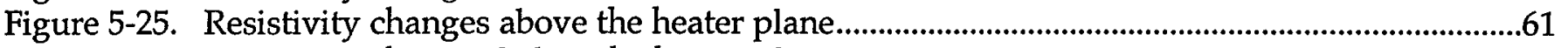

Figure 5-26. Resistivity changes below the heater plane ..............................................................................61

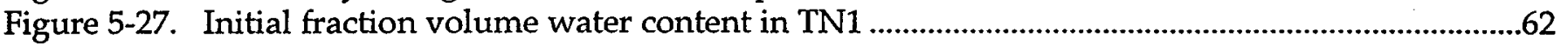

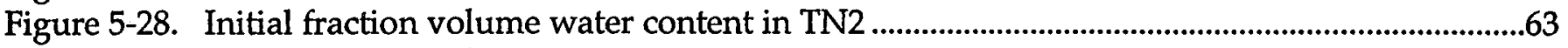

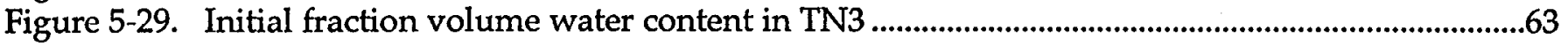

Figure 5-30. Initial fraction volume water content in TN4 .........................................................................63

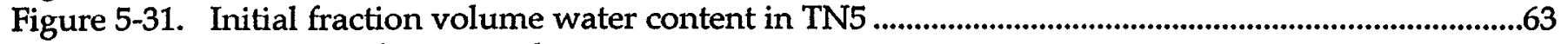

Figure 5-32. Difference fraction volume water content in TN1 ...................................................................64

Figure 5-33. Difference fraction volume water content in TN2 .................................................................65

Figure 5-34. Difference fraction volume water content in TN3 ..............................................................65

Figure 5-35. Difference fraction volume water content in TN4 ..................................................................66

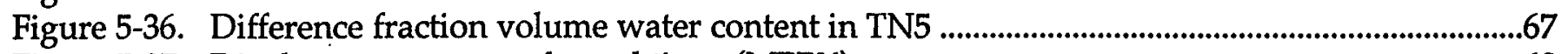

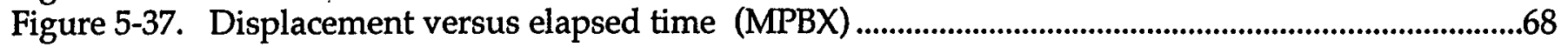

Figure 5-38. Displacement versus elapsed time for large block faces.........................................................69 


\section{Acronyms and Abbreviations}

AZ
DAS
DHLW
DOE
EBS
ERT
ESF
LA
LANL
LBL
LBT
LLNL
MPBX
NF
NFE
NFER
NTS
QA
REKA
RIB
RTD
SCP
SNF
SHT
SZ
T-H
T-H-M-C
TSPA
TSW
UZ
VA
WP
YM
YMP
YMSCO

YNA

altered zone

data acquisition system

defense high-level waste

U.S. Department of Energy

engineered barrier system

electrical resistivity tomography

Exploratory Studies Facility

license application

Los Alamos National Laboratory

Lawrence Berkeley National Laboratory

Large block Test

Lawrence Livermore National Laboratory

multiple-point borehole extensometer

near field

near-field environment

Near-Field Environment Report

Nevada Test Site

quality assurance

rapid evaluation of $\mathrm{K}$ and alpha

Reference Information Base (DOE, 1995)

resistance temperature device

Site Characterization Plan (DOE, 1988)

spent nuclear fuel

Single Heater Test

saturated zone

thermal-hydrological

thermal-hydrological-geomechanical-geochemical

Total System Performance Analysis

Topopah Spring Tuff of the Paintbrush Group

unsaturated zone

viability assessment

waste package

Yucca Mountain

Yucca Mountain Site Characterization Project

Yucca Mountain Site Characterization Project Office 


\subsection{Introduction}

\subsection{Purpose of this Report}

This report is intended to serve as a status report, which essentially transmits the data that have been collected to date on the Large Block Test (LBT). The analyses of data will be performed during FY98, and then a complete report will be prepared. This status report includes introductory material that is not needed merely to transmit data but is available at this time and therefore included. As such, this status report will serve as the template for the future report, and the information is thus preserved.

\subsection{Background}

The United States Department of Energy (DOE) is investigating the suitability of Yucca Mountain (YM) as a potential site for the nation's first high-level nuclear waste repository. As shown in Fig. 1-1, the site is located about $120 \mathrm{~km}$ northwest of Las Vegas, Nevada.

Favorable aspects of Yucca Mountain as a potential repository site include its arid nature and the sorptive properties of the rock materials. The arid environment results in unsaturated conditions at the potential emplacement horizon, which is the Topopah Spring Tuff (TSw) of the Paintbrush Group. The major advantages of unsaturated conditions are that container corrosion, waste-form leaching, and radionuclide transport mechanisms are minimized because of the lack of contact between liquid water and the waste package (WP). Although recent studies indicate that percolation fluxes may be higher than originally anticipated, the major advantages should still apply, but their significance must be evaluated.

Because a repository is required to isolate radioactive wastes for long periods of time, the evaluation of that isolation is unprecedented. Specifically, evaluation must be made of the isolation potential of the repository system, composed of both natural and engineered components, for a minimum of 10,000 years, but times could extend up to a million years. The processes that must be considered include hydrologic processes in unsaturated fractured porous rock, which is poorly understood, further complicated by the significant processes that will result from the introduction of heat generated by radioactive decay of the waste.

Because of the long time frames that must be evaluated, it will be impossible to directly measure the performance except for very small portions of the entire waste/natural system interactions. Therefore, analyses based on conceptual models using computer codes to evaluate or predict the performance will be the basis for determining the potential for the repository to properly function (that is, to provide isolation) over the long times required. Such an analysis entails more than merely achieving a scientifi-

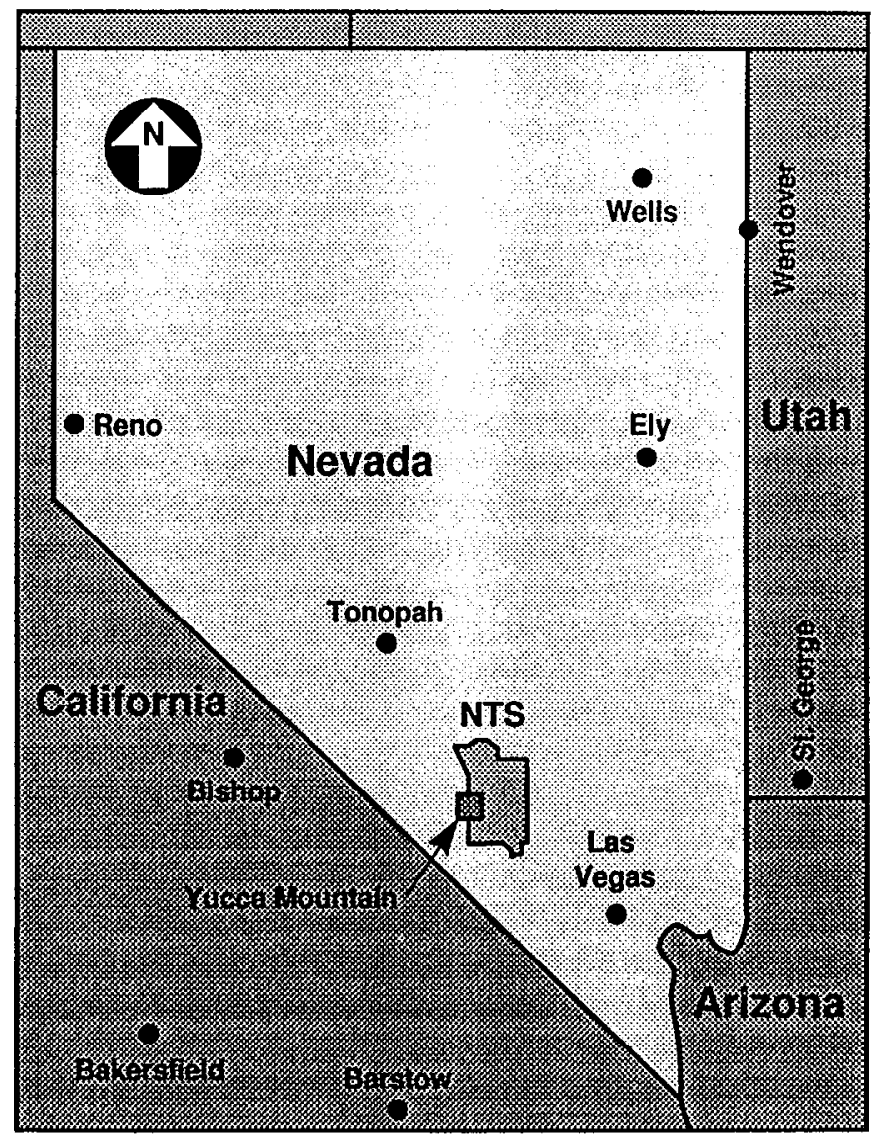

Figure 1-1. Location of the Yucca Mountain site. 
cally believable view of the repository. It must provide sufficient rigor in evaluation of the models and assumptions to be useful in a regulatory process wherein the analyses will be subject to challenge by those opposed to the project. Thus, the models need to be tested and verified to the extent possible.

\subsection{Testing Strategy and Test Scales}

The testing strategy that has been developed is designed to evaluate the models by accelerating portions of the testing to address different segments of the time frames of interest and to look at the functional relationships of different geometric scales. The Large Block Test (LBT) was designed to be one of a series of tests at different scales and conditions that assist in defining the physical processes that need to be considered in models of a potential repository in Yucca Mountain and to provide real-world testing of the conceptualizations and model approaches used to evaluate the behavior or development of the environment that interacts with the Engineered Barrier System (EBS). A more detailed discussion of the processes that are considered to be important in terms of testing is contained in the Near-Field and Altered-Zone Environment Report (Wilder, 1997). Planning for the field testing is discussed in Buscheck et al. (1993, 1995).

Because no single test can address all of the issues that must be studied for a potential repository, several different test approaches are being used to assess the models. The types of tests, identified in order from the smallest geometric scale to the largest, and generally from the shortest duration to the longest, fall into the following categories:

- Laboratory tests of core-size samples.

- Laboratory tests of $\sim 1$-m-scale block samples (small block tests).

- Large block test (LBT).

- In situ tests, such as the Single Heater Test (SHT) and the Drift Scale Test.

- Confirmation tests.

Laboratory testing on core-sized samples has been used to measure properties of intact samples as well as processes that occur within the intact core sample. These laboratory tests essentially measure matrix properties and processes or, at most, properties of single fractures. The duration of such tests tends to be short, usually a few hours or days. However, imbibition or similar measurements may require tests of many days, and the longest tests that involve geochemical processes may require several months.

The next scale of tests include those performed in the laboratory on block samples that are as large as $1 \mathrm{~m}$ on a side. These samples are large enough to allow testing of fracture or discontinuities and even some multiple-fracture responses and interactions. To distinguish the larger scale represented by the LBT from the 1-mscale block tests, these latter tests are sometimes designated as the small block tests (although their dimensions are not small). The small block tests measure block properties, including fractures. They provide an understanding of the processes and properties of a fractured rock mass and help develop a functional relationship in terms of the influence of scale of testing on properties and processes.

The next scale of testing is represented by the LBT, which is unique in both size and test conditions. The LBT is a critical test because it is of sufficient size to incorporate a fracture system that is representative of the distribution of fracture dimensions and characteristics that would likely be present in a repository-with the possible exception of major geologic structures, such as faults. The LBT location was chosen to include large, through-going fractures as well as small, healed fractures that are of limited extent. The LBT location also includes a variety of fracture sizes, connectivities, and characteristics that fall between the bounds of the large and very small fractures. The LBT allows for boundary controls and monitoring that are somewhat similar to those typical of laboratory studies, and it allows for 3D characterization and monitoring. The unique combination of size with boundary controls of the LBT allows processes to be evaluated and models to be tested more completely than in tests of any other scale. The focus of the LBT is, thus, to evaluate and test process understandings, conceptualizations, and models. This test is not intended to characterize $\mathrm{YM}$ or to measure responses of potential repository horizon rock mass. Rather, its purpose is to provide testing and data related to the conceptual understanding of processes and to build 
confidence in models by testing against appropriately sized rock mass responses.

The next scale of planned tests are in situ tests, such as the Single Heater Test (SHT), and the Drift Scale Test. These are relatively large tests that involve hundreds of cubic meters and extend for many months or years. They incorporate sufficient volumes of rock mass to be representative of total rock-mass responses (with the caveat that fracture domains can vary, and faulting is a localized phenomena that might not be well represented in field studies). These tests have boundary conditions that are less controlled than those of the LBT. Thus, they are focused more on hypotheses testing for processes that are scale-dependent (thus cannot be tested at the LBT) and on characterization of repository rockmass behavior. The in situ tests focus on testing of the actual repository rock mass under conditions of stress, and so forth, that are more representative of the repository. Whereas these tests last several years, they are nonetheless highly accelerated in comparison with the rates and other processes that will be typified by an actual repository. In a repository, processes such as heating, moisture redistribution, and rock-water interaction will occur at time scales of thousands of years.

The final type or scale of tests are confirmation tests, wherein the rock mass is monitored for the processes and parameters that are associated with the actual emplacement waste.

Confirmation testing does not involve issues of scale, because the actual repository and its associated process rates will be monitored. Thus, one of the primary purposes of such testing is to confirm that the testing performed at smaller scales and abbreviated time frames accurately reflects or predicts the behavior of the system. However, even this type of testing or monitoring will not address all of the issues because only very early responses can be monitored ( 100 to 200 years as opposed to 10,000 to $1,000,000$ years).

\subsection{Objectives of the LBT}

As mentioned, the LBT is one of a series of tests intended to assist in defining the physical processes that must be considered in models of a potential repository at Yucca Mountain. As such, it provides real-world testing of the conceptual- izations and model approaches used to evaluate the behavior or development of the environment that interacts with the EBS. Thus, the LBT is focused on what has been defined as the nearfield environment (NFE) and the altered zone (AZ) environment (Wilder, 1997). The LBT is not intended to characterize the properties or processes that are unique to the potential YM repository horizon. Rather, its purpose is to test the conceptualizations in a representative rock mass so that the tools are appropriate for characterization and analyses of YM.

The question as to how best to build confidence in models has been the focus of considerable discussion over the years. Validation of models was discussed frequently during the Yucca Mountain Site Characterization Plan (SCP; $\mathrm{DOE}, 1988$ ), and considerable debate developed over how to validate models [see, for example, Buscheck in the Near-Field Environment Report, Vol. II (NFER) (Wilder, 1996)]. The concept of testing to build confidence in models replaced the concept of validation, and this is the objective of the LBT. As noted by Konikow and Bredehoeft (1992), models "...provide a means to organize our thinking, test ideas for their reasonableness, and indicate which are the sensitive parameters. They point the way for further investigation. They help formulate critical experiments with which to test hypotheses." Buscheck (1993) notes that no individual model of the repository-unsaturated zone-saturated zone system is itself a "valid" representation. However, the combined use of suites of model calculations provides a means to identify critical dependencies, evaluate worst-case scenarios, and develop fundamental hypotheses, which can be addressed by subsequent analysis and testing. Buscheck $(1993,1995)$ identified a list of major hypotheses, based on model analyses, that should be tested in field tests. He noted in Volume II of the NFER (Wilder, 1996) that field tests, including the LBT performed at Fran Ridge and in situ thermal tests in the ESF, will provide the most conclusive means of evaluating issues associated with thermal loading, including resolution of the major hypotheses.

The objectives of the LBT are based on numerical modeling of the important aspects of a potential repository, on previous laboratory and field studies, and on recommendations derived from 
the results of those studies. One of the main determinants of what the NFE and AZ environments will be is the coupling of heat from radioactive decay of the waste to the geologic materials and water present within those materials. As noted in the Volume I of the NFER (Wilder, 1997), many coupled processes must be understood to determine the environmental conditions of the EBS . Understanding the coupling is one of the primary objectives of the LBT.

Because the LBT is designed to create controlled boundary conditions, it becomes possible to observe and test some of the specific coupled thermal-hydrological-geomechanicalgeochemical ( $\mathrm{T}-\mathrm{H}-\mathrm{M}-\mathrm{C})$ processes. The LBT can help determine: (1) the dominant heat-transfer mechanism, (2) if there is coincidence of the dryout zone and the boiling-point isotherm, (3) the relation between rewetting and cooling of the dryout zone, (4) refluxing of condensate water above the heated zone, (5) the change of water chemistry in the condensate zone, and (6) the mechanical responses of the block.

The objectives of the LBT, as stated in the activity plan (Lin, 1994), are to:

1. Assist in understanding the processes that are expected to occur within the NF and $\mathrm{AZ}$ environments.

2. Provide a test of the models and conceptualizations.

3. Allow evaluation of techniques and equipment that will be used in subsequent in situ tests. (This objective is less applicable because the LBT did not start early enough to provide these data prior to fielding of the in situ tests.)

Major issues, related to the first two objectives listed above, that will be tested at the LBT are to determine the likelihood of refluxing and the conditions under which it can occur. More specifically, we need to determine whether condensate can build up above the heated zone (and thus the repository drifts) or if condensate will penetrate the boiling zone, whether dryout can occur, and whether temperatures will be limited to the boiling point.
One of the major advantages of the LBT is that geochemical processes can be evaluated by carefully observing the mineralogy that develops within the block in response to the refluxing. The LBT is the only field-scale test that allows for such analysis. Although this is not the only, or even primary, objective of the test, it is nonetheless a critically important objective of the LBT. In addition, the LBT has as secondary objectives to evaluate the responses of introduced materialsspecifically cement and steels typical of WPs-to the potential environmental conditions of the repository. Coupons of certain candidate WP materials placed in the block will be examined both before and after the test for their response to the environment. Furthermore, the LBT provides an opportunity to evaluate microbial survival and mobility.

Finally, the LBT will provide tests on a block of rock that is closer in scale to the repository than previous heater test blocks (Zimmerman et al., 1986). The rock mass can be characterized from five exposed surfaces and multiple boreholes. The block will be dismantled after testing for further characterization, especially for studying rock-water interactions.

The LBT does not have as one of its primary purposes the characterization of property values. This is in contrast to the important role of the in situ thermal tests identified by Buscheck (1997), in calibration of thermal-hydrological properties that are required by models supporting the Total System Performance Analysis for Viability Assessment (TSPA-VA) and the TSPA for License Application (TSPA-LA).

\subsection{Quality Assurance (QA) Controls}

Data and results reported here and in monthly data reports are those transmitted electronically by e-mail. The QA data set is that which is archived on CD-ROM, copies of which are included with this report. Until the data transmitted electronically can be compared with the CD-ROM, the quality must be considered to be undetermined. 


\subsection{Block Preparation and Pretest Characterization}

\subsection{Site Selection and Block Preparation}

The site at Fran Ridge, Nevada Test Site, was selected for the LBT because of its desirable rock type, fracture characteristics, and accessibility. The LBT was first located, in general terms, on the basis of a location that was cleared from an environmental standpoint for development but that was also in the general vicinity of the two USGS test pits. The location chosen was on a slope on the side of Fran Ridge.

The general location was stripped of vegetation and soil covering to expose the rock. The area was then mapped, noting observed fractures. The mapping was corrected for the slope of the outcrop by use of levels, plumb bob, and tape measures. The results of the mapping are shown in Fig. 2-1. Based on this mapping, it was judged that the general site was adequate for the LBT, specifically that the rock fracturing and matrix block sizes were consistent with what was anticipated to exist at YM (Wilder, 1993). Block preparation proceeded by excavating a level surface from which to work (Fig. 2-2) and providing a sump to collect and recirculate water. After the surface was leveled, more detailed mapping was performed, and final block locations were selected.

(Continued on page 13.)

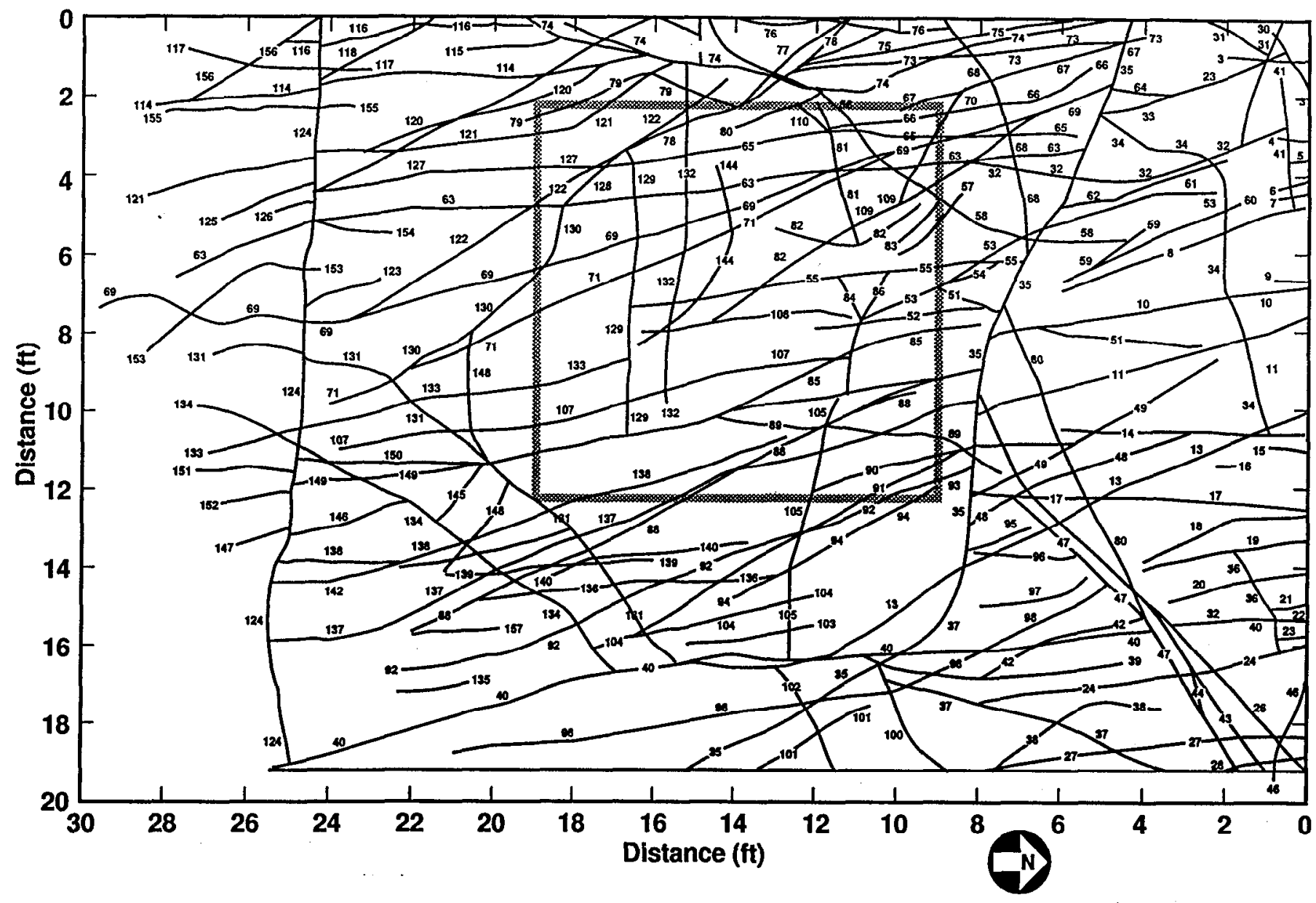

Figure 2-1. Initial fracture mapping at Fran Ridge (plan view). 
Possible locations for the LBT were then selected where a sufficient number of fractures would be included in the block to account for observed flow in fractured rock wherein less than $10 \%$ of the fractures were responsible for $90 \%$ of the flow. It was judged that approximately 100 fractures needed to be present to have a few fractures that would be open to flow of the magnitudes of interest. Pretest thermal-hydrological $(\mathrm{T}-\mathrm{H})$ and thermal-mechanical $(\mathrm{T}-\mathrm{M})$ calculations were performed to verify that the block size was suitable. It was deemed important to measure permeabilities to ensure that there were adequate zones for the tests and that the fractures were neither too open because of being near the surface nor too plugged by calcite. (The top portion of rock was removed not only to obtain a level surface but to place the test beneath a possible zone where calcite filled the fractures, as was observed in the two USGS test pits or holes.) Therefore, a pattern of instrumentation and measurement boreholes was laid out that could also serve as exploratory boreholes. The pattern was arranged so that the LBT could be centered around one of two different boreholes that would become either the center or edge of the array of instrument boreholes. Air permeability tests were then conducted to assist in selecting a final location that had sufficient permeability for the test to be conducted.

Vertical instrument holes within the block were drilled and cored before the sawing and excavation. The block was isolated by cutting slots, as shown in Fig. 2-3. A belt saw was used to saw four vertical slots that formed the boundary of the large block. After these slots were cut, the slots were filled with expanding foam in plastic bags to support the block and to isolate it from the effects of excavation-induced damage, e.g., from vibration. A large back-hoe or excavatormounted hydraulic hammer ram (jack hammer) was used to excavate the surrounding rocks in about 2- to 3-foot vertical sections (see Fig. 2-4, which shows the partial excavation). The top of the block was trimmed to its final surface using a wire saw, and a top cross member (welded steel
Figure 2-2. Excavation of a level surface.

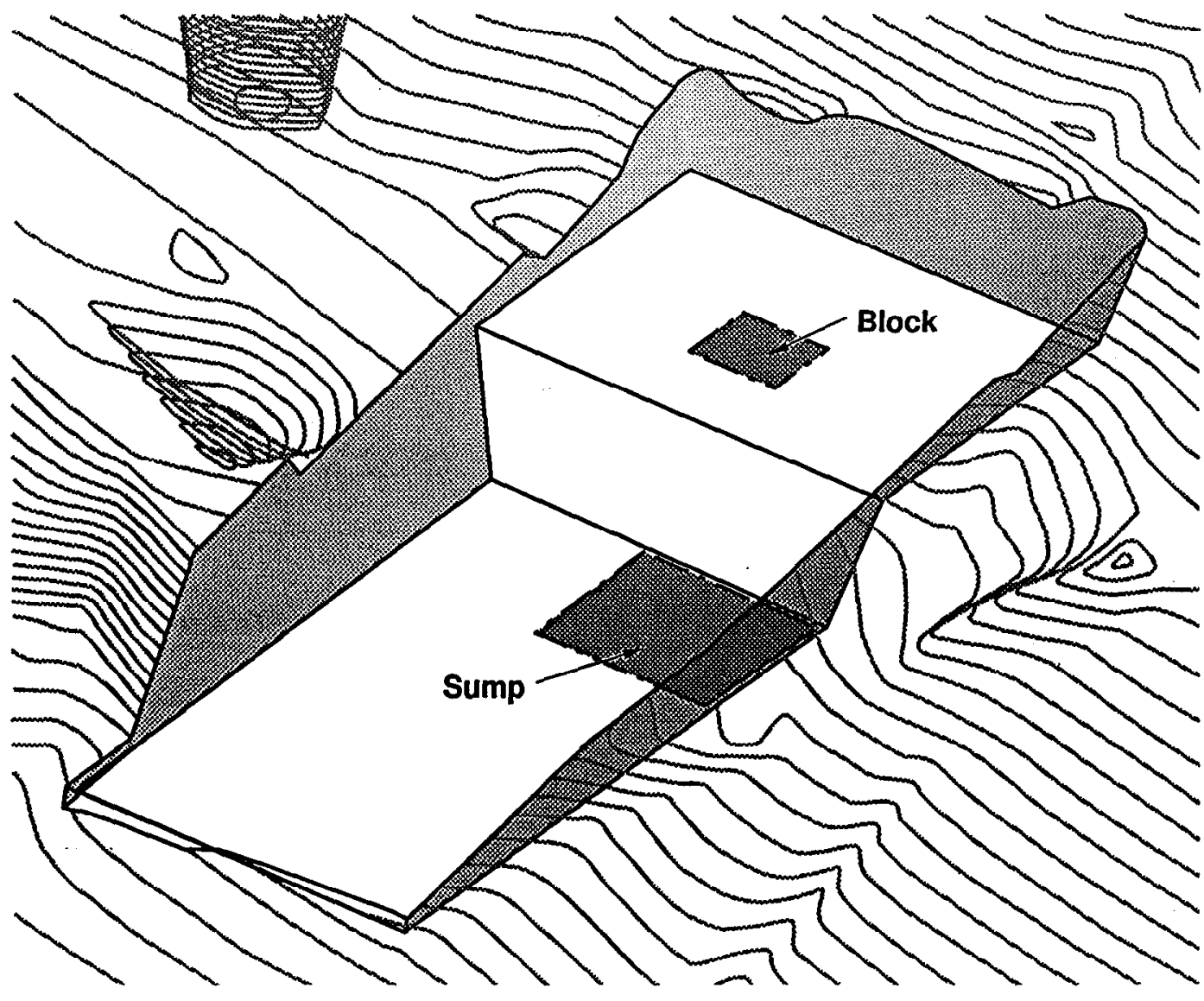

Large Block Test Status Report 
I-beams) was placed on the top and connected to rock bolts on the four sides and center. Excavation then proceeded in 2- to 3-foot stages with the emplacement of trucker-type straps. A commercial wire saw was used to trim the top of the block. Some smaller blocks of rock, about $30 \mathrm{~cm}$ in size, were collected within a $1-\mathrm{m}$ region around the large block for laboratory tests. By this excavation process, a block of Topopah Spring Tuff measuring $3 \times 3 \times 4.5 \mathrm{~m}$ was isolated at Fran Ridge (Fig. 2-5).

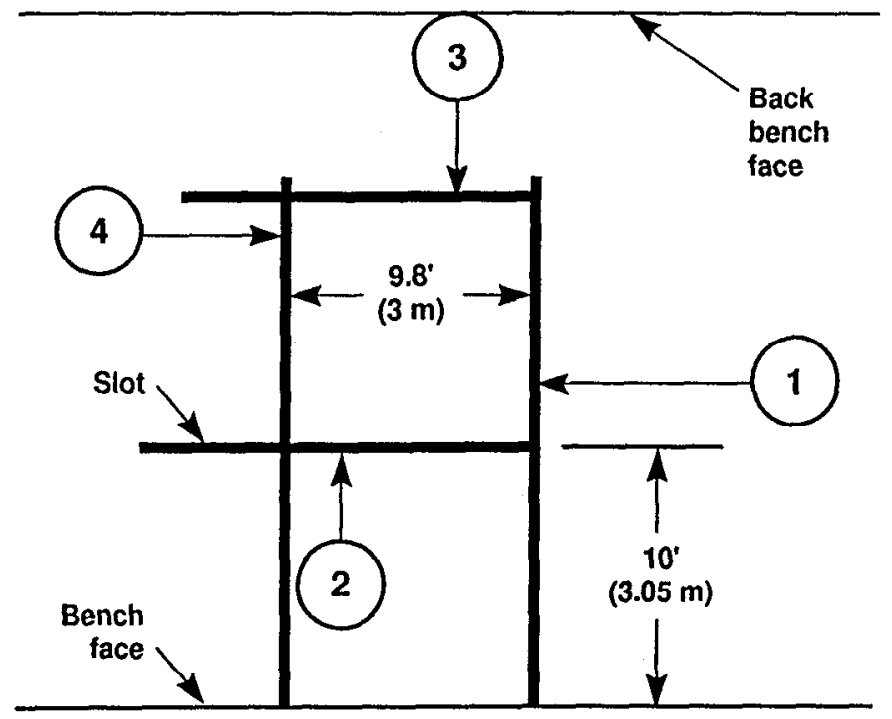

Figure 2-3. Slots for block isolation.

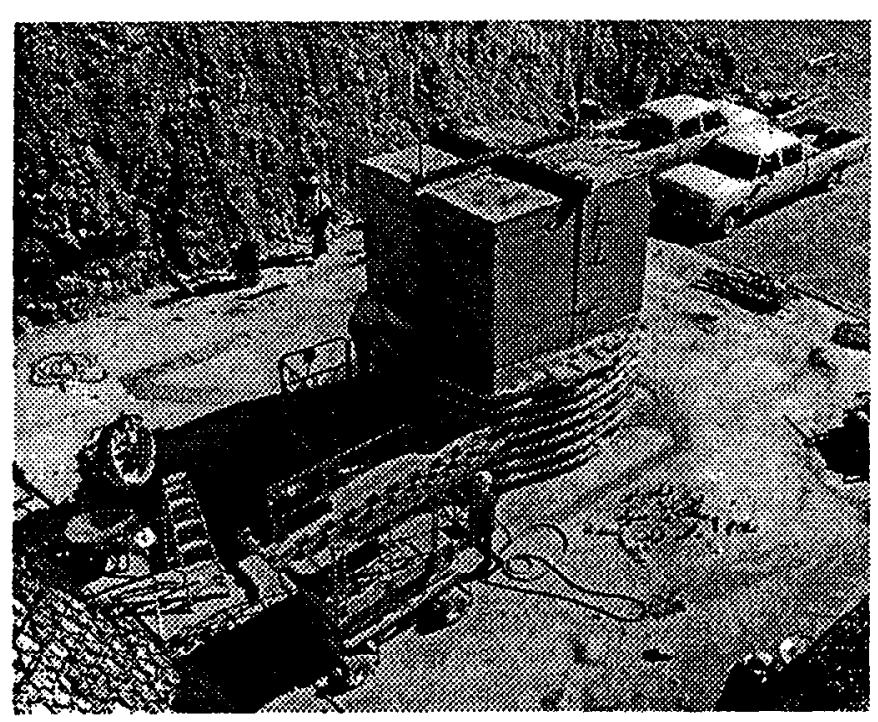

Figure 2-5. Excavated large block at Fran Ridge.
After block excavation was completed and the surfaces were mapped, horizontal (vertical holes had been drilled prior to excavation) boreholes were located for the emplacement of instrumentation and heaters, as discussed in Section 4. The horizontal instrumentation boreholes were drilled using a drill rig mounted on a built-up steel platform (Fig. 2-6). The location of boreholes and types of instruments are discussed further in Section 4 . In addition to the horizontal instrument

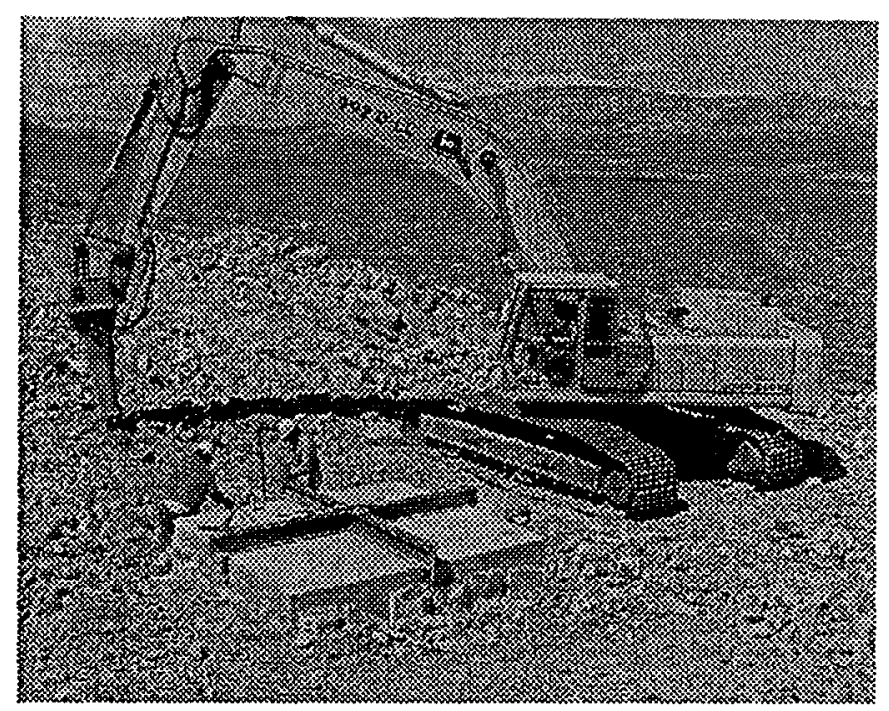

Figure 2-4. Partial excavation of the block.

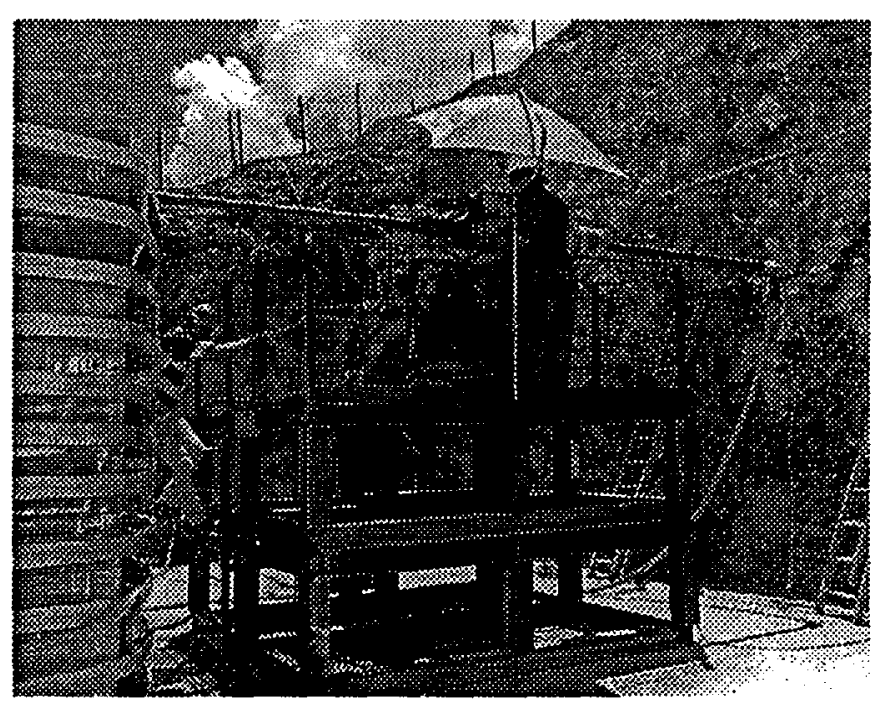

Figure 2-6. Drilling rig mounted on a steel platform to drill horizontal boreholes. 
holes, a series of five heater holes were drilled from

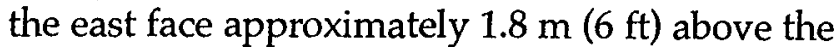
pad at the base of the block and equally spaced to form a line of horizontal heater holes.

\subsection{Block Characterization}

Block characterization began with mapping and analysis of the distribution of fractures, mechanical and hydrological properties, the initial moisture content, and mineralogical composition of the matrix and the fracture coating.

\subsubsection{Fracture Mapping and Analysis}

Fractures were carefully mapped as shown in Figs. 2-7 through 2-11 (top, north, east, south, west, respectively), and information on fracturing was collected from cores and video logs of boreholes. The information was analyzed by two methods. First, the fractures were evaluated for their significance on the basis of size, extent, and other considerations, and the major fractures were selected to be included in a three-dimensional (3D) model. Examples of the fractures so modeled

(Continued on page 13.)

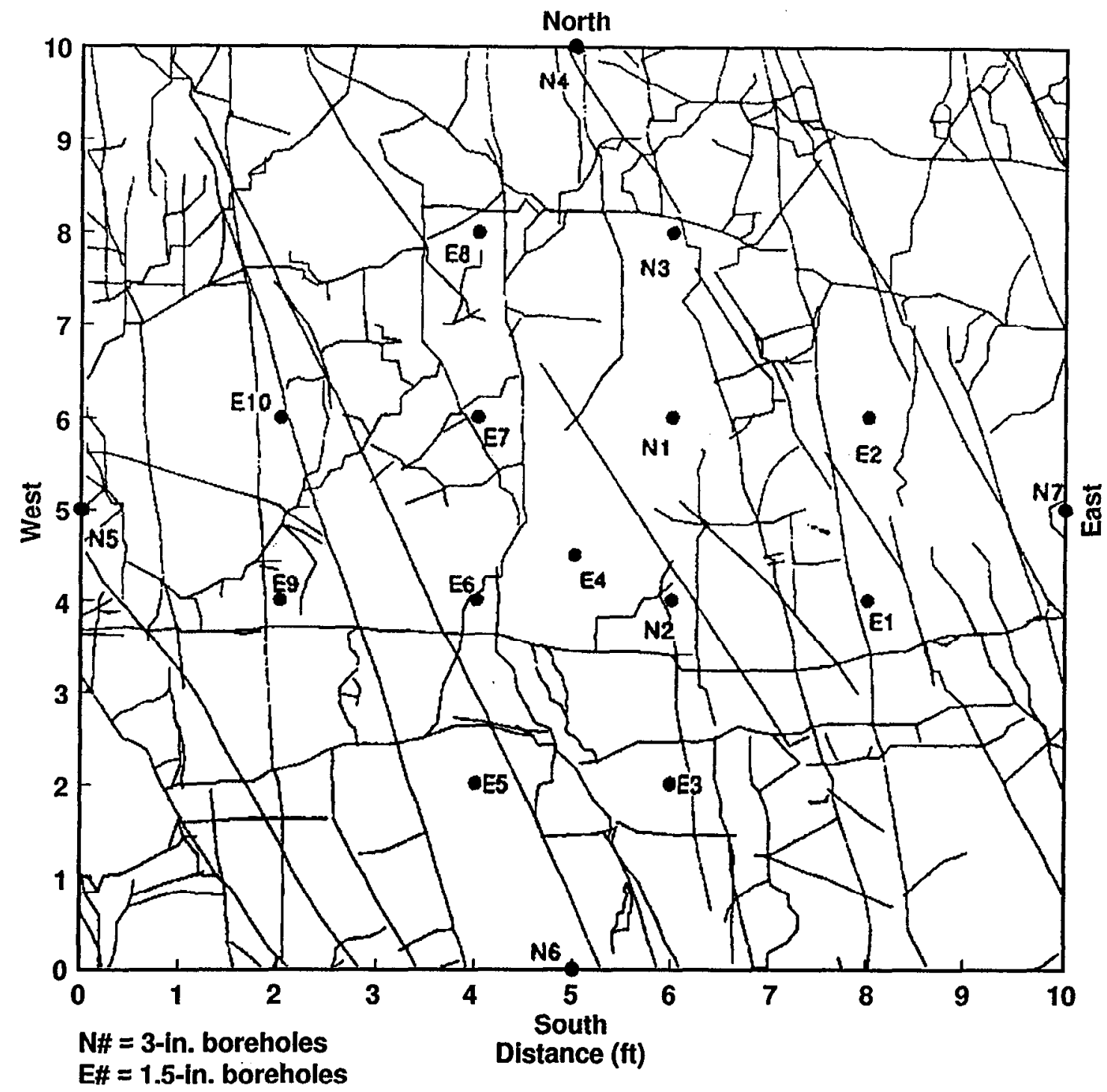

Figure 2-7. Map of surface fractures on the top face of the block. Hole N1 is the location of the air permeability test. 


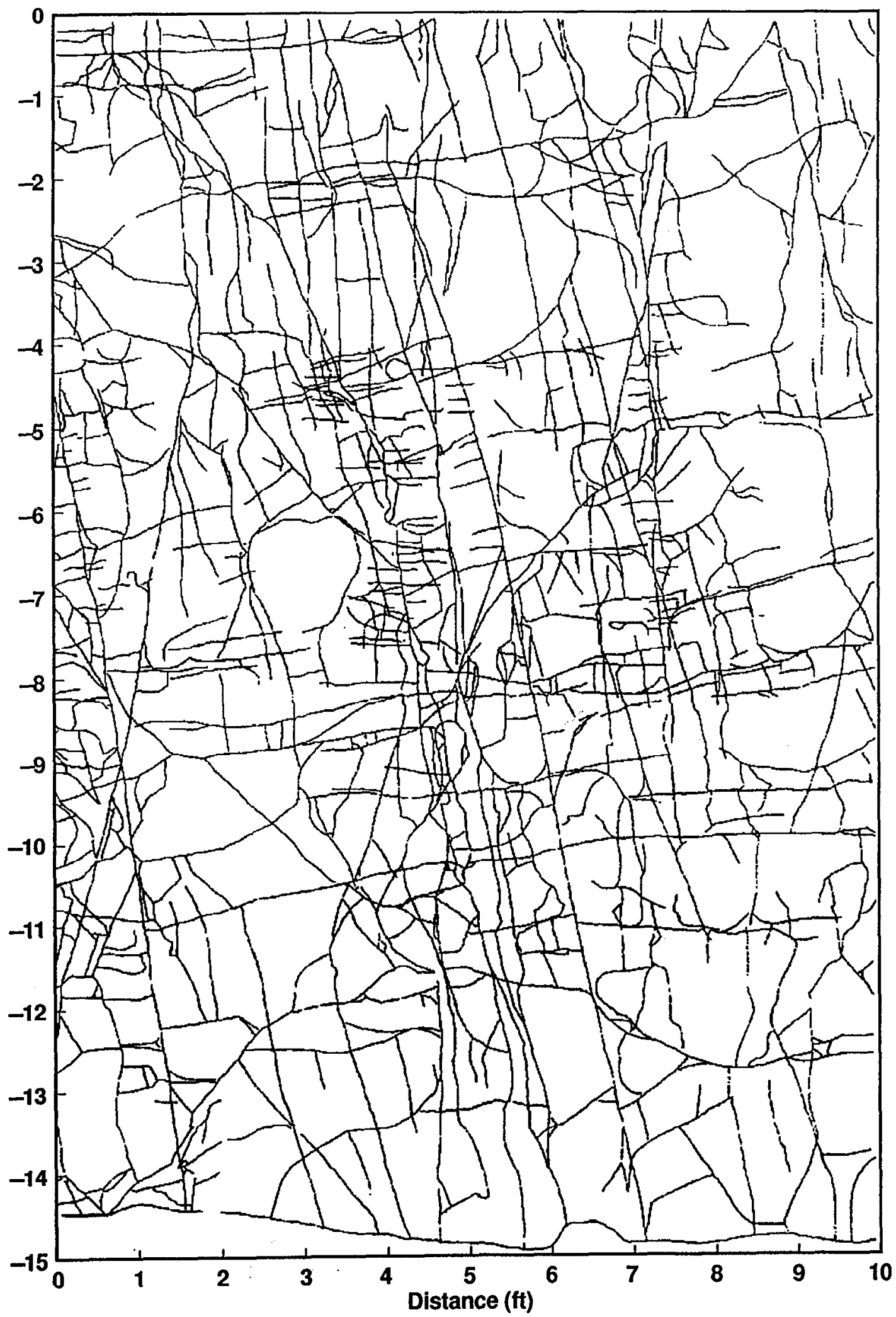

Figure 2-8.

Map of surface fractures on the north face of the block. 
Figure 2-9.

Map of surface fractures on the east face of the block.

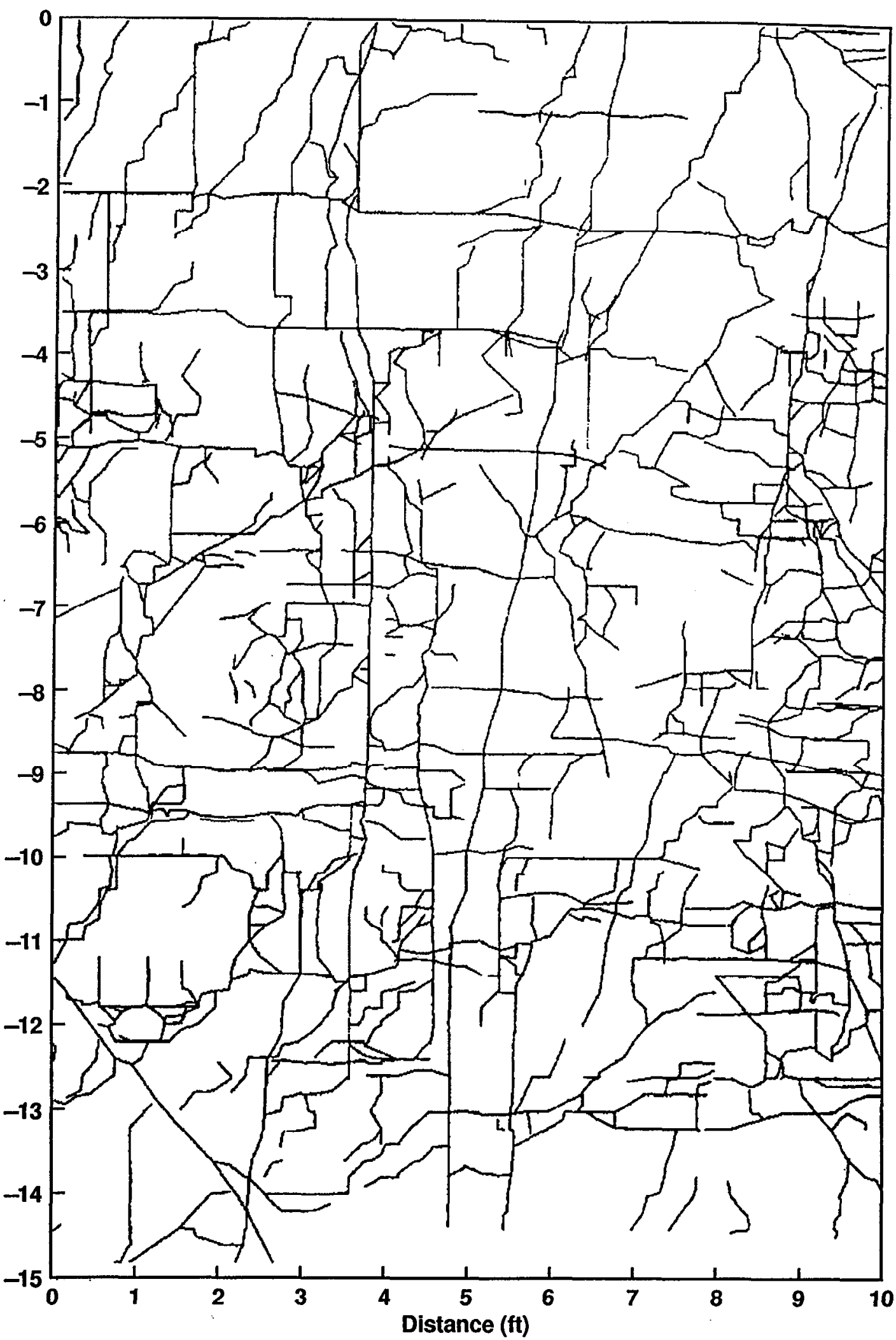




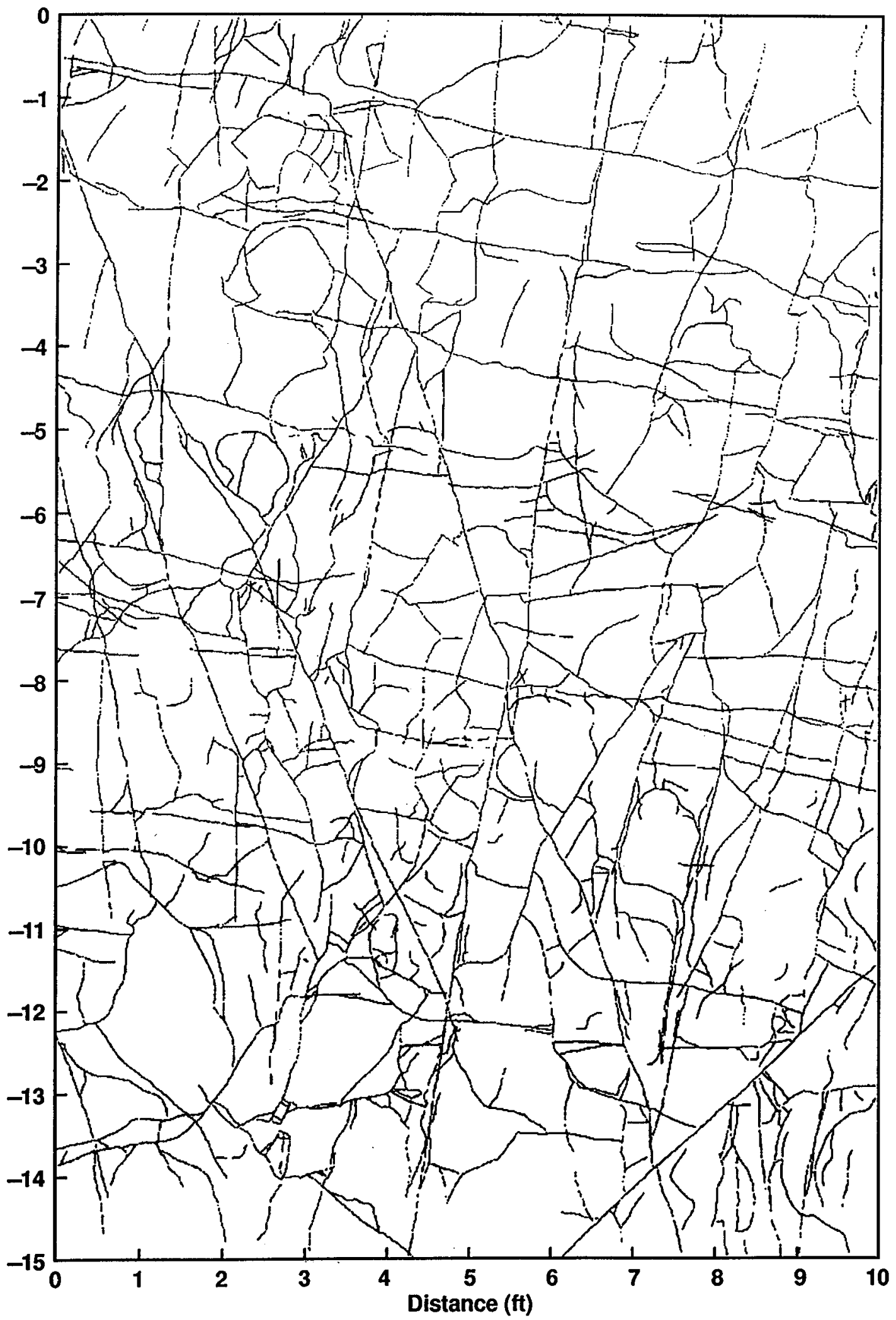

Figure 2-10.

Map of surface fractures on the south face of the block. 
Figure 2-11.

Map of surface fractures on the west face of the block.

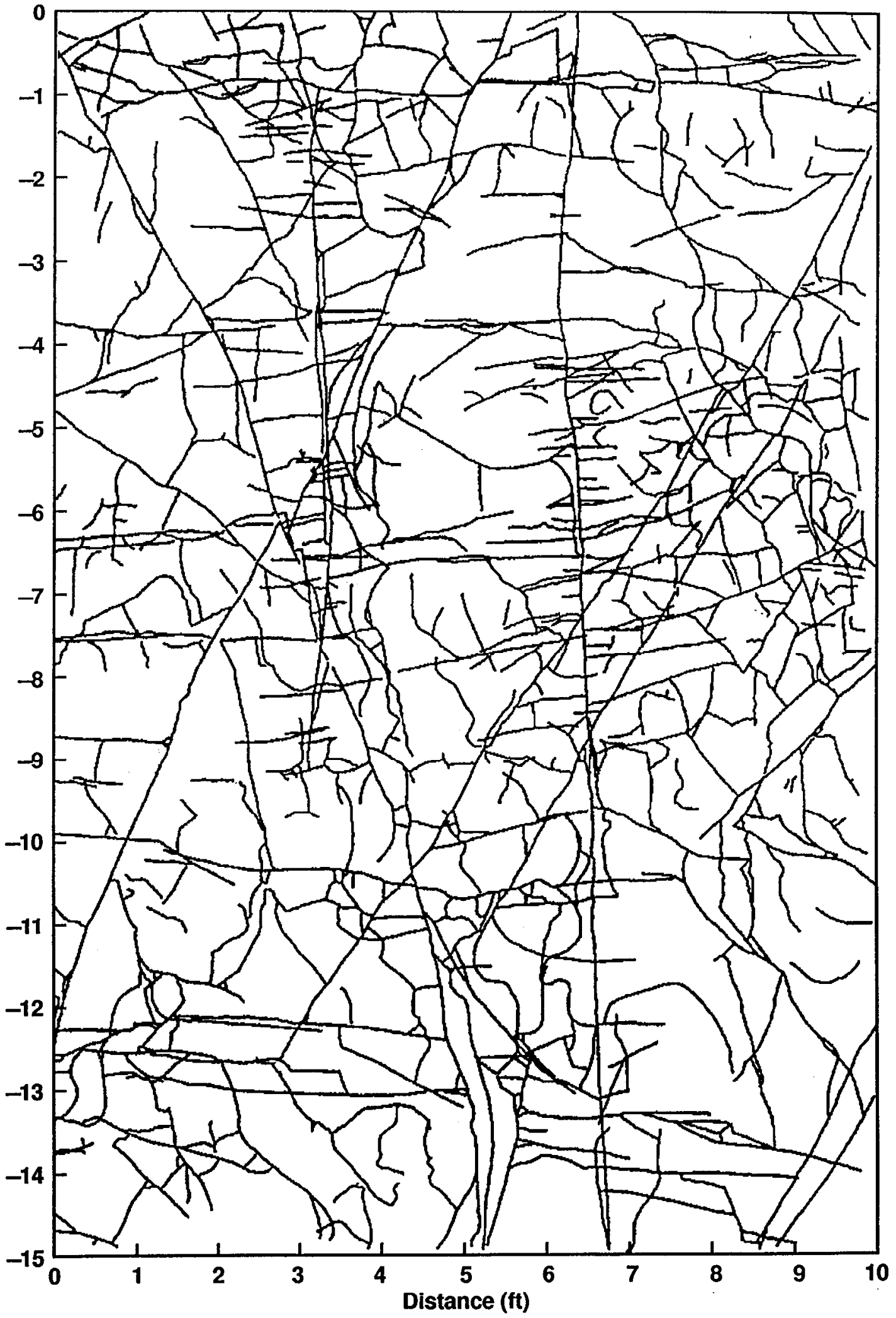



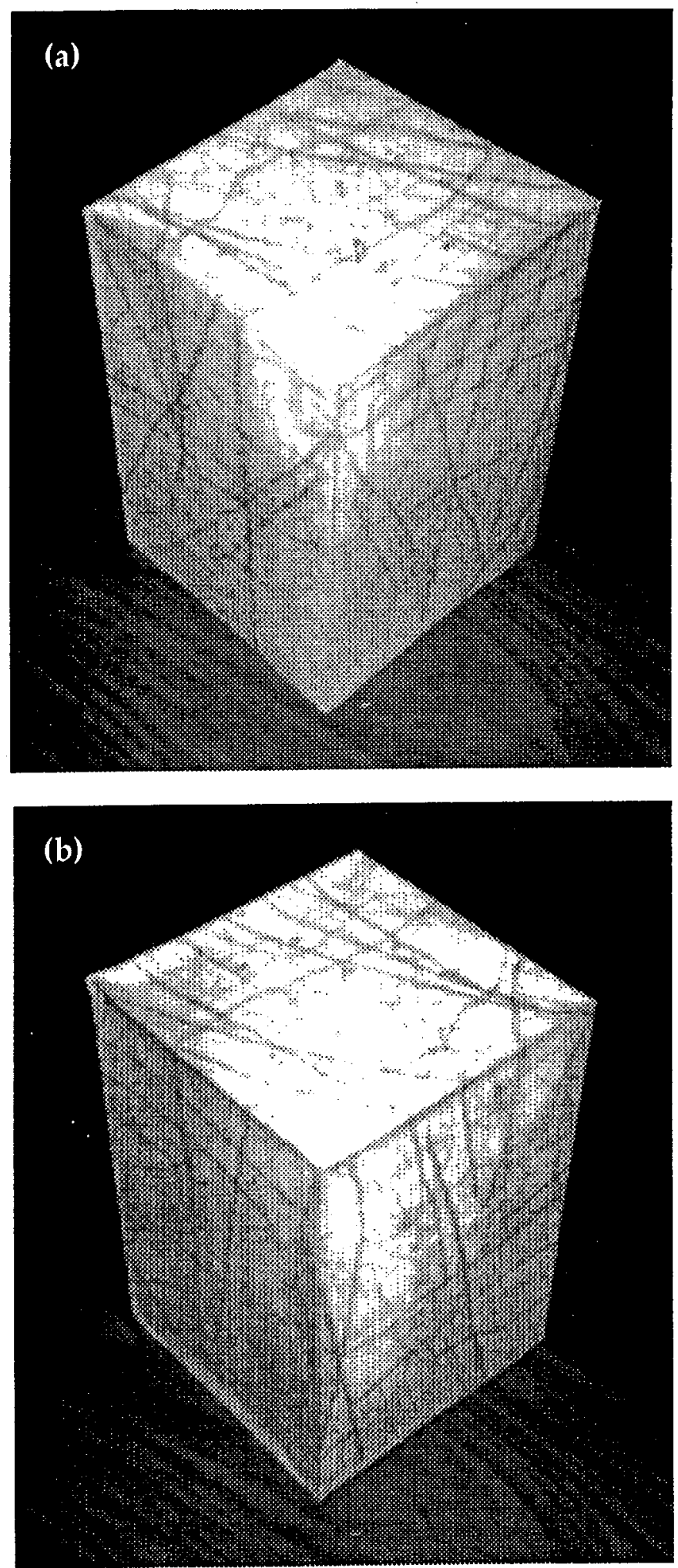

Figure 2-12. 3D physical model of fractures within the block. are shown in Fig. 2-12. Second, although the LBT is not being used to characterize YM, its usefulness as a test of processes, models, and so forth, is enhanced if the rock mass is similar to the repository horizon rock mass. For this reason, Fran Ridge was selected so that the rock type would be the same. Although the stress conditions are not the same, therefore fracture apertures will not necessarily be the same, it is helpful if the fractures are similar in distribution to those in the repository. Therefore, the second analysis was of the fracture distribution compared with that of the main ESF drift that is in the repository area.

Figure 2-13 is an analysis of the fractures mapped after the top surface was leveled above the large block. As can be seen, there are a large number of fractures, and they are dominantly found in a single, near-vertical set. Figure 2-14a (USGS) shows the mapping results from the main drift from station $35+00$ to $42+00$, which is just beyond the vicinity of the thermal testing alcove at about 28+00, and Figure 2-14b shows mapping results from $42+00$ to $49+00$. These results cover the major portions of the potential repository area.

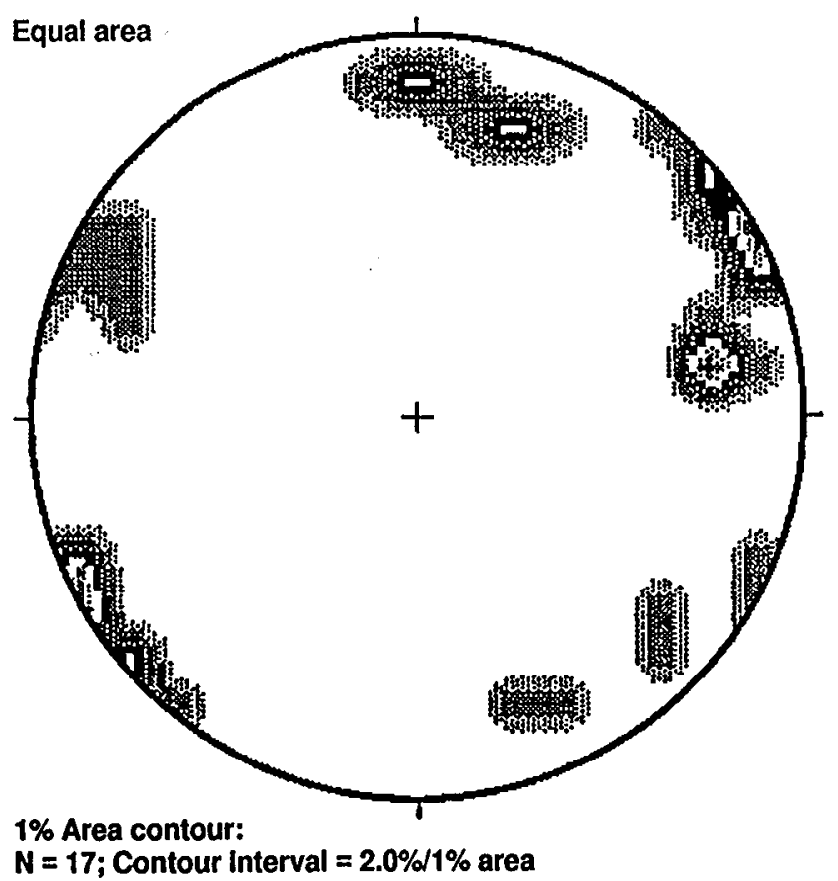

Figure 2-13. Analysis of mapped fractures displayed as stereonets. 
Figure 2-14.

(a) Mapping results from the main drift in the vicinity of the thermal testing alcove (from USGS).
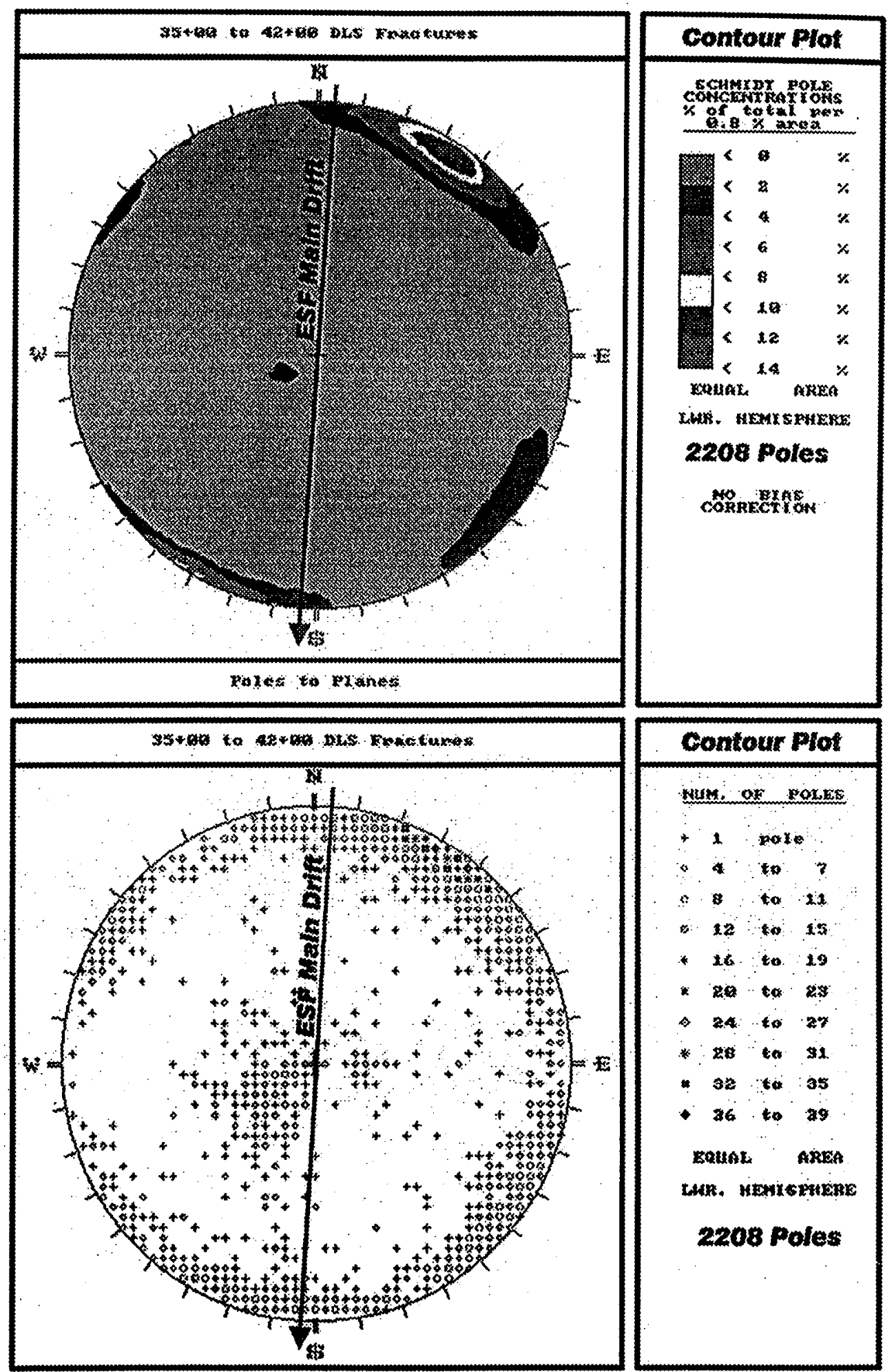

\section{Contour Plot}

Nuxt ox pous

+1 pore

4 a

$\therefore$ to th

o 12 on 15

4 ta to 19

- $2 a$ ta

- 24 to ar

* $\operatorname{tac}$ is

- st to 35

-36 to 29

Eatuak arisa

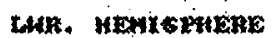
zano palas 

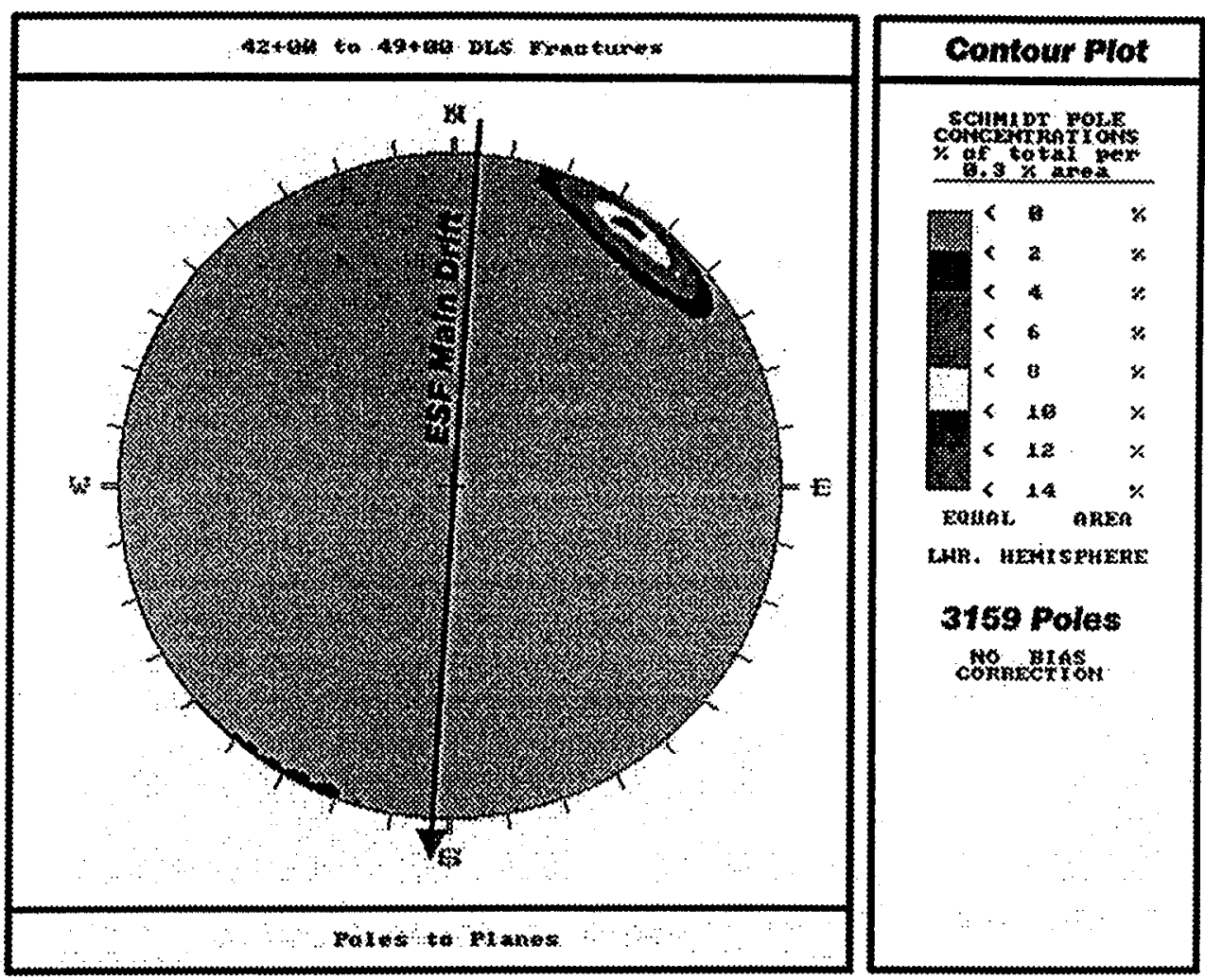

Figure 2-14.

(b) Mapping results in the main drift beyond the ESF test area.

\section{Scatter Mot}

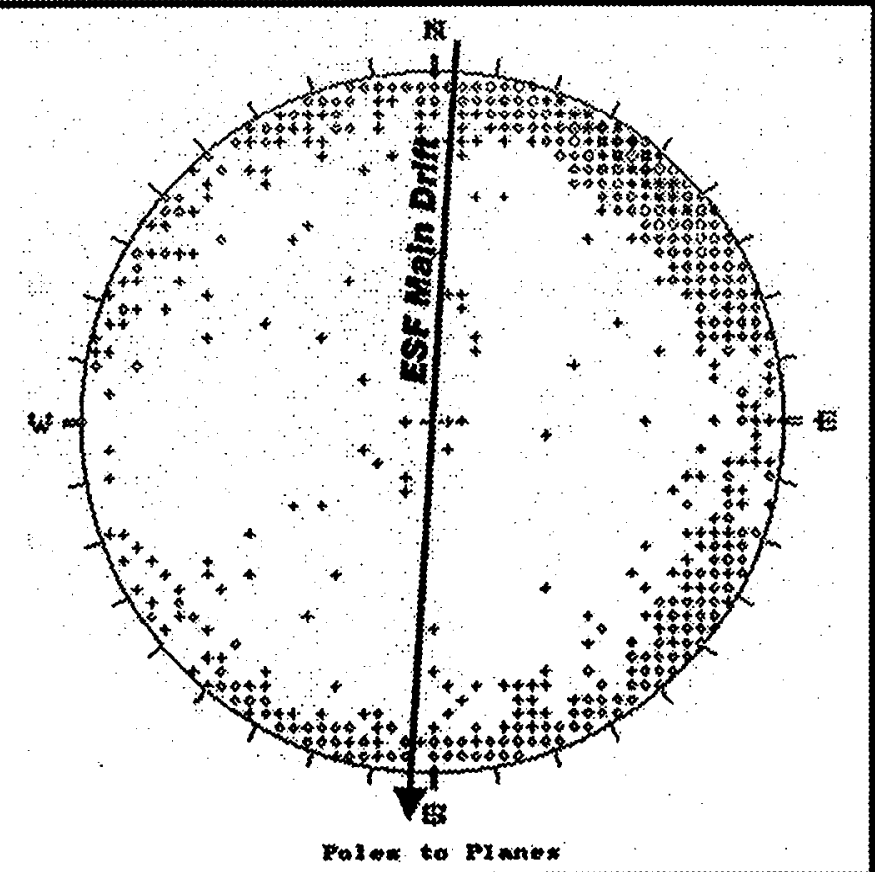

wut of polies

$+x$ pare

- 10 ta 19

- यू $\operatorname{tatas}$

*. \$a to so

1 * to to

- wo to $\$$

- 50 to 69

- 7o to

- 4 to

- 90 to 99

veliar anza

rum; Mratrseftemte

31 we polas 
As can be observed, the fractures are again dominantly vertical, although there are two sets that have been observed in the interval closer to the ESF. In addition, the orientation of the sets is somewhat different than those found at the LBT.

There are several possible reasons that the data from the LBT do not more closely match those from the ESF in terms of orientations. The most likely reason can be found when the orientations of the mapping surfaces are considered. The ESF, as shown in Figure 2-14a, has a nearly N-S orientation. Therefore, the drift would not encounter as many fractures that had a nearly $N-S$ strike (poles would plot nearly east on stereonet). The effects of this orientation bias have been discussed and approaches proposed to correct for this bias (Terzaghi, 1965); however, when the fractures and the mapping surface are very close in orientation, any trig corrections become problematical (Yow and Wilder, 1993). The data shown in Figure 2-14a have not been corrected for orientation bias. The data shown in Figure 2-13 do not have this bias because the mapped surface was a $3 \times 3 \mathrm{~m}$ surface, and no strike orientation would be under-represented

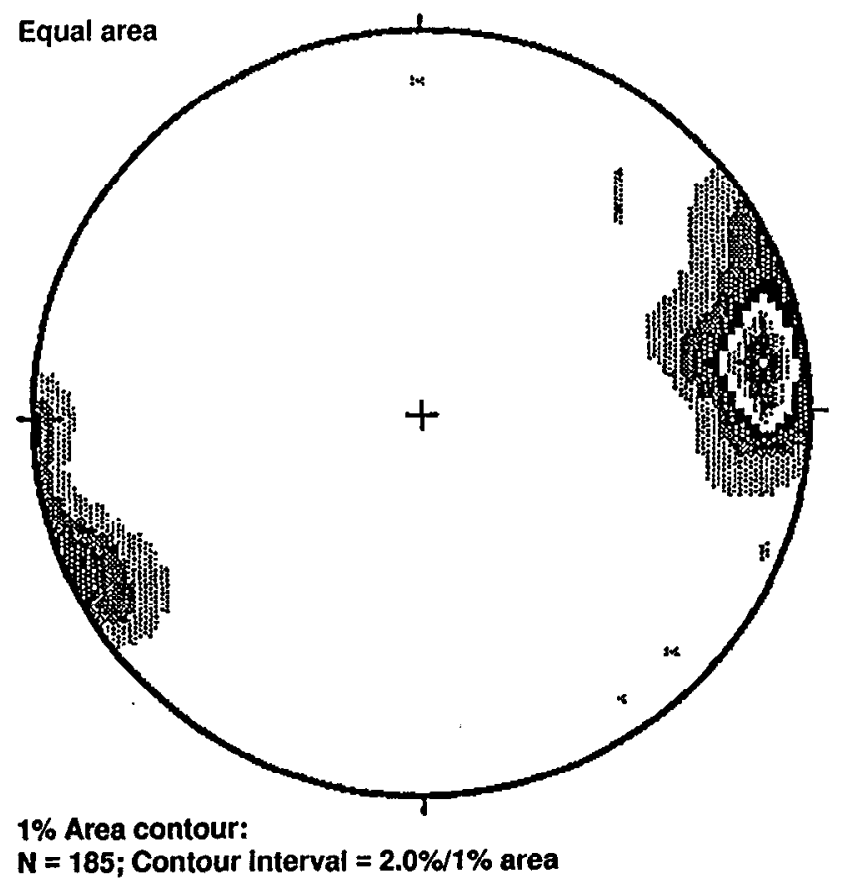

Figure 2-15. Mapping results on block surface before it was cut. (although low-angle fractures would be underrepresented in this plot). A second reason may have to do with the mapping criteria or differences in exposures of fractures. Figure 2-15 shows the results of mapping on the excavated block surface but before it was cut. The fracture sets identified are much more similar to those identified in the ESF, although there are more sets shown. Notice, however, that the data set is much smaller for this mapping. Because of the smaller data set, sets that may be less prevalent are not swamped by the more prevalent sets. Why this is so can be argued. One possibility is that until the surface was well prepared, only more obvious fractures were mapped. If this is the case, it would indicate that Figure 2-13, although accurate for all fractures considered, is placing undue weight on smaller but more numerous fractures rather than on larger (longer) fractures, which presumably are the ones of interest to thermal-hydrologic-geochemical processes.

Figure 2-16 shows the fracture distribution in the drift. As noted, there were about three fractures per meter in the section near the ESF with an increase to about five per meter in Domain 3. If the fractures mapped at the LBT are determined strictly on N-S scan lines (fracture intersections were counted along ten $\mathrm{N}-\mathrm{S}$ lines spaced every $2 \mathrm{ft}$ ), the fracture frequency is in the range of 5 to 6 fractures per meter. Thus, the fracture distribution is more typical of that of Domain 3, but is basically similar to that seen in the main access drift. This leads to the overall conclusion that the basic LBT fracture geometry and distribution are representative of that within the repository horizon as characterized in the main access drift.

\subsubsection{Permeability}

The properties of the matrix that were determined include porosity, permeability, moisture retention curves, electrical resistivity versus moisture content, stress-strain curves, and acoustic wave velocity. The average porosity of the block was determined to be $11.55 \pm 2.28 \%$.

2.2.2.1. LLNL Single Hole. Air injection tests were conducted after the first vertical hole (N1) was drilled to estimate bulk permeability. Figure 2-17 shows the air permeability as a function of depth. Most of the sampled depths have a 
permeability greater than $10^{-11} \mathrm{~cm}^{2}$. It should be noted that the permeability is dominated by the fractures that intersect the injection hole.

Because of the high fracture density in the block, the bulk permeability is likely to be more homogeneous.

Wang and Ahlers (1996) compared the results of the air permeability tests with those conducted within the ESF for the Single Heater Test. They noted that the permeability results were more heterogeneous for the LBT than the SHT (Figure 2-18). As they noted, it is possible that the near-surface exposure does not generate sufficient stress to close up the larger fractures. In contrast, at the repository level the stress may be sufficiently large that

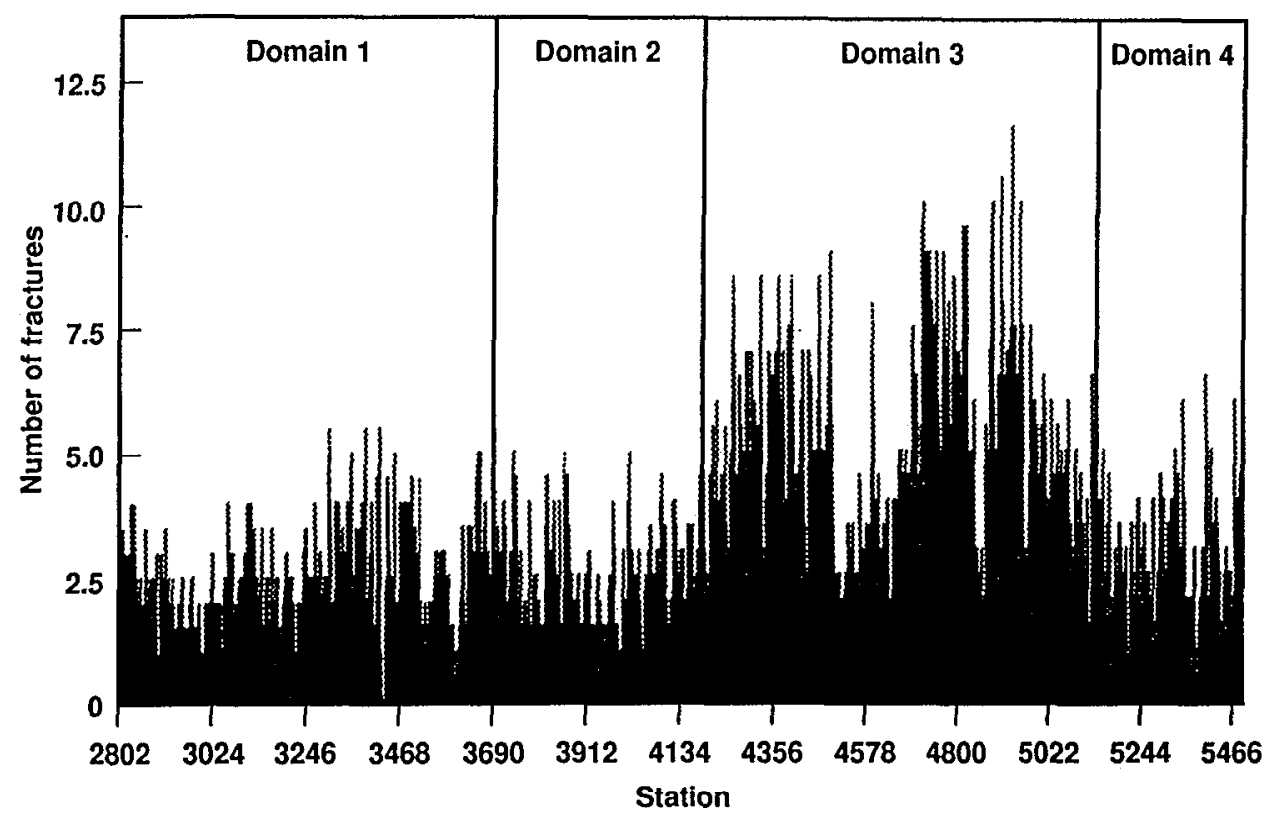

Figure 2-16.

Fracture distrib-

ution in the

main drift.

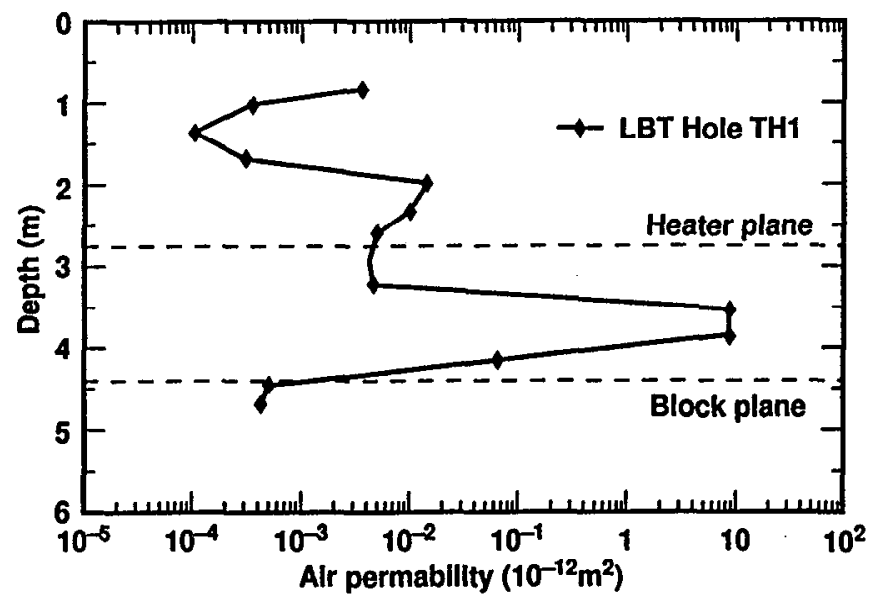

Figure 2-17. Air permeability from a single borehole (N1) as a function of depth.

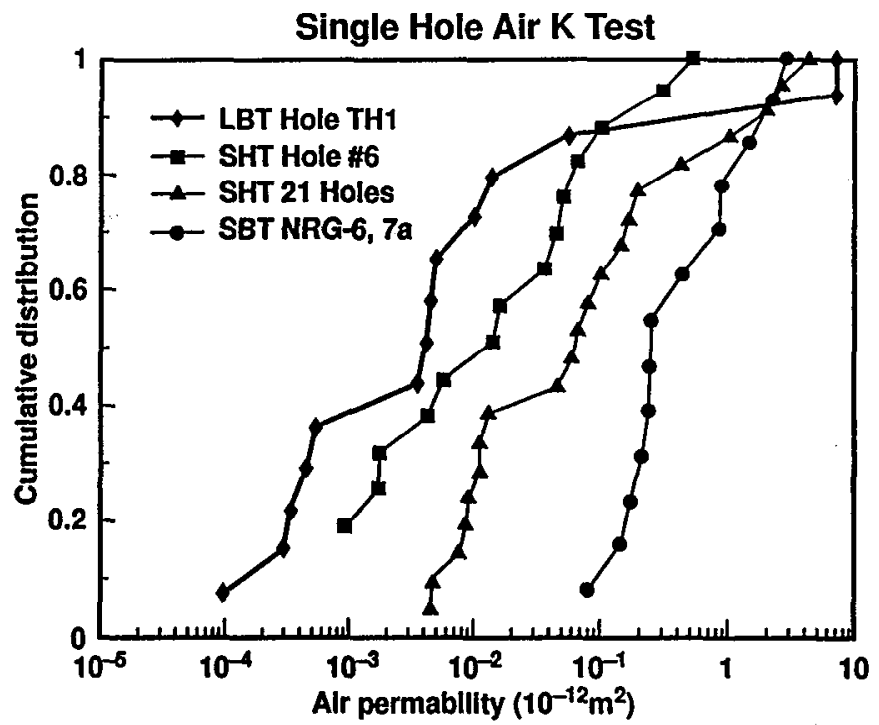

Figure 2-18 Air permeability results for the LBT versus SHT. 
the apertures of the fractures would tend to be reduced. It is of interest to note that the LBT rock in general is much tighter than the SHT rock, but that the more permeable zones are more permeable than the SHT. A possible implication is that after the air permeability tests were completed and the block was isolated by saw cut and excavation, then these fractures may have opened more, although the stresses near the surface may be so low that isolation of the block would have little effect.

Permeability tests conducted in 1997 prior to instrumentation do not support the hypothesis of further opening of fractures after the block was isolated. (See results in Section 5.)
2.2.2.2. LBL Cross Hole. Air injection tests were conducted after all instruments were installed and the boreholes were sealed (except heater holes and hydrology holes, which would have packers in them). Injections used controlled flow rate into packed borehole intervals with crosshole transient pressure responses simultaneously measured in surrounding boreholes. Figure 2-19 shows the heterogeneous pneumatic permeability variation along five heater boreholes. High permeability zones are present near the block boundaries. In the block interior, two heater boreholes (EH-2 and EH-3) penetrate low-permeability zones in the first half of the boreholes. The heterogeneous permeability variation within the

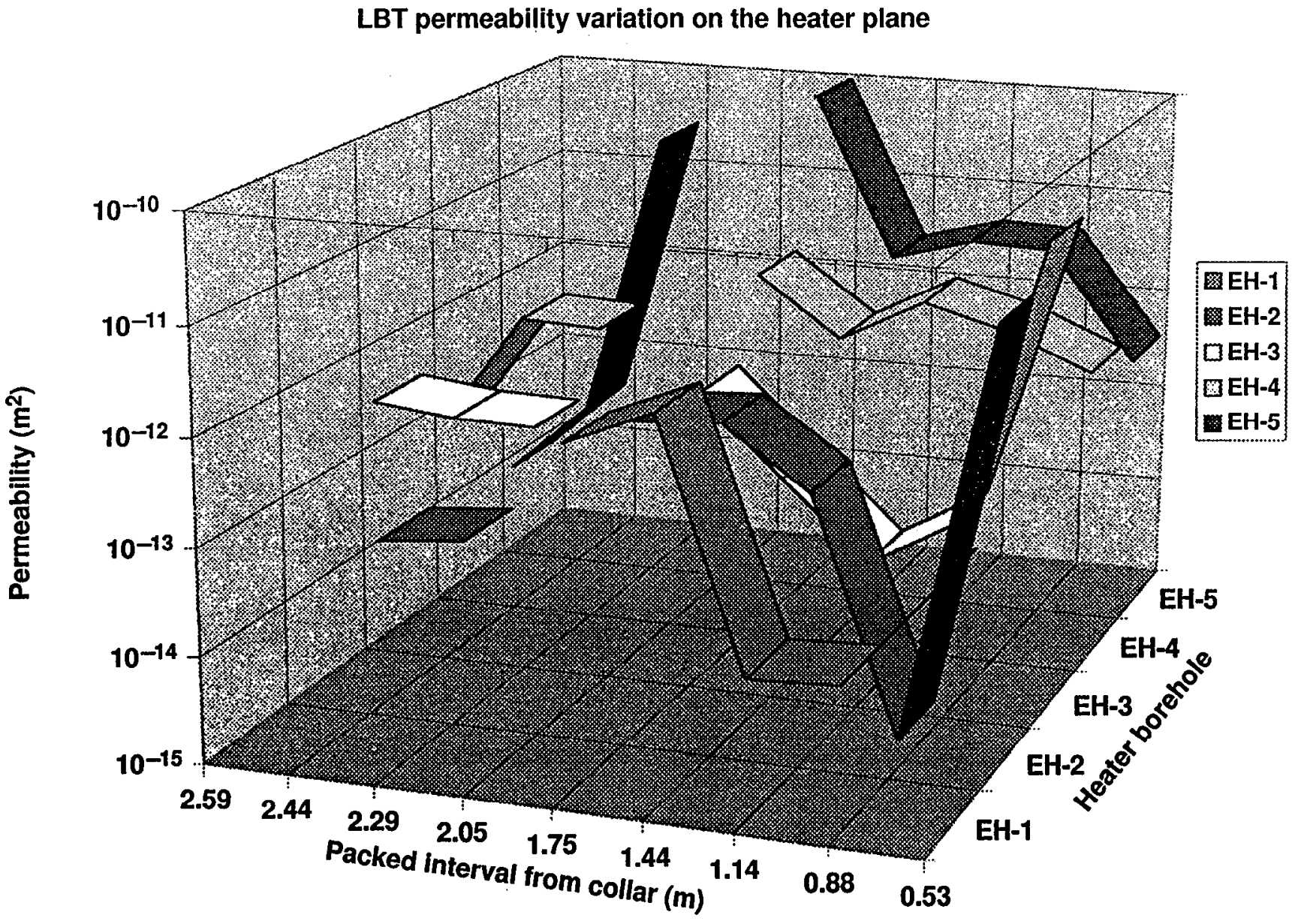

Figure 2-19. Air permeability variations along five heater boreholes at the Large Block Test site. 
block indicates that the heater-induced vapor flow processes can be very different in different zones in the block, with vapor flowing easily near the northern and eastern boundaries, and in the back (western side) of the block away from the bottom of the boreholes. A "hard core" with low permeability and low vapor convection exists southeast, off center in the block.

Figure 2-20 illustrates the air permeability variations along three horizontal hydrological monitoring boreholes. Two hydrological boreholes are located on the western side of the block with WH1 $1.5 \mathrm{~m}(5 \mathrm{ft})$ and WH2 $0.5 \mathrm{~m}(1.5 \mathrm{ft})$ above the heater plane. Two sets of tests were conducted at WH1 as shown in Figure 2-20. The third hydrological borehole NH1 from the north face is $0.3 \mathrm{~m}$
( $1 \mathrm{ft})$ above the heater plane. The air permeability variations along these three hydrological monitoring boreholes do not exhibit the high permeability $\left(10^{-11}\right.$ to $10^{-10} \mathrm{~m}^{2}$ or 10 to 100 darcy), leaky boundary effects observed in some of the heater boreholes. Localized tight zones with air permeability values one to two orders of magnitude lower than the average permeability in the $10^{-12} \mathrm{~m}^{2}$ (1 darcy) range were identified along the boreholes. The horizontal permeability profiles in Figure 2-20 supplement the vertical permeability profile previously measured along vertical borehole TH1 (Lee, 1995).

2.2.2.3 LBL Tracer. Tracers were released in the heater boreholes at different intervals and detected at other locations above and below the

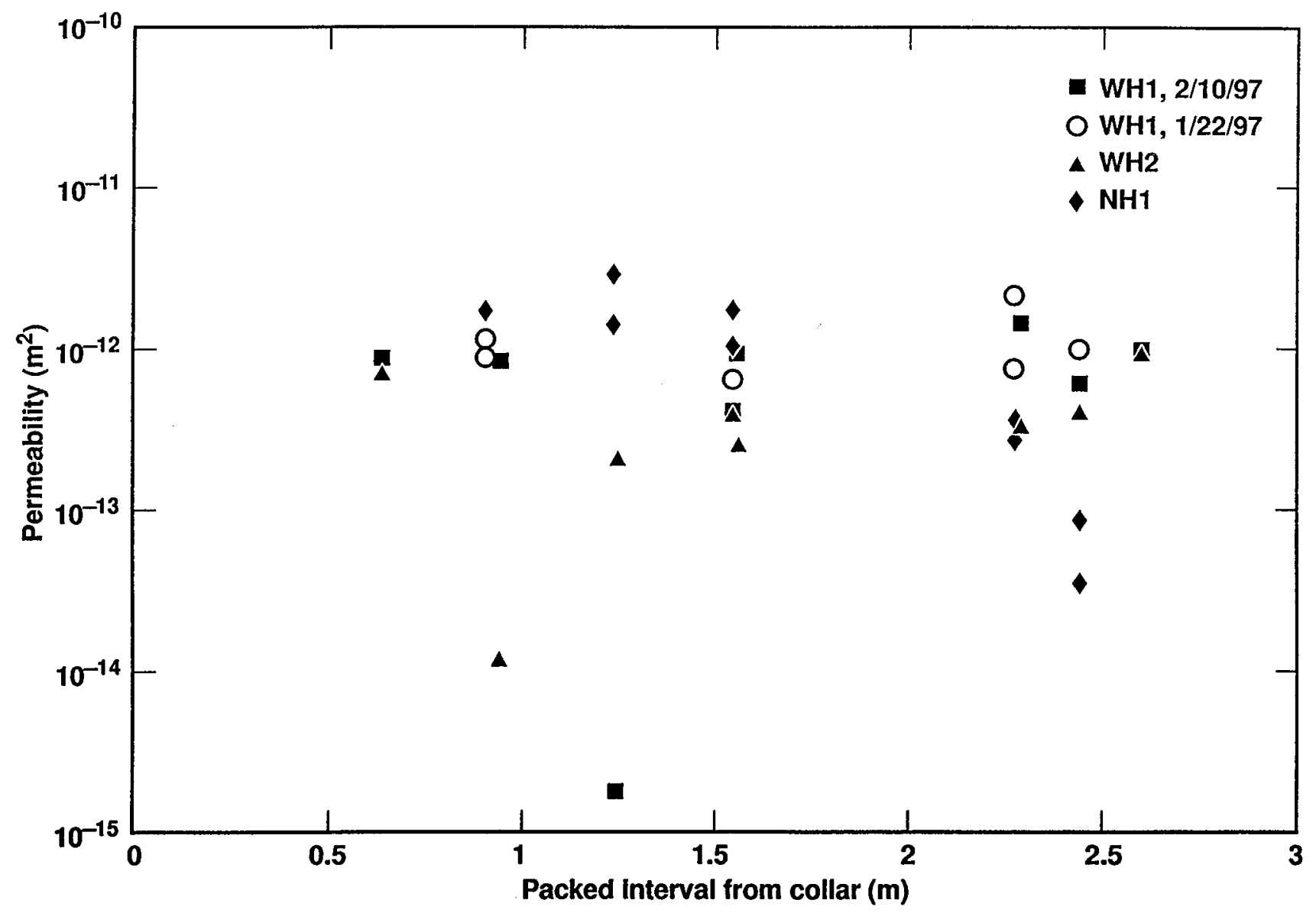

Figure 2-20. Air permeability variations along three horizontal monitoring boreholes at the Large Block Test site. 


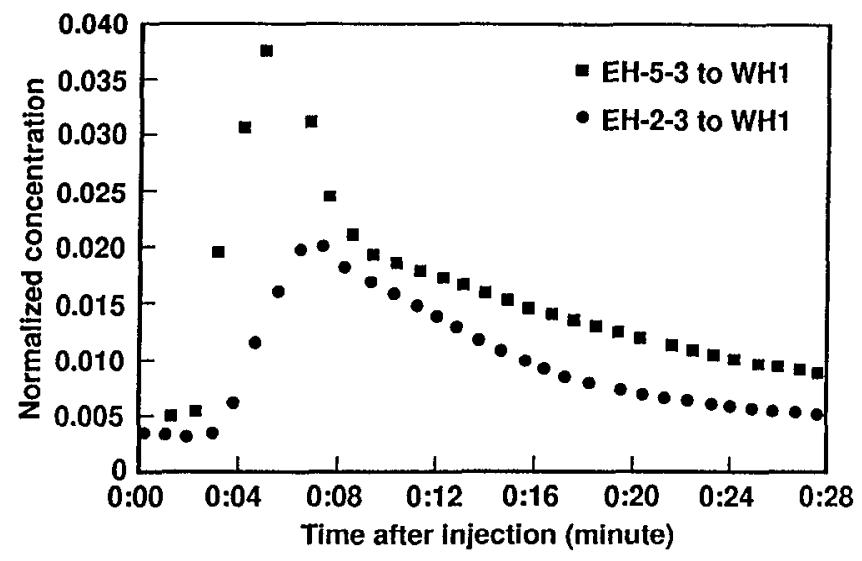

Figure 2-21. Tracer breakthrough curves from heater borehole intervals to a hydrological monitoring borehole WH1 at the Large Block Test site.

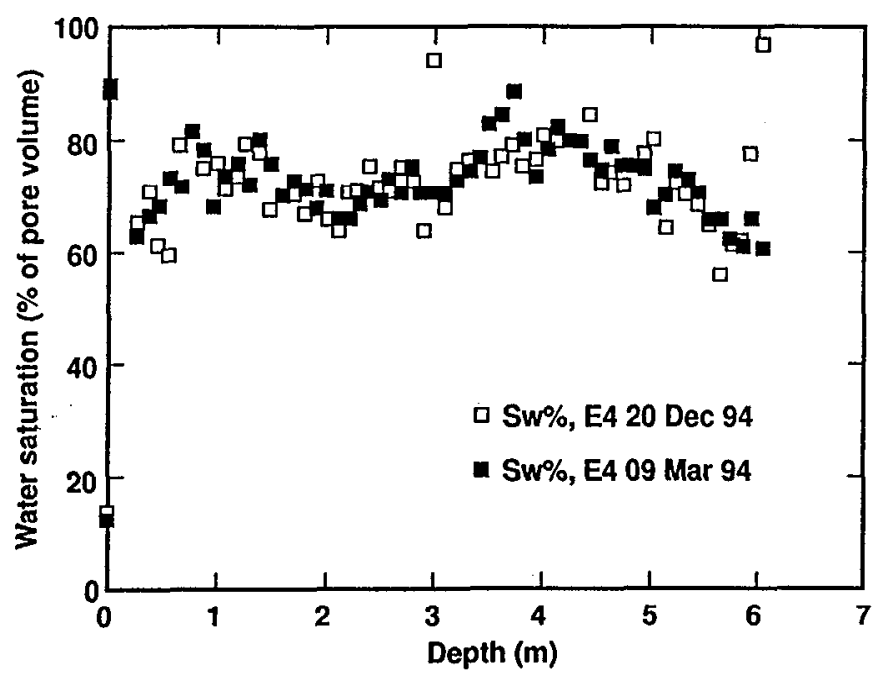

Figure 2-22. Water saturation as a function of depth. heater plane. Figure 2-21 shows the tracer breakthrough detected at borehole $\mathrm{WH} 1 ; 5 \mathrm{ft}$ above the heater plane and $11 \mathrm{ft}$ above the ground. The tracers were released from the middle interval. (interval 3) of borehole EH-2 south of the block center and EH-5 near the northern boundary. EH-5-3 has the highest permeability measured in the block. Potential leakage through the north shield could have contributed to the high value. The tracer released at this interval moved easily to the WH1 hole, compared to the tracers released at EH-2-3, near the center of the block. Both breakthrough curves also have long tails, indicating that many other pathways in the block contribute to the tracer transport at different rates. The tracer breakthrough results substantiate the pneumatic test results with respect to high permeability zones enhancing flow and transport through heterogeneous, fractured rock media in the block. Comparison of thermal-hydrological analyses and heater test results can assess the importance of block-scale heterogeneity in determining near-field heaterinduced impacts.

\subsubsection{Neutron Logging and Moisture Conditions}

Neutron logging was conducted in holes E2, E3, E4, and E9 before and after the sawing to estimate the moisture content in the block. Figure 2-22 shows the water saturation as a function of depth, determined from neutron logging in hole E4. The water saturation determined in other holes agrees well with the values shown here. Neutron logging was performed again to estimate the initial moisture content of the block before the experiment started. 


\subsection{Pretest Predictive Analyses}

\subsection{Thermal-Hydrologic Calculations}

A series of two-dimensional (2D) and threedimensional (3D) thermal-hydrologic calculations have been conducted in support of the LBT.

Preliminary 2D analyses and one 3D analysis that modeled only thermal conduction were presented by Lee (1995a, 1995b). Those efforts were followed by ongoing thermal-hydrologic $3 \mathrm{D}$ analyses. This section briefly reviews some of the earlier findings and summarizes the current 3D work.

Modeling results assumed either a homogeneous block having the dominant bulk permeability as measured by single-borehole air injection, or a heterogeneous block with the permeability profile obtained from air injection. The heterogeneous permeability field had a "layer-cake" distribution because the permeability measured at any depth was assumed to be constant for that depth.

\subsubsection{Homogeneous and Heterogeneous Cases}

Since heat and fluid flow are symmetrical about a vertical plane drawn through the axis of the block and parallel to the heater emplacement boreholes, it was only necessary to model a halfsymmetry section of the block. It was assumed that heating power levels in the boreholes are identical and that heat is delivered uniformly along the heated length of each borehole. The top-surface temperature of the block was fixed at $60^{\circ} \mathrm{C}$, and the heating power level varied to attain a maximum temperature of 138 to $140^{\circ} \mathrm{C}$ at the walls of the heater boreholes. An equivalent continuum model was used.

For the homogeneous case, a distinct dryout zone was observed in and around the heater plane, with well-developed condensation zones above and below the heaters. In contrast, the heterogeneous case did not show a well-developed condensation zone above the heaters. A distinct dryout zone was observed, and a welldeveloped condensation zone was formed only below the heater plane. For the heterogeneous case, there was clearly a net loss of liquid above the heater plane. The results suggest that the saturation changes might be sensitive to permeability distribution.

Higher gas pressures were generated for the heterogeneous case. Peak gas phase pressure for the homogeneous case was only $97 \mathrm{kPa}(14 \mathrm{psia})$, compared to $157 \mathrm{kPa}$ (23 psia) for the heterogeneous case. The higher pressure is caused by additional confinement of water vapor and air by layers of bulk permeability substantially lower than those for the homogeneous permeability case.

\subsubsection{Thermal-Hydrologic Discrete Fracture Model}

The modeled fracture system consisted of $200-\mu \mathrm{m}$-aperture fractures at a uniform spacing of $30 \mathrm{~cm}$. The fractures were vertical, parallel to the heater borehole axes. They were assumed to intersect the borehole axes and to occur midway between two boreholes.

Distinct dryout and recondensation zones were observed both above and below the heater plane. The dryout zone was thickest at the fractures and thinnest in the matrix, midway between the fractures. Block temperatures were not significantly affected by fracture location. The peak gas pressure in the system was about $177 \mathrm{kPa}$ (26 psig), located in the matrix at the heater level.

\subsubsection{Three-Dimensional Thermal-Hydrologic Model}

The 3D thermal-hydrologic analysis includes a simulation run using rock properties from the Reference Information Base (RIB, DOE, 1995), with the bulk permeability adjusted to approximate the median value obtained by single-borehole airinjection measurements on the block. This predictive simulation is designated as Case A. The rock was heated at $450 \mathrm{~W}$ per heater for six months (182.5 days), after which the power was turned off, and the cool-down was simulated for an additional six months. The initial liquid saturation for Case A was $92 \%$.

Six additional runs were conducted using two rock property sets with different initial liquid 
saturations to study the effect of rock properties and initial conditions on the calculated rock response. Power failures that occurred during the test were incorporated in these simulations. The six runs are designated as Case 1 through Case 6. Case 1 is identical to Case A, except that the power failures are included in Case 1.

The results for Case A are presented first in some detail. This is followed by comparisons of temperature and liquid saturation histories at a node for Cases 1 through 6 . An equivalent continuum, homogeneous model was used for all calculations. A more detailed 3D heterogeneous model that incorporates the permeability field obtained by air flow and gas tracer tests (Wang and Ahlers, 1996) will be presented in the final report.

A quarter-symmetry section was modeled, similar to the section used for the conductiononly model (Lee, 1995b). The grid is rectangular with 28,875 nodes including 11,856 null nodes, giving 17,017 active nodes. Grid dimensions vary from $5 \mathrm{~cm}$ at the heater boreholes to a maximum of $20 \mathrm{~cm}$ within the block.

Table 3-1 lists the values used for hydraulic and thermal properties of the rock units. Rock properties for TSw2 were obtained from Klaveter and Peters (1986), with some modification. Properties for tsw34 were obtained from Lawrence Berkeley National Laboratory (LBL) Parameter Set 4 (Bodvarsson and Bandurraga, 1996). Table 3-2 shows the initial liquid saturations for Cases 1 through 6 .

Figures 3-1 through 3-6 show the results of the predictive simulation run, Case A, using Case 1 rock properties and initial liquid saturation. Figure 3-1 shows images of temperatures along a vertical north-south plane through the center of the block. Temperatures are shown at 1 , 6, 7, and 12 months. Figure 3-2 shows images of liquid saturations for the same times. Vertical temperature and liquid saturation profiles through the center of the block are shown in Fig. 3-3. Profiles, like the images, are also shown at 1, 6,7 , and 12 months. A temperature history for a node at the heater level, adjacent to the heater midpoint, and $35 \mathrm{~cm}$ from the center heater, is presented in Fig. 3-4. A similar history is presented for a node $90 \mathrm{~cm}$ above the heaters in Fig. 3-5, and a node $90 \mathrm{~cm}$ below the heaters in Fig. 3-6.
Table 3-1. Hydraulic and thermal properties of rock units.

Properties
Bulk permeability $\left(\mathrm{m}^{2}\right)$

Matrix permeability $\left(\mathrm{m}^{2}\right)$

Fracture permeability $\left(\mathrm{m}^{2}\right)$

Matrix van Genuchten a (1/Pa)

Fracture van Genuchten a (1/Pa)

Matrix porosity

Fracture porosity

Matrix van Genuchten b (1/Pa)

Fracture van Genuchten b $(1 / \mathrm{Pa})$

Wet thermal Conductivity $(\mathrm{W} / \mathrm{m}-\mathrm{C})$

Dry thermal Conductivity $(\mathrm{W} / \mathrm{m}-\mathrm{C})$

Specific heat $(\mathrm{J} / \mathrm{kg}-\mathrm{C})$
TSw2

$9.87 \times 10^{-12}$

$3.30 \times 10^{-15}$

$4.00 \times 10^{-18}$

$8.33 \times 10^{-10}$

$6.40 \times 10^{-7}$

$1.34 \times 10^{-3}$

0.11

$1.19 \times 10^{-4}$

$3.96 \times 10^{-6}$

1.47

3.00

2.10

2.10

928 tsw34

$1.59 \times 10^{-12}$

$1.01 \times 10^{-15}$

$6.55 \times 10^{-9}$

$7.72 \times 10^{-7}$

$6.86 \times 10^{-4}$

0.11

$2.34 \times 10^{-4}$

1.47

1.48

2.33

1.56

948
Table 3-2. Initial liquid saturation for the six cases.

Case No. Rock unit

Case 1

Case 2

Case 3

Case 4

Case 5

Case 6
Liquid saturation

0.92

TSw2

0.70

TSw2

0.65

TSw2

0.92

tsw34

tsw34

tsw34

0.70

0.80 
Figure 3-7 shows temperature histories for Case 1 through Case 6 for a node at the heater level, adjacent to the heater midpoint, and $35 \mathrm{~cm}$ from the center heater. The results show substantially higher temperatures for TSw2, compared with tsw34. This difference may be partially explained by the lower permeability of TSw2, as shown in Table 3-1.

\subsection{TOUGH2}

Lawrence Berkeley National Laboratory (LBL) performed scoping calculations to assist in the design of tracer studies (Wang and Ahlers, 1996). They assumed 10 vertical fractures in the N-S direction, 10 vertical fractures in the $\mathrm{E}-\mathrm{W}$ direction,
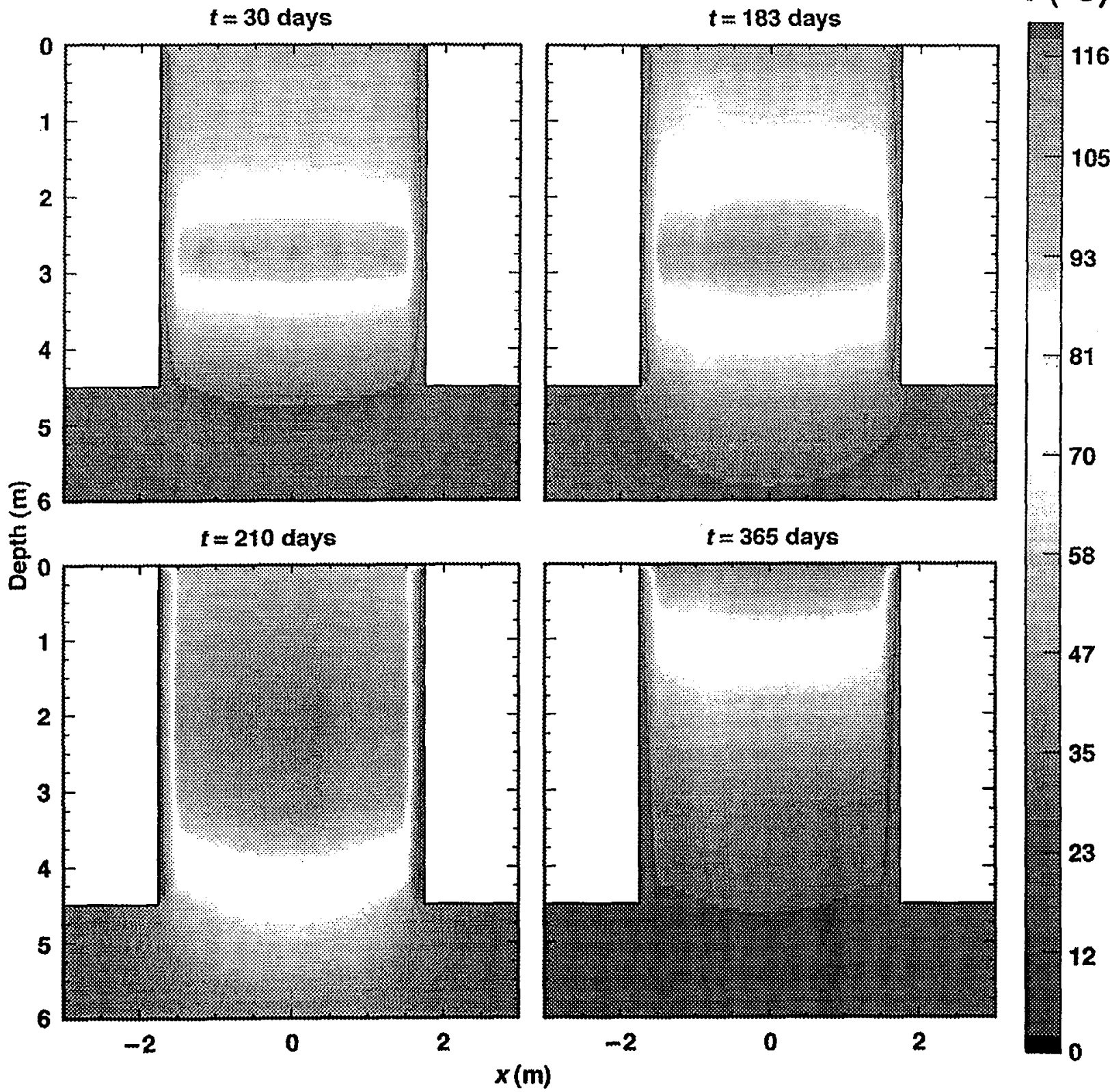

Figure 3-1. Case A rock temperature $\left({ }^{\circ} \mathrm{C}\right)$ along a vertical north-south plane through the center of the block at $1,6,7$, and 12 months. 
and 15 horizontal fractures with $200-\mu \mathrm{m}$ apertures to determine a total fracture volume of $0.08 \mathrm{~m}^{3}$. They then calculated the volume of tracer gases that would be appropriate for a tracer test. Whereas the fracture distribution assumed is not entirely representative of that mapped (essentially one N-S set dominates), these calculations are merely scoping in nature and are sufficient for the purpose of designing a tracer experiment.

A significant factor in the tracer analyses is the interaction between matrix and fractures. In the LBL study, the assumed flow parameters were based on the unsaturated zone (UZ) SiteScale Model (Bodvarsson and Bandurraga, 1996).
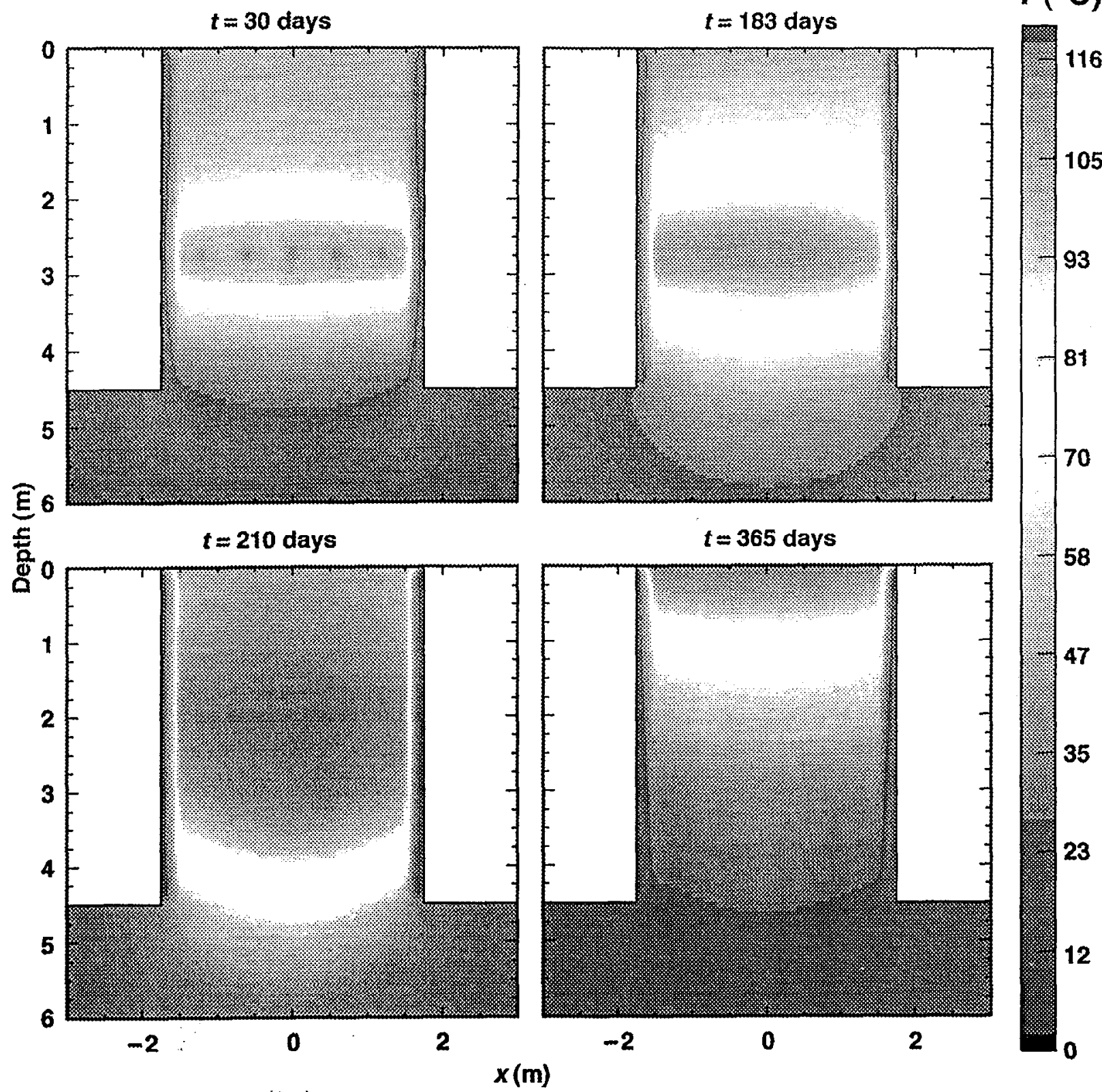

Figure 3-2. Case A liquid saturation $\left(S_{\text {liq }}\right)$ along a vertical north-south plane through the center of the block at $1,6,7$, and 12 months. 


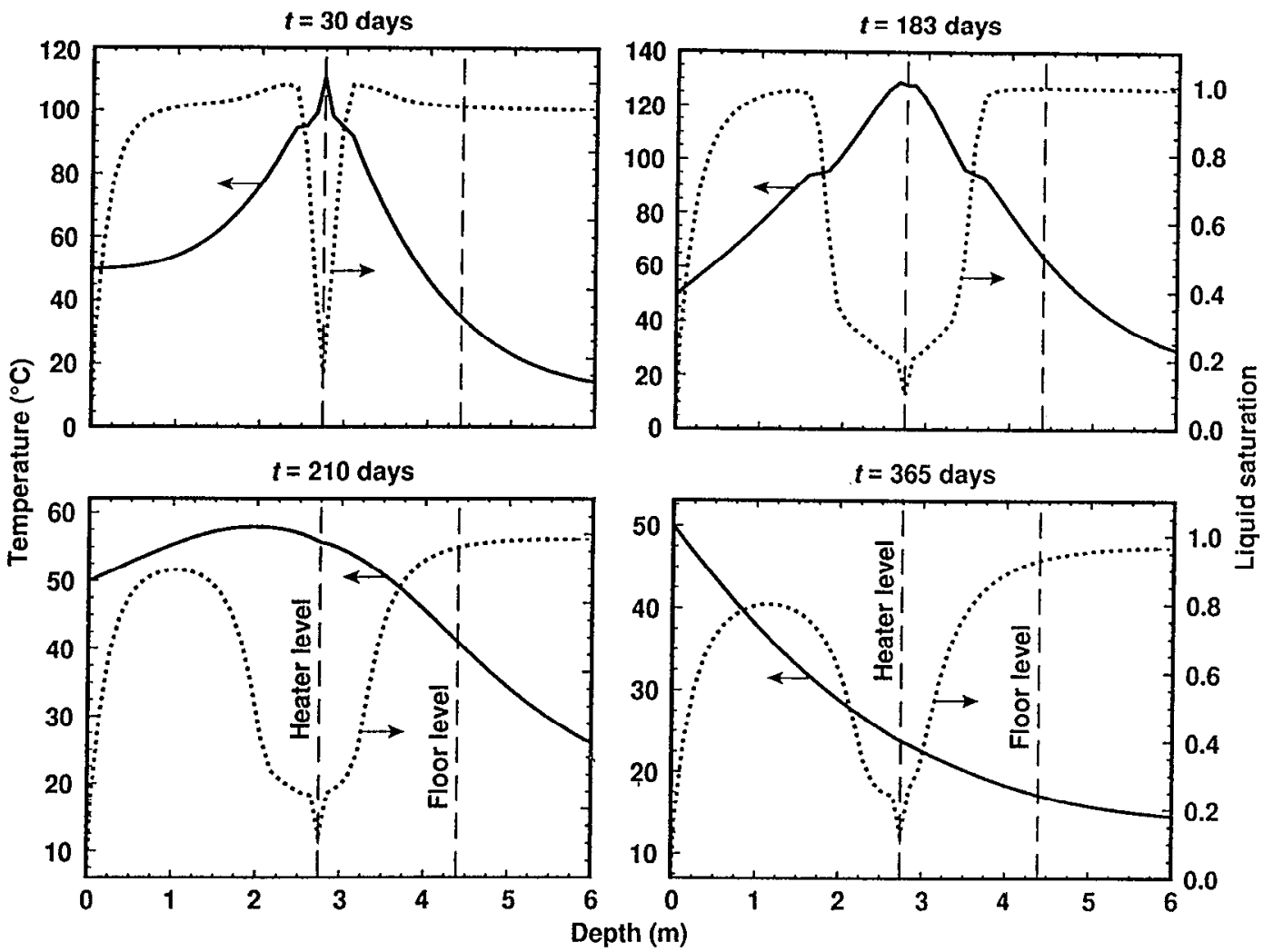

Figure 3-3.

Case $A$ vertical temperature and liquid saturation profile down the center of the block at $1,6,7$, and 12 months.

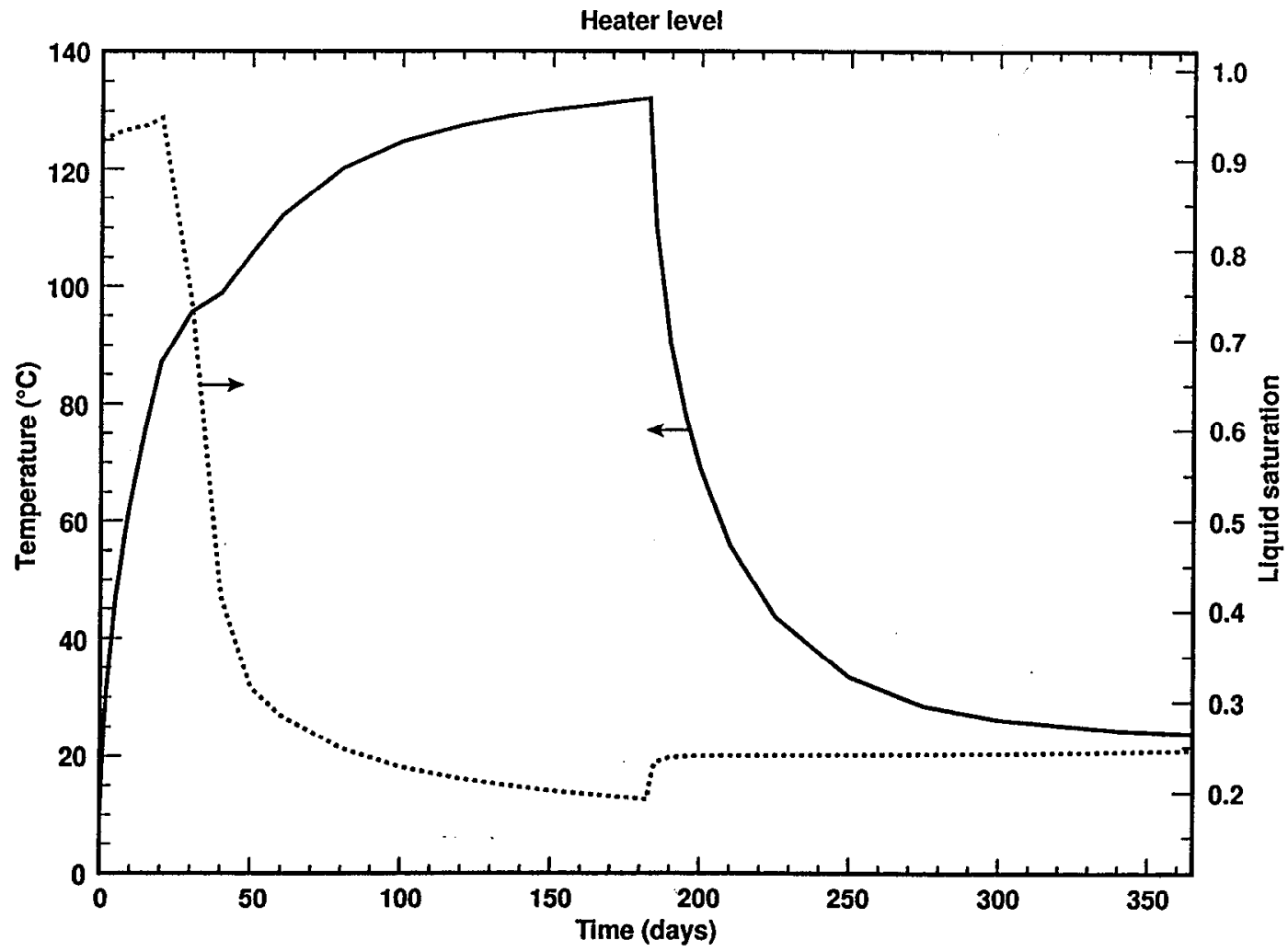

Figure 3-4.

Case $\mathbf{A}$ temperature and liquid saturation history for a node at the heater level, adjacent to the heater midpoint, and $35 \mathrm{~cm}$ from the center heater. 
Figure 3-5.

Case $A$ temperature and liquid saturation history for a node $90 \mathrm{~cm}$ above the heater level, adjacent to the heater midpoint, and $35 \mathrm{~cm}$ from the center heater.

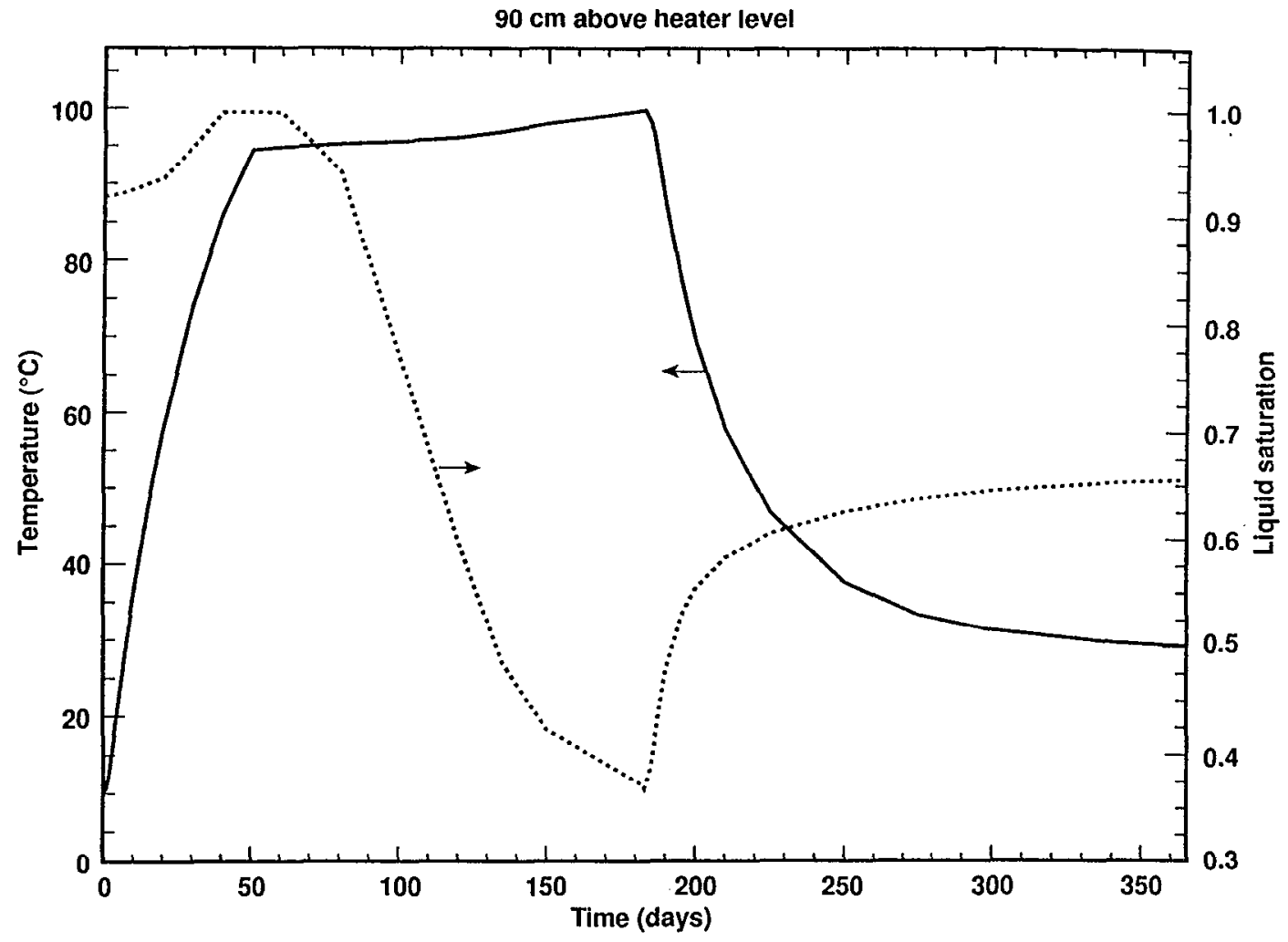

Figure 3-6.

Case A temperature and liquid saturation history for a node $90 \mathrm{~cm}$ below the heater level, adjacent to the heater midpoint, and $35 \mathrm{~cm}$ from the center heater.

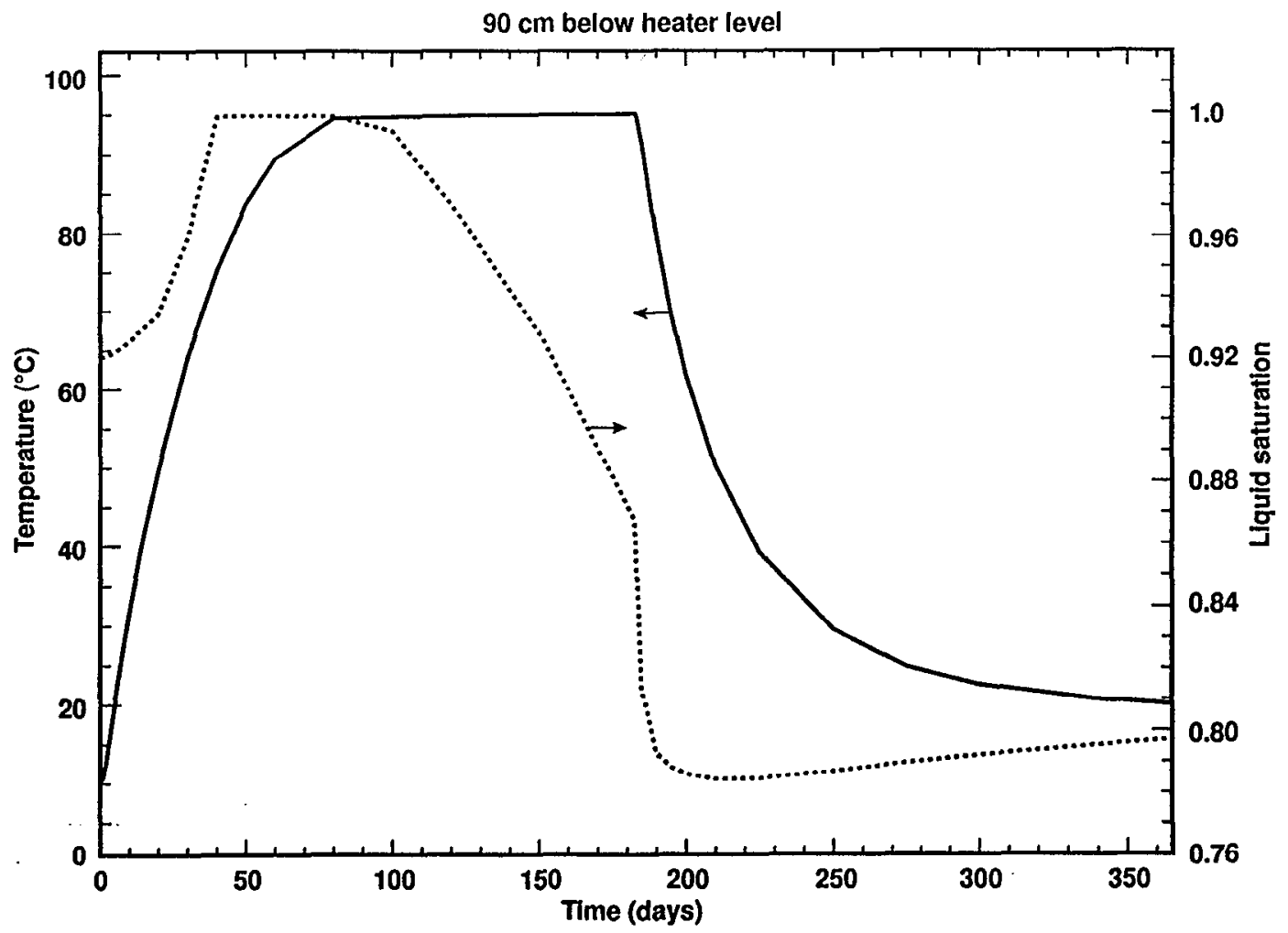


Analyses by Buscheck (1997) have indicated that these properties may be inappropriate for modeling of the LBT. He notes that using those properties, calculations would indicate that the temperatures never exceed boiling or do not exceed boiling by very much. This may suggest that some caution needs to be used when analyzing the tracer data based on these property values.

Wang and Ahlers (1996) performed analyses of the tracer movement using several different approaches. Portions of their report are reproduced here, in summary form.

Wang and Ahlers analyzed isobars and particle movements along advective velocity lines at time $t=10,100,1000$, and $10000 \mathrm{~s}$ after air injection starts for two cases: (1) lateral atmospheric boundary conditions and (2) lateral noflow boundary conditions. For the atmospheric (unrestricted flow) boundary, they found that the high-permeability layer suppressed the pressure buildup and channeled the particles along the high-permeability layer toward the side boundary. Most of the particles escaped from the block through the side boundary instead of through low-permeability layers above the injection point to the top atmospheric boundary.

In contrast, the no-flow boundary slowed down the particle migration toward the boundary and diverted some of the particles to move either upward toward the top boundary or downward into the ground. Because the sides of

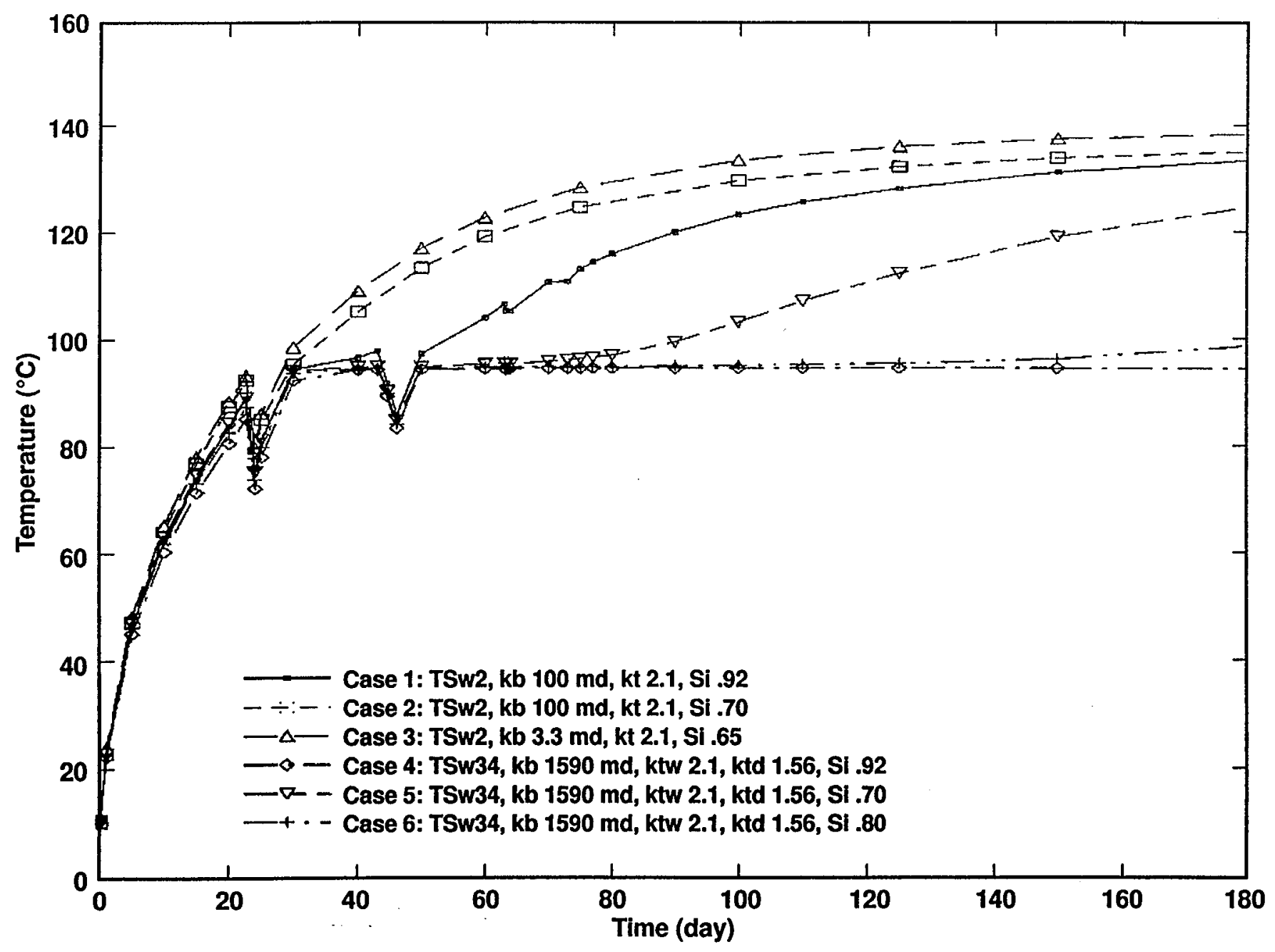

Figure 3-7. Comparison of Case 1 through Case 6 temperature histories for a node at the heater level, adjacent to the heater midpoint, and $35 \mathrm{~cm}$ from the center heater. 
the block were sealed, but possibly imperfectly, the conditions during the tracer studies should be more represented by the no-flow case.

\subsubsection{D Tracer Injection Simulations in Layer Model}

The second set of simulations used a 3D grid with 1- $\times 1-\times 1$-ft elements. Both the air pressure and tracer concentration were simulated. The grid size was chosen to represent the packer interval along available boreholes likely to be used in the tests. The nominal straddle packer intervals were usually longer than $1 \mathrm{ft}$. Multipacker strings were fabricated with nominal 1-ft intervals for the LBT tracer tests. The tracer tests were designed to evaluate the effective fracture porosity. To guide the test design, two cases with

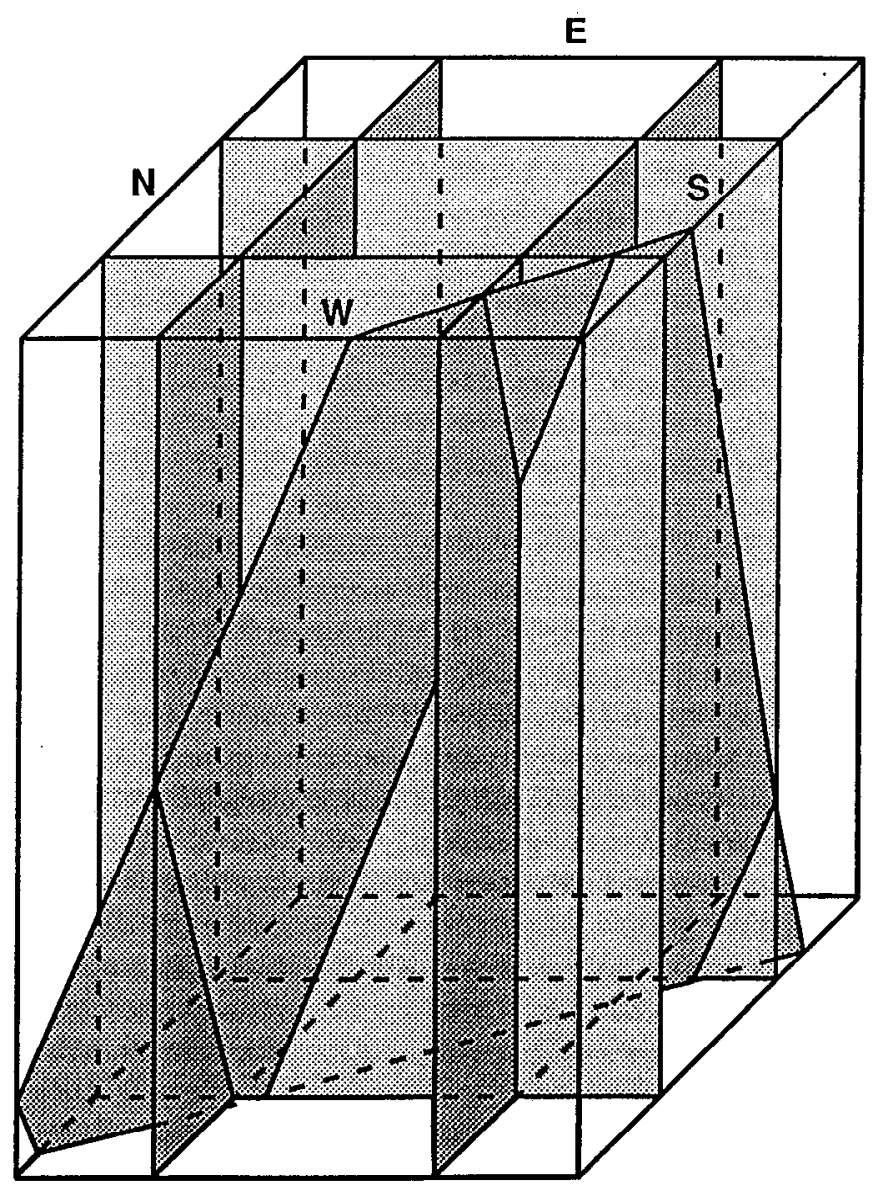

Figure 3-8. Discrete fractures incorporated in the layer fracture model. different porosity values were simulated. The $3 \mathrm{D}$ model used the same layer heterogeneity as the 2D particle movement model. The injection point was chosen at $z=-2.6 \mathrm{~m}$ near the center of the block. The initial conditions for the tracer injection simulations were created by air injection with flow rate of $Q_{\mathrm{air}}=1 \mathrm{slpm}$ until steady-state flow was achieved. The tracer injection was set at the rate $q_{\text {tracer }}=0.01 \mathrm{slpm}$. Constant pressure, pneumatically static, and zero tracer conditions were applied on the top and lateral boundaries of the block.

Wang and Ahlers compared tracer concentrations for two cases: porosity $n=0.001$, and porosity $n=0.01$. Tracer concentrations were normalized to injection concentration at time $t=$ $21,45,100,210,450,1000,2100$, and $10000 \mathrm{~s}$ after tracer injection. The higher porosity value kept the tracer closer to the injection point, and more tracer remained in the block. The layer permeability heterogeneity distorted the concentration plume and kept the tracers in the vicinity of the high-permeability layer. In comparison with 2D simulations, less tracers seemed to escape from the block. Essentially no tracer escaped from the top in this layer model.

\subsubsection{3-D Tracer-Injection Simulations with Vertical and Inclined Fracture Model}

Because vertical and inclined fractures are evident in the block, additional high-permeability flow and tracer paths were added to the layer model. Two E-W vertical fractures, two N-S vertical fractures, and one inclined fracture were included in the model, as shown in Fig. 3-8. Only two vertical fractures in each direction were included because the video logs of many horizontal holes show that most vertical fractures are sealed, and only a few major fractures are open. The inclined fracture is an obvious continuous fracture based on the traces on the fracture maps of the block surfaces. The inclined fracture chosen for inclusion in the model intersects the central borehole at depth. Both vertical and horizontal continuity of the fracture grid blocks were maintained in the inclined fracture representation. The permeability value assigned to grid elements with the additional fractures was 10 darcy. The effective porosity for the fracture grid elements was 
set at $n_{\mathrm{f}}=0.0001$. The other grid elements not intersected by the discrete fractures had the layer porosity of $n=0.001$. The porosity of discrete fracture grid blocks was reduced compared to "bulk" fracture continuum blocks to account for the porosity of the single fracture feature.

Wang and Ahlers compared tracer concentrations normalized to injection concentration at time $t=21,45,100,210,450,1000,2100$, and $10000 \mathrm{~s}$ after tracer injection for the layer model versus the fracture-layer model. The layer model took into account only the vertical heterogeneity of permeability distribution. The fracture-layer model represented the 3D heterogeneity field. The tracer concentration field was very sensitive to the vertical and inclined fractures, which effectively channeled the flow and transport upward toward the top surface and downward into the ground below the base of the block.

A major observation from these studies is the strong influence of the assumed permeability structure on the shape of the flow of injection. This is likely to be important in the thermalhydrologic predictions as well. As can be seen by inspection of their Fig. 12 in the Wang and Ahlers report, the flow conditions are much more heterogeneous and directed along fracture pathways for the cases that consider the inclined fracture (right-hand portion of the figure) than the rather smooth and nearly spherical results shown on the left.

\subsubsection{D Thermal-Hydrological Evolution with Vertical and Inclined Fracture Model}

In addition to the scoping calculations for tracer studies, Wang and Ahlers also performed a 3D analyses of the thermal-hydrologic behavior of the LBT. Wang and Ahlers reported their results as a series of contour plots of matrix and fracture saturations and temperature distributions during heating in their Fig. 13 and for cooldown in their Fig. 14. They found that vertical and inclined fractures were effective flow paths for thermally induced vapor flows. The high-permeability fractures were also effective in the enhancement of drying in the fractures and the adjacent matrix. With effective transport of vapor, condensation occurred above and below the heater. The loca- tions of condensation and drying zones depended on the proximity of fractures. Preheating characterization of the block is therefore essential in determining the distributions of heatinduced changes in heterogeneous, fractured tuff formations.

When compared to data from the test and from other numerical predictions based on different models and approaches, these calculations can provide some insight into the analysis approaches that are most appropriate. However, because the results of analyses are highly dependent on the parameters used, and the parameters used by LBL do not always match those used by LLNL, which reflect those reported by Klavetter and Peters (1986), the comparisons need to be made using a great deal of caution. Future analyses will be made to further compare these approaches.

An important point is the potential impact that assumed property values have on the results of these calculations. The calculations by LBL indicate temperatures remaining below $100^{\circ} \mathrm{C}$ until nearly eight weeks of heating. The elevated temperatures are never calculated to be widespread in the block, nor do they exceed $120^{\circ} \mathrm{C}$. In contrast, calculations by LLNL indicate that temperatures will exceed $100^{\circ} \mathrm{C}$ after about five weeks of heating and are about $130^{\circ} \mathrm{C}$ at the heater horizon.

\subsection{Thermal-Mechanical Predictive Modeling}

The objectives of this modeling are to aid in the experimental design of the test, to evaluate different thermal and constitutive models, and to evaluate different numerical methods. In this report, we present results (see Section 5) of thermal-mechanical simulations of the heatup phase of the LBT conducted using two different numerical codes that are commercially available, a two-dimensional (2D) finite difference model (FLAC) and a three-dimensional (3D) finite element model (ABAQUS).

The purpose of this initial numerical modeling is to calculate temperatures, stresses, and displacements in two and three dimensions for a simplified representation of the large 
block. In reality, numerous joints and fractures complicate the behavior of the large block significantly. Nonetheless, these simulations provide a general understanding of the thermal-mechanical behavior to be expected in the LBT.

The geomechanical modeling reported here was based on the following assumptions or test designs. The large block is $3.0 \mathrm{~m} \times 3.0 \mathrm{~m}$ at the base and is $4.5 \mathrm{~m}$ tall. Five heaters span the width of the block at a height of $1.5 \mathrm{~m}$ above the ground surface. The heaters will eventually raise the block temperature to about $140^{\circ} \mathrm{C}$ in the plane of the heaters, and a thermal gradient will be developed between the heater plane and the top of the block, which will be maintained at a constant temperature of $60^{\circ} \mathrm{C}$. The heat flux on the sides of the block will be maintained at zero. (It should be noted that this is no longer a correct boundary condition assumption, in that computer controlled heaters are not part of the LBT; therefore, there will be a flux that will be measured, but not controlled to be zero.) The block will be essentially unconfined, with a maximum horizontal stress of $0.2 \mathrm{MPa}$ ( $30 \mathrm{psi}$ ) imposed on the sides of the block.

Additional assumptions are that the block will be heated for about 75 days, until the temperature at the heater plane reaches about $140^{\circ} \mathrm{C}$. This will be accomplished by supplying constant power to the heaters during this period. After the heater plane reaches $140^{\circ} \mathrm{C}$, the heater power will be reduced until a steady-state condition is reached in the block. This is expected to occur at about 180 days after the start of heating. The steady-state condition will then be maintained for the duration of the heating phase. 


\subsection{Instrumentation and Monitoring}

The following parameters are being measured in the LBT: temperature, relative humidity, gas pressure, moisture content (using both neutron logging and electrical resistivity tomography), thermal conductivity, thermal diffusivity, and displacements (both in boreholes and on fractures on the block surfaces). In addition to the measured parameters, monitoring is being conducted as follows: coupons of waste package material and man-made material were placed in some of the boreholes in the block so that they can be examined periodically. Microbes were introduced in the block so that their survivability and migration can be studied. Four observation holes were constructed near the bottom of the block for observing water drainage away from the block.

\subsection{Installation of Instruments}

Monitoring instruments within the block include:

- Resistancc temperature devices (RTDs) to measure temperatures in the block. A bundle of RTDs was grouted with cement in temperature holes. Some of the RTDs were placed in thin-walled stainless-steel tubes so that they could be calibrated or replaced during the test.

- Rapid evaluation of K and alpha (REKA) in situ. These thermal probes are used to determine thermal conductivity and thermal diffusivity (Danko et al., 1991).

- Extensometers and displacement transducers either installed in boreholes or mounted on the surface of the block.

- Relative humidity sensors (Humicaps), pressure transducers, and coupons of waste package materials (such as carbon steel and copper) installed in a packer system; the same holes are used to measure air permeability.

- Neutron logging within holes that are kept open with a Teflon tube liner. The annular space between the liner and borehole is sealed with cement grout.

- Electrical resistivity tomography (ERT) electrodes grouted in the ERT holes.

In addition, one 2.44-m-long, 300-W heating element with three RTDs attached to the heaters was installed in each of the five heater holes. Coupons of the WP material were also placed in the heater holes. Prior to emplacing the heaters, the holes were swabbed in preparation for microbe studies. The opening of the heater holes was plugged to prevent heat loss and to minimize moisture movement along the opening.

The following devices were mounted on the block surface:

- A temperature monitoring system at the top and side surfaces.

- ERT electrodes on the block sides.

After installation of the instruments and heaters, the block was sealed with thermal and moisture barriers on its four sides.

\subsection{Location of Instruments}

Figures 4-1 through 4-5 show the location of instrumentation that was installed in the block. The location of instruments is also shown in cross

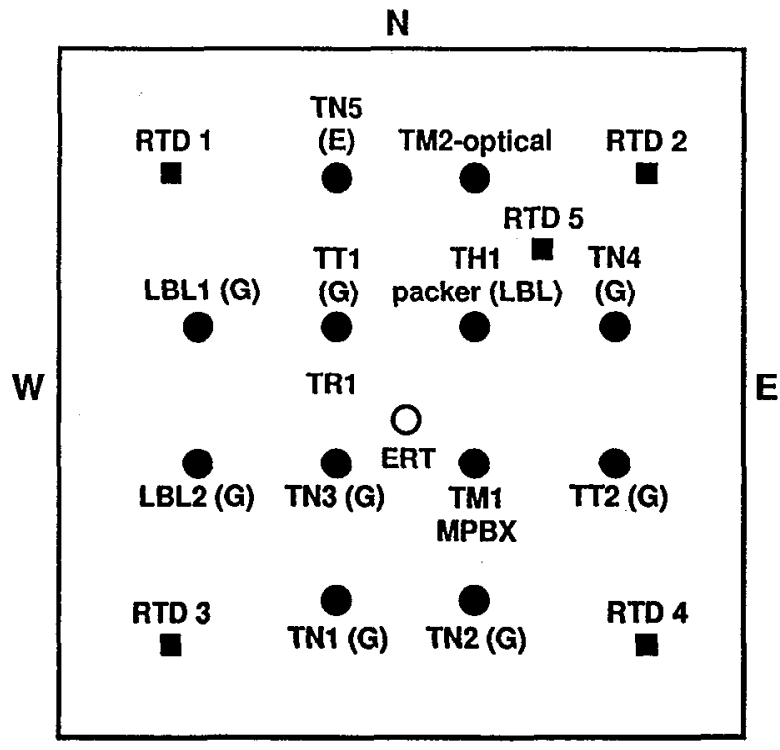

$\mathbf{S}$

TI\# - Temperature measurements - borehole RTD\#-Temperature - Surface mounted RTD

LBL\#-Open holes to be used by LBL for air and then grouted

TN\# - Neutron holes to be lined and grouted

TR1 - REKA probe - to be grouted

TM\# - Mechanical - MPBX borehole

Figure 4-1. Location of instruments on the top surface of the large block. 
sections in the results section of this report (Section 5). Table 4-1 summarizes the instrumentation types for each of the sides and the top of the block; Table 4-2 lists the instrumentation or holes by types and total numbers. Figure 4-6 shows the location of all the boreholes in the large block.
The 3D geomechanical response of the rock to the heating is being monitored using borehole extensometers and surface-mounted fracture gauges. Multiple-point borehole extensometers . (MPBXs) have been deployed a total of eight boreholes; three of these are horizontal with an
North side

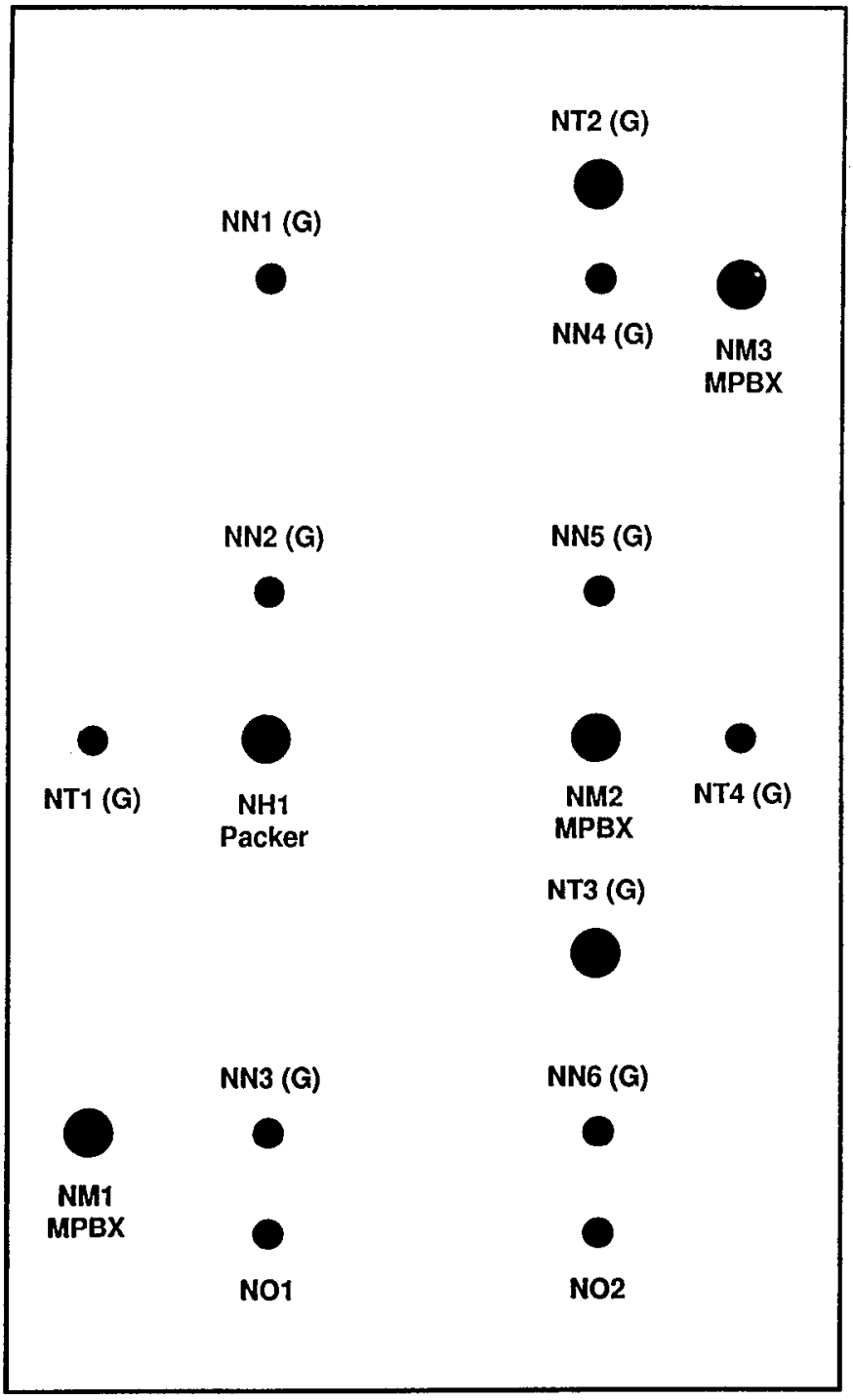

NN\# - North side neutron hole - to be lined and grouted

NT\# - North side temperature (RTD bundle) all to be grouted

NM\# - North side mechanical

NO\# - North side observation hole

NH\# - North side hydrology - packer assembly to be installed

Figure 4-2. Location of instruments on the north face of the large block.

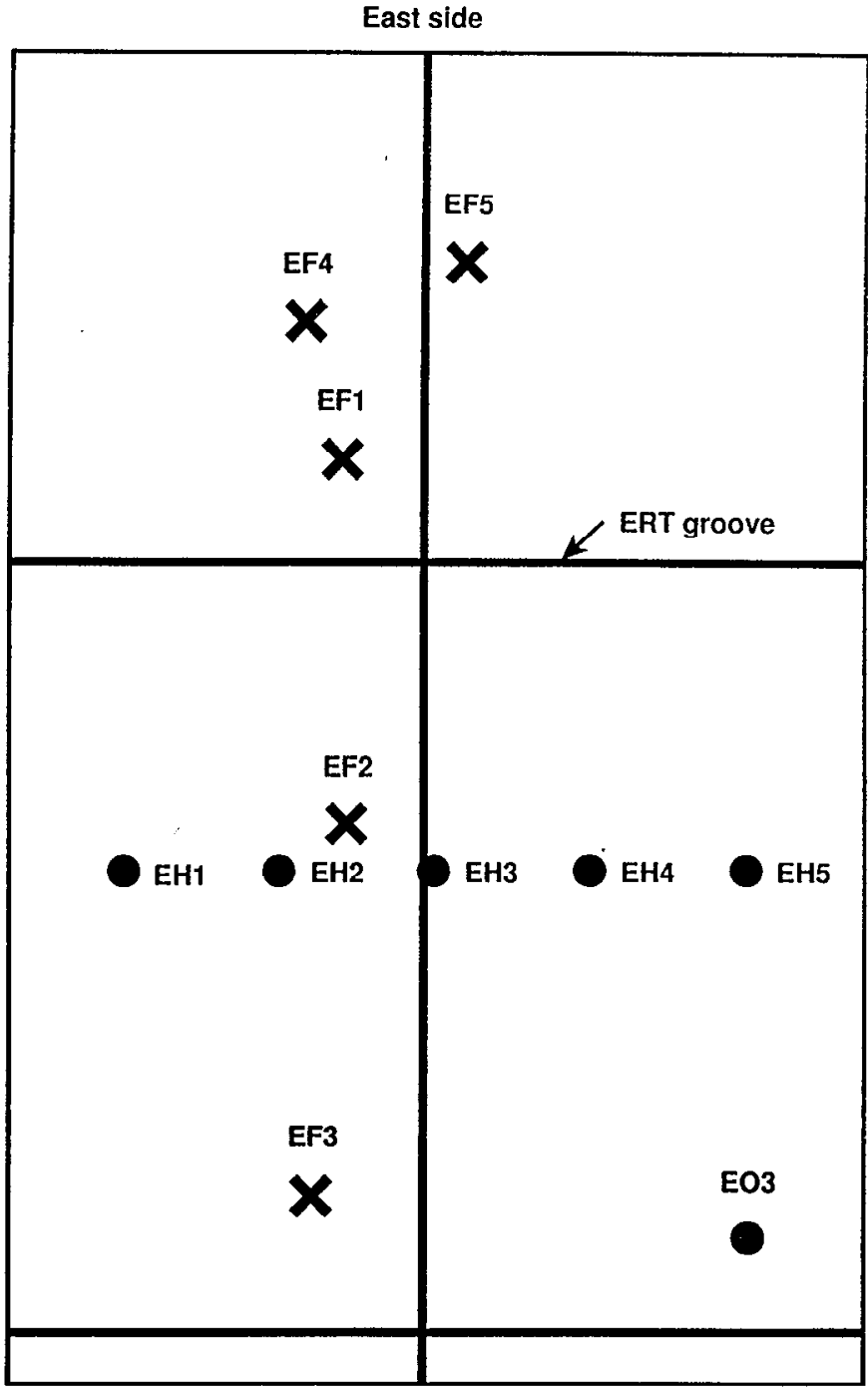

EH\# - East heater hole (heater assembly w/ERT)

EO - East observation

EF\# - Fracture monitors

Figure 4-3. Location of instruments on the east face of the large block. 
E-W orientation, three are horizontal with a N-S orientation, and two are vertical. Furthermore, two different types of MPBXs are being used. Conventional MPBXs have been installed in six of the holes. The locations of these holes and MPBX anchors in them are shown in Fig. 4-7.

\section{South side}

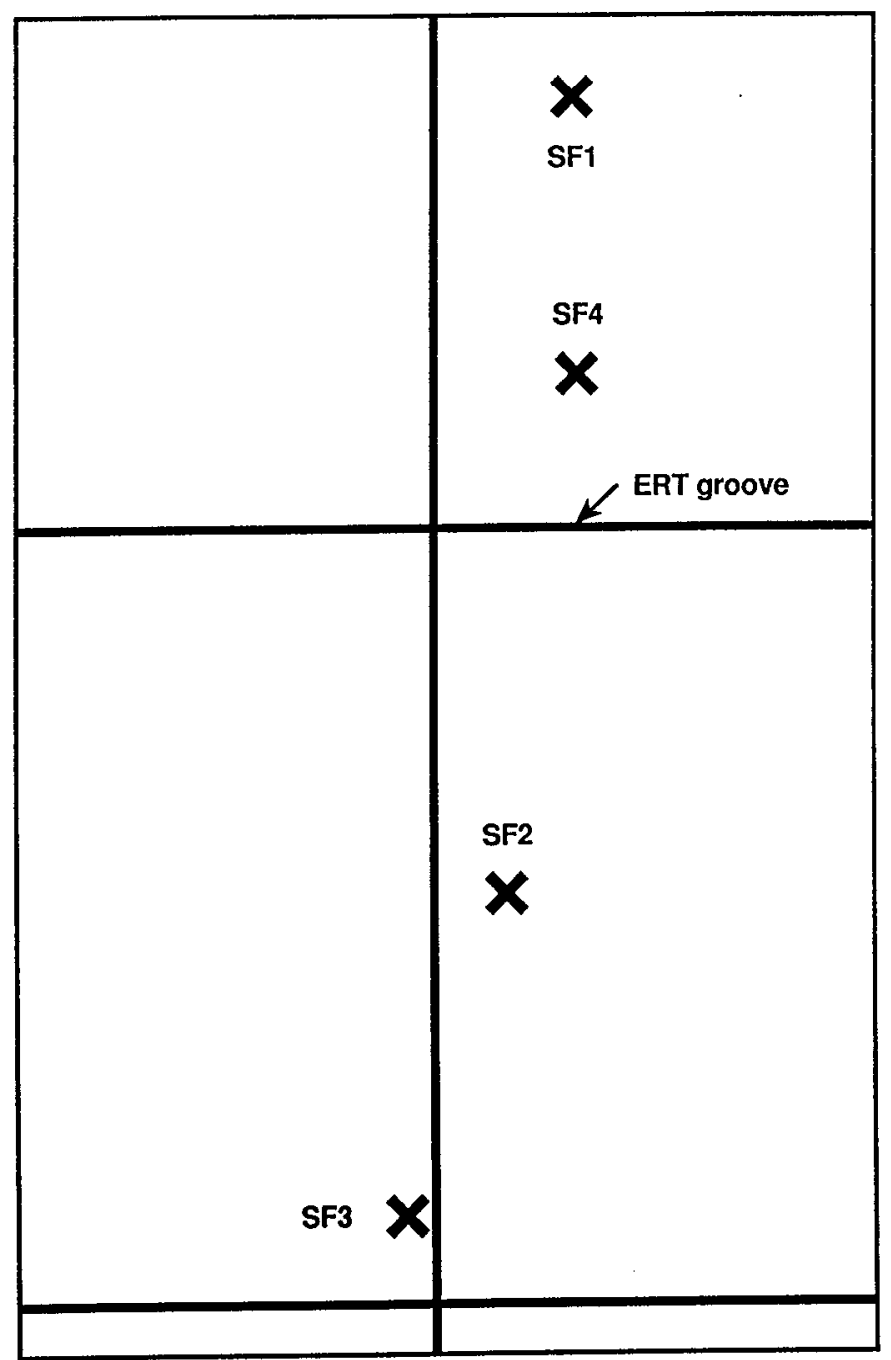

No boreholes with instruments

South fracture monltors (SF\#) and ERT only

Figure 4-4. Location of instruments on the south face of the large block.
A new optical extensometer is being used to monitor deformation in two of the holes (Blair, 1997). Deformation across fractures that intersect the surface is being monitored using three-component fracture monitors that have been installed at 17 locations on the surface of the block.

(Continued on page 37)

West side

WN1 (G) WT1 (G)

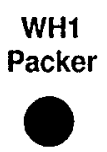

WM2

MPBX

WN2 (G)

WT2 (G)

WN4 (G)
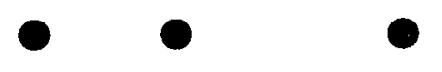

WH2 Packer

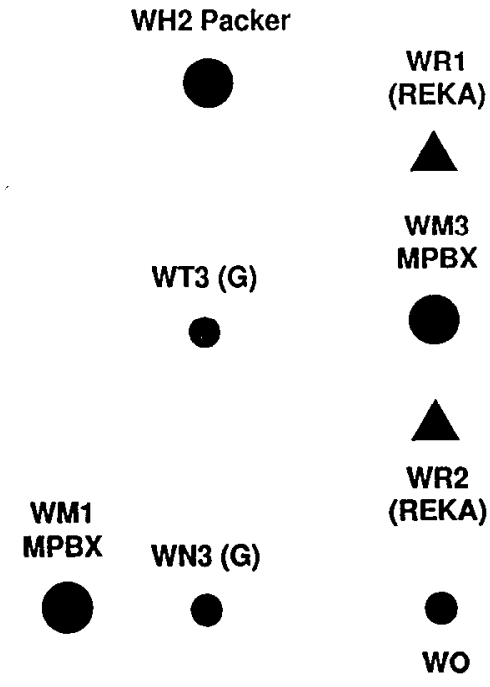

WN\# - West side neutron hole - to be lined and grouted WT\# - West side thermal (RTD bundle) to be grouted WH\# - West side horizontal - packer assembly to be installed WM\# - West side mechanical (MPBX) hole - to be grouted WO\# - West side observation hole

Figure 4-5. Location of instruments on the west face of the large block. 
Table 4-1. Borehole listing and instrument type by block surface.

\begin{tabular}{|c|c|c|c|}
\hline $\begin{array}{l}\text { Hole or } \\
\text { instrument } \\
\text { number }\end{array}$ & Description & Installation method & $\begin{array}{l}\text { Borehole } \\
\text { size } \\
\text { (inches) }\end{array}$ \\
\hline \multicolumn{4}{|c|}{ Top of block } \\
\hline RTD1 & Surface Mounted on Al plate & Clamp or epoxy after coils emplaced & \\
\hline RTD2 & Surface Mounted on Al plate & & \\
\hline RTD3 & Surface Mounted on Al plate & & \\
\hline RTD4 & Surface Mounted on Al plate & & \\
\hline RTD5 & Surface Mounted on Al plate & & \\
\hline TN1 & Neutron liner grouted in place & & 1.5 \\
\hline TN2 & Neutron liner grouted in place & & 1.5 \\
\hline TN3 & Neutron liner grouted in place & & 1.5 \\
\hline TN4 & Neutron liner grouted in place & & 1.5 \\
\hline TN5 & Neutron liner grouted in place & & 1.5 \\
\hline I'M1 & Mech MPBX grouted in & & 3.0 \\
\hline TM2 & Optical extens with liner & & 3.0 \\
\hline TH1 & Hydrol with packer & LBL will used for $K$ test, then install & 3.0 \\
\hline TT1 & RTDs grouted & 30 RTD bundle & 1.5 \\
\hline TT2 & RTDs grouted & 30 RTD bundle & 1.5 \\
\hline TR1 & Reka probe & 4-ft deep hole grouted after installed & 0.5 \\
\hline LBL1 & Open hole & Used for $K$ test and then grouted in & 1.5 \\
\hline LBL2 & Open hole & Used for $\mathrm{K}$ test and then grouted in & 1.5 \\
\hline \multicolumn{4}{|c|}{ North side } \\
\hline NN1 & Neutron liner grouted in place & & 1.5 \\
\hline NN2 & Neutron liner grouted in place & & 1.5 \\
\hline NN3 & Neutron liner grouted in place & & 1.5 \\
\hline NN4 & Neutron liner grouted in place & & 1.5 \\
\hline NN5 & Neutron liner grouted in place & & 1.5 \\
\hline NN6 & Neutron liner grouted in place & & 1.5 \\
\hline NT1 & RTDs grouted & 14 RTD bundle & 1.5 \\
\hline NT2 & RTDs grouted & 14 RTDs-larger borehole to grout & 3.0 \\
\hline NT3 & RTDs grouted & 14 RTDs-larger borehole to grout & 3.0 \\
\hline NT4 & RTDs grouted & 14 RTD bundle & 1.5 \\
\hline NM1 & Mech MPBX & Grouted after install & 3.0 \\
\hline
\end{tabular}


Table 4-1. (Continued)

\begin{tabular}{|c|c|c|c|}
\hline $\begin{array}{l}\text { Holc or } \\
\text { instrument } \\
\text { number }\end{array}$ & Description & Installation method & $\begin{array}{l}\text { Borehole } \\
\text { size } \\
\text { (inches) }\end{array}$ \\
\hline NM2 & Mech MPBX & Grouted after install & 3.0 \\
\hline NM3 & Mech MPBX & Grouted after install & 3.0 \\
\hline NH1 & Hydrol with packer & LBL may use for $\mathrm{K}$ test-then install & 3.0 \\
\hline NO1 & Observation hole & pyrex liner w/crape paper-pvc support & 1.5 \\
\hline \multirow[t]{2}{*}{$\mathrm{NO} 2$} & Observation hole & pyrex liner w/crape paper-pvc support & 1.5 \\
\hline & & West side & \\
\hline WN1 & Neutron liner grouted in place & & 1.5 \\
\hline WN2 & Neutron liner grouted in place & & 1.5 \\
\hline WN3 & Neutron liner grouted in place & & 1.5 \\
\hline WN4 & Neutron liner grouted in place & & 1.5 \\
\hline WM1 & Mech MPBX & grouted after emplacement & 3.0 \\
\hline WM2 & Mech MPBX & grouted after emplacement & 3.0 \\
\hline WM3 & Mech MPBX & grouted after emplacement & 3.0 \\
\hline WT1 & RTDs grouted & 14 RTD bundle & 1.5 \\
\hline WT2 & RTDs grouted & 14 RTD bundle & 1.5 \\
\hline WT3 & RTDs grouted & 14 RTD bundle & 1.5 \\
\hline WH1 & Hydrol w/ packer & LBL may use for $\mathrm{K}$ test-then install & 3.0 \\
\hline WH2 & Hydrol w/ packer & LBL may use for $K$ test-then install & 3.0 \\
\hline WR1 & Reka Probe & Grout after install & 0.5 \\
\hline WR2 & Reka Probe & Grout after install & 0.5 \\
\hline \multirow[t]{3}{*}{ wo } & Observation hole & pyrex liner w/crape paper-pvc support & 1.5 \\
\hline & & $\begin{array}{l}\text { South side: } \\
\text { no boreholes }\end{array}$ & \\
\hline & & East side & \\
\hline EH1 & heater & Centralizers, RTDs and heaters & 1.5 \\
\hline $\mathrm{EH} 2$ & heater & Centralizers, RTDs and heaters & 1.5 \\
\hline EH3 & heater & Centralizers, RTDs and heaters & 1.5 \\
\hline EH4 & heater & Centralizers, RTDs and heaters & 1.5 \\
\hline EH5 & heater $\quad \cdots \cdot$ & Centralizers, RTDs and heaters & 1.5 \\
\hline EO & Observation hole & pyrex liner $w /$ crape paper-pvc support & 1.5 \\
\hline
\end{tabular}


Table 4-2. Borehole and instrument listing by instrument type.

\begin{tabular}{cllc}
$\begin{array}{c}\text { Hole or } \\
\text { instrument } \\
\text { number }\end{array}$ & \multicolumn{1}{c}{$\begin{array}{c}\text { Description } \\
\text { Neutron holes }\end{array}$} & $\begin{array}{c}\text { Borehole } \\
\text { size } \\
\text { inches) }\end{array}$ \\
\hline TN1 & Neutron liner grouted in place & $1 / 16 / 97$, grouted & 1.5 \\
TN2 & Neutron liner grouted in place & $1 / 16 / 97$, grouted & 1.5 \\
IN3 & Neutron liner grouted in place & $1 / 16 / 97$, grouted & 1.5 \\
TN4 & Neutron liner grouted in place & $1 / 16 / 97$, grouted & 1.5 \\
TN5 & Neutron liner grouted in place & $1 / 16 / 97$, grouted & 1.5 \\
NN1 & Neutron liner grouted in place & $1 / 16 / 97$, grouted & 1.5 \\
NN2 & Neutron liner grouted in place & $1 / 16 / 97$, grouted & 1.5 \\
NN3 & Neutron liner grouted in place & $1 / 16 / 97$, grouted & 1.5 \\
NN4 & Neutron liner grouted in place & $1 / 16 / 97$, grouted & 1.5 \\
NN5 & Neutron liner grouted in place & $1 / 16 / 97$, grouted & 1.5 \\
NN6 & Neutron liner grouted in place & $1 / 16 / 97$, grouted & 1.5 \\
WN1 & Neutron liner grouted in place & $1 / 16 / 97$, grouted & 1.5 \\
WN2 & Neutron liner grouted in place & $1 / 16 / 97$, grouted & 1.5 \\
WN3 & Neutron liner grouted in place & $1 / 16 / 97$, grouted & 1.5 \\
WN4 & Neutron liner grouted in place & $1 / 16 / 97$, grouted & 1.5 \\
Total $=15$ & & & \\
\hline
\end{tabular}

\begin{tabular}{clll}
\hline & & & \\
TT1 & RTDs grouted & RTD holes & 1.5 \\
TT2 & RTDs grouted & 30-RTD bundle & 1.5 \\
NT1 & RTDs grouted & 30-RTD bundle & 1.5 \\
NT2 & RTDs grouted & 14-RTD bundle & 3.0 \\
NT3 & RTDs grouted & 14 RTDs-larger borehole to grout & 3.0 \\
NT4 & RTDs grouted & 14 RTDs-larger borehole to grout & 3.0 \\
WT1 & RTDs grouted & 14-RTD bundle & 1.5 \\
WT2 & RTDs grouted & 14-RTD bundle & 1.5 \\
WT3 & RTDs grouted & 14-RTD bundle & 1.5 \\
Total $=9$ & & 14-RTD bundle & 1.5 \\
\hline
\end{tabular}

MPBX holes

TM1 Mech MPBX grouted in 3.0

NM1 Mech MPBX $\quad$ Grouted after install $\quad 3.0$

NM2 Mech MPBX $\quad$ Grouted after install 3.0 
Table 4-2. (Continued)

\begin{tabular}{|c|c|c|c|}
\hline $\begin{array}{l}\text { Hole or } \\
\text { instrument } \\
\text { number }\end{array}$ & Description & Installation method & $\begin{array}{l}\text { Burehole } \\
\text { size } \\
\text { (inches) }\end{array}$ \\
\hline \multicolumn{4}{|c|}{ MPBX holes (continued) } \\
\hline NM3 & Mech MPBX & Grouted after install & 3.0 \\
\hline WM1 & Mech MPBX & grouted after emplacement & 3.0 \\
\hline WM2 & Mech MPBX & grouted after emplacement & 3.0 \\
\hline WM3 & Mech MPBX & grouted after emplacement & 3.0 \\
\hline \multicolumn{4}{|l|}{ Total $=7$} \\
\hline \multicolumn{4}{|c|}{ Optical extensometer } \\
\hline TM2 & Optical extens with liner & & 3.0 \\
\hline \multicolumn{4}{|l|}{ Total $=1$} \\
\hline \multicolumn{4}{|c|}{ Hydro packers } \\
\hline TH1 & Hydrol w/ packer & LBL will used for $\mathrm{K}$ test-then install & 3.0 \\
\hline $\mathrm{NH} 1$ & Hydrol w/ packer & LBL may use for $K$ test-then install & 3.0 \\
\hline WH1 & Hydrol w/ packer & LBL may use for $\mathrm{K}$ test-then install & 3.0 \\
\hline WH2 & Hydrol w/ packer & LBL may use for $K$ test-then install & 3.0 \\
\hline \multicolumn{4}{|l|}{ Total $=4$} \\
\hline \multicolumn{4}{|c|}{ Observation } \\
\hline NO1 & Observation hole & pyrex liner $w /$ crape paper-pvc support & 1.5 \\
\hline $\mathrm{NO} 2$ & Observation hole & pyrex liner $w /$ crape paper-pvc support & 1.5 \\
\hline WO & Observation hole & pyrex liner w/crape paper-pvc support & 1.5 \\
\hline EO & Observation hole & pyrex liner $w /$ crape paper-pvc support & 1.5 \\
\hline Total $=4$ & & & \\
\hline
\end{tabular}

Temperature and fluid movement in the block are also being monitored, and the geomechanical data are being interpreted in conjunction with these other data sets.

\subsection{Data Acquisition}

The LBT features two data acquisition modes: automated data acquisition by a data acquisition system (DAS) and manual data acquisition. The data acquired by the DAS include temperature, pressure, displacement, wattage, voltage output from chemical sensors and Humicaps, and ERT. Data being collected manually include neutron logging, REKA, acoustic emission and velocity, and air permeability. Water sampling is also being conducted manually. Data from the DAS are transferred to Los Alamos National Laboratory (LANL) for incorporation into their data control system and are placed on CDs for permanent $Q A$ data records. 


\subsection{Microbial Studies}

Installation of labeled microbe samples into the large block is described in a letter report by Meike and Horn (SPLG1BM4, 1997). The following is a summary of that report.

Two strains (and their drug-resistant variants) used in the LBT are LB-71h-50-4 (Bacillus subtillus) and LB-CW-6 (Arthrobacter oxydans). The strains were isolated in 1995 from rocks collected at the LBT site. Cell colonies were estimated by a Coulter Counter, and live plating on R2A agar was also used to enumerate bacterial and cell concentrations.

Two types of microbe tests were installed in the large block. The survival test contains temporary-class items that will be retrieved after the test. The migration test contains permanent material (agar and inoculum) that may not be entirely retrieved after the test.

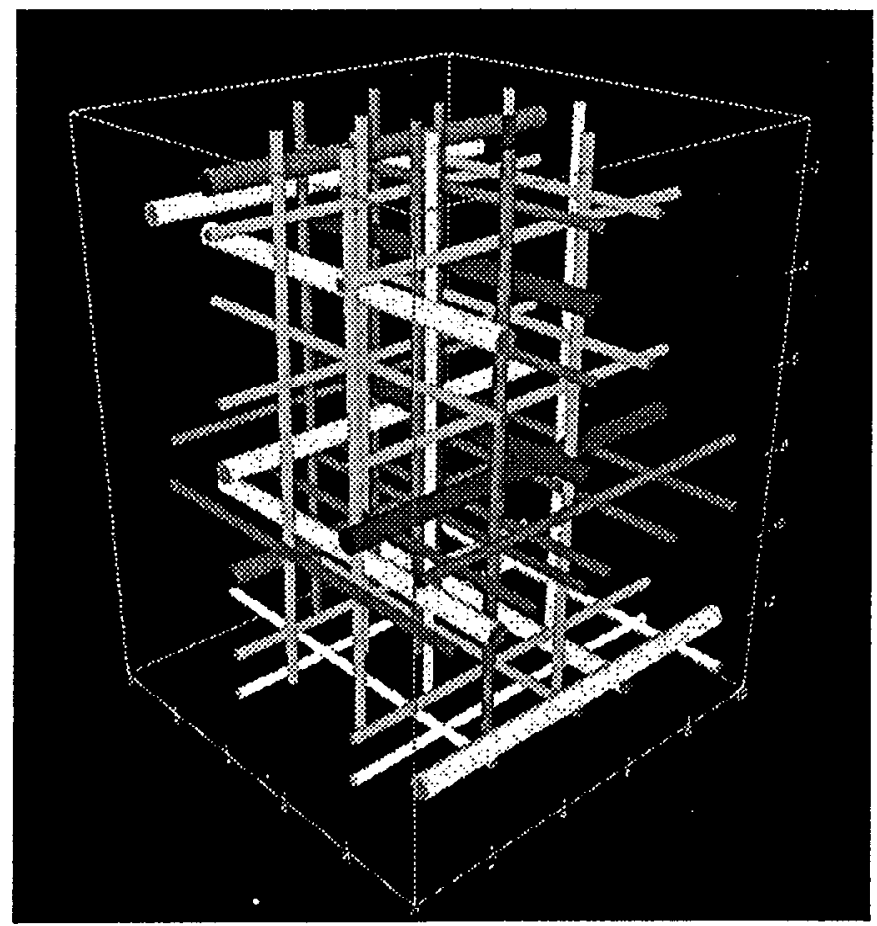

Blue $=$ Hydrology

Green $=$ Neutron

White = Observation Yellow $=$ MPBX Red $=$ Heater Brown $=$ Temperature

Figure 4-6. Location of all boreholes in the large block.

\subsubsection{Survival Test}

Three types of emplacements will provide information on material survival as a function of temperature, interaction with grout contact, and rock-water interaction. In two emplacements, $10^{7}$ cells of each strain were emplaced onto each filter. In the third emplacement, each strain was emplaced on a separate filter and bagged separately. Two emplacements were made on February 14, 1997 using C-spring clips. Microbes were strained onto a fiberglass filter placed in semipermeable dialysis tubing. The sample bag was sandwiched between a thin silicon rubber gasket and an Ultem ${ }^{\mathrm{TM}} \mathrm{c}$ clip, to press the microbe sample against the rock. The gaskets were manufactured by curing sheets of 2-part 3110 RTV silicone rubber compound. Both macroporous and nonmacroporous gaskets were used.

The clips were emplaced in boreholes LBL1 and LBL2 (see Fig. 4-1) using a mandril to hold the

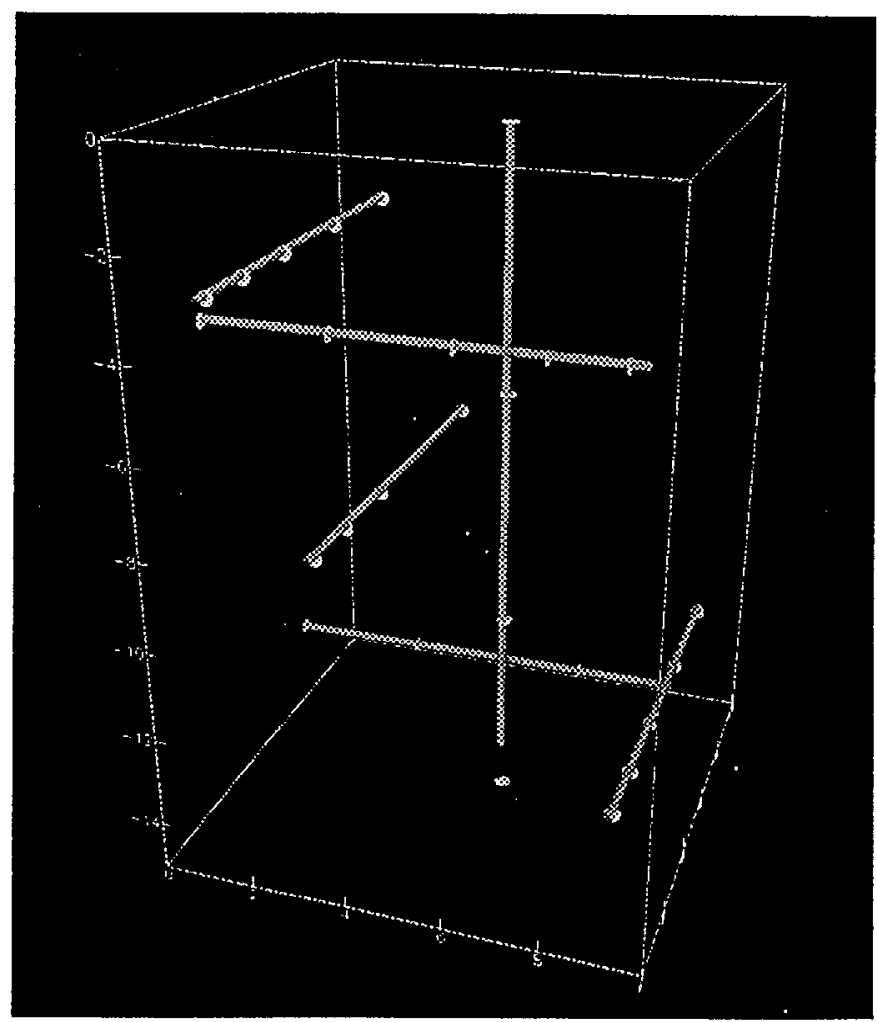

Figure 4-7. Location of boreholes with extensometers and MPBX anchors. 
specimens at the desired depth and removing the clip by means of an attached cable. Eight macroporous samples were emplaced in LBL1 at depths from about 12.5 to $2 \mathrm{ft}$ from the block's upper surface. Eight nonmacroporous samples were emplaced in LBL2 at depths from 15 to $1 \mathrm{ft}$ from the upper surface. A third emplacement was made coincident with emplacement of ERT sensors on January 15, 1997. Microbe coupons were taped to a PVC pipe at 2-ft intervals such that the upper coupon was $1 \mathrm{ft}$ from the surface.

\subsubsection{Migration Test}

Inoculated agar was extruded into the five horizontal heater holes on 14 February, 1997. Agar was extruded laterally from the end of a 9-ft length of PCV pipe. A total of $4 \mathrm{~L}$ of agar was evenly distributed among five boreholes. These microbes were labeled using one of two methods; double drug resistance (Rifampicin and Streptomycin) or a fluorescent dye. In addition to the microbes, $1-\mu \mathrm{m}$-diameter microspheres were added to the agar to assess nonself-motile particle migration.

Samples will be collected from a statistically determined, 3D matrix of locations throughout the large block during disassembly to determine whether the microbes have migrated from their original positions. It is expected that most of the microbes will not be recovered. Given that the strains were originally isolated from the area and extant in the block and adjacent area, complete recovery of microbes is not necessary.

\subsection{Baseline Data Collection and Heater Turn-On}

After all instrumentation was installed in the block and the moisture barrier and insulation were installed outside of the block, final characterization was completed with the cross-hole permeability and tracer tests described earlier. When the final characterization was completed, heaters and packers were installed (heater holes and hydrology holes had been used in the permeability and tracer tests), and baseline monitoring was initiated. A minimum of two weeks of baseline data were collected. (Some instrumentation was able to take baseline data earlier. Nearly a month of baseline temperature data were collected.) The heaters were then turned on February 28, 1997. 


\subsection{Results}

This section summarizes measurements on pre-heat air permeability, temperature, moisture content by electrical resistivity tomography (ERT), moisture content by neutron logging, and displacements.

\subsection{Air Injection Measurements}

We performed single-borehole air injection measurements to characterize the bulk permeability profile of the fractured rock mass along a vertical borehole. We used a two-packer assembly to inject air at different pressures into packed-off sections of borehole TH1, then estimated the bulk permeability of the rock adjacent to the section from the steady-state injection rate and test zone pressure. The permeability profile was measured prior to cutting the block and then repeated following block construction. The measurements were repeated to investigate the effects of block construction, borehole drilling, and grouting on the permeability profile. To observe any effects of the heating on bulk permeability, the measurements will be repeated after completion of the heating and cooling cycle.

Air was injected into a packed-off section of the borehole. The air-mass flow rate and the testcavity pressure and temperature were measured and used to estimate the bulk permeability of rock mass around the test zone. Permeability is computed using Forcheimer's flow equation, the continuity equation, and the ideal gas law. For the final report, a more detailed analysis of the data will be done using numerical modeling.

The packer assembly was first placed in the borehole with the test cavity centered at a depth of about $4 \mathrm{ft}$ from the collar. The packers were inflated to about $\mathbf{1 1 0}$ psi pressure to seal and isolate the test interval. Air was injected to obtain a steady-state pressure of at least 2 psig. The mass flow rate of air into the test interval, the interval pressure, and temperature were recorded. At each borehole depth, the measurements are done for two to five steady-state pressures.

\subsubsection{Data Analysis}

For gas flow through porous media, under both laminar and turbulent conditions, the appropriate flow equation is Forcheimer's quadratic equation, which in radial coordinates is:

$$
-\frac{d P}{d r}=\frac{\mu q}{k}+\beta \rho q^{2}
$$

where

$P=$ gas pressure

$r=$ radial flow distance

$\mu=$ viscosity

$q=$ darcy velocity

$k=$ bulk permeability

$\beta=$ turbulence factor

$\rho=$ gas density.

The relevant continuity and constitutive equations are:

$$
Q_{m}=2 \pi r \rho q L
$$

and

$$
\rho=\frac{M P}{Z R T}
$$

where

$Q_{\mathrm{m}}=$ mass flow rate

$L=$ length of borehole test interval

$M=$ molecular weight of gas

$\mathrm{Z}=$ gas compressibility factor (approximately 1.0

for low pressures used here)

$R=$ universal gas constant

$T=$ absolute temperature.

For steady-state, radial, isothermal flow of a gas injected into a packed-off borehole interval, the 
following equation can be derived to obtain the bulk permeability:

$$
\frac{\pi L M\left(P_{b}^{2}-P_{e}^{2}\right)}{\pi R T Q_{m} \ln \left(r_{e} / r_{b}\right)}=\frac{\beta Q_{m}\left(1 / r_{b}-1 / r_{e}\right)}{2 \mu \pi L \ln \left(r_{e} / r_{b}\right)}+\frac{1}{k}
$$

Equation (4) may be rewritten in the form of a linear equation:

$$
Y=\beta X+\frac{1}{k}
$$

\subsubsection{Results}

Figure 5-1 shows the results of the permeability measurements both before and after cutting the block. Test results are also presented in Table 5-1. The permeability, measured in a 19-inch borehole interval, varies by over six orders of magnitude, from about $4 \times 10^{-5}$ darcy at a depth of $5.5 \mathrm{ft}$ to 8 darcy at $10.8 \mathrm{ft}$. No significant permeability changes due to block construction were observed.

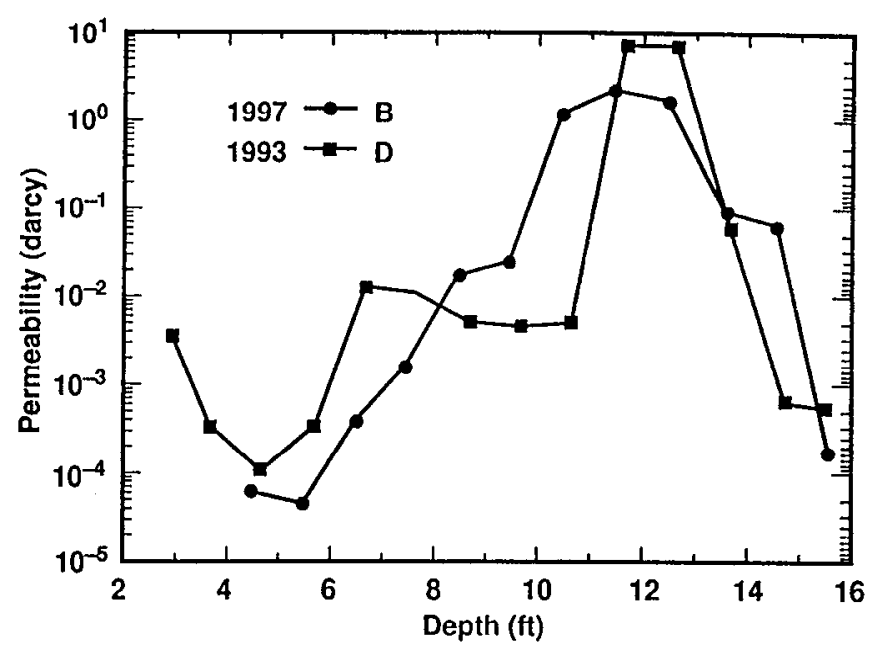

Figure 5-1. Comparison of air permeability profiles along borehole TH1 from 1993 and 1997 tests.

Table 5-1. Preliminary results of LBT air injection tests conducted in boreholes TH1 and WH2 on January 27 and 28, 1997.

\begin{tabular}{llccc}
\hline Hole & Test & Depth (ft) & $\begin{array}{c}\text { Permeability with other } \\
\text { holes sealed (darcy) }\end{array}$ & $\begin{array}{c}\text { Permeability with other } \\
\text { holes open (darcy) }\end{array}$ \\
\hline TH1 & Tst16.5 & 15.5 & $1.59 \times 10^{-4}$ & $1.48 \times 10^{-4}$ \\
TH1 & Tst15.5 & 14.5 & $6.45 \times 10^{-2}$ & $3.82 \times 10^{-2}$ \\
TH1 & Tst14.6 & 13.6 & $8.91 \times 10^{-2}$ & \\
TH1 & Tst13.5 & 12.5 & 1.80 & 2.10 \\
TH1 & Tst12.5 & 11.5 & 2.26 & 1.52 \\
TH1 & Tst11.5 & 10.5 & 1.20 & \\
TH1 & Tst10.5 & 9.5 & $2.46 \times 10^{-2}$ & $1.94 \times 10^{-2}$ \\
TH1 & Tst9.5 & 8.5 & $1.81 \times 10^{-2}$ & \\
TH1 & Tst8.5 & 7.5 & $1.63 \times 10^{-3}$ & $4.2 \mathrm{e} \times 10^{-5}$ \\
TH1 & Tst7.5 & 6.5 & $3.75 \times 10^{-4}$ & \\
TH1 & Tst6.5 & 5.5 & $4.74 \times 10^{-5}$ & \\
TH1 & Tst5.5 & 4.5 & $6.07 \times 10^{-5}$ & \\
WH2 & Tsth5.0 & 5.0 & 0.265 & \\
WH2 & Tsth4.0 & 4.0 & 0.307 &
\end{tabular}




\subsection{Temperature}

Temperatures in the large block are measured using resistance temperature devices (RTDs) both in boreholes and on the surfaces of the block. Borehole temperature measurements are being conducted in fourteen boreholes: two vertical holes (TT1 and TT2), seven horizontal holes (NT1, NT2, NT3, NT4, WT1, WT2, and WT3), and the five heater holes (EH1 to EH5). The location of these holes was described in Section 4 of this report.

The two vertical RTD holes and the seven horizontal RTD holes were sealed with cement grout; the five heater holes are not sealed. The temperatures measured from the surfacemounted RTDs on the four vertical sides of the large block are to monitor the heat flux away from the block. The temperatures measured from the RTDs on the top of the block are used to monitor the temperature on top of the block, which is controlled by a heat exchanger to be at $60^{\circ} \mathrm{C}$. In this report, the temperature measured from the two vertical RTD holes and the seven horizontal RTD holes will be presented in figures. The RTDs in those holes were separated by a spacing of $20 \mathrm{~cm}$. The RTD numbering was always starting from the bottom of a hole. For example, TT1-1 is the RTD at the bottom of the vertical RTD hole TT1, and NT1-14 is the RTD near the collar of the horizontal RTD hole NT1, which was drilled from the north face of the block and ended at a distance about $30 \mathrm{~cm}$ from the south face of the block. All of the other temperature data are available in spread sheets in the LLNL data base.

The five heaters of the LBT were energized at about 10 am on February 28, 1997 to a power level of about $450 \mathrm{~W}$ each. Background ambient temperature in the block was collected about 18 hours before the heaters were turned on. The data collection frequency was once per hour. The data acquisition frequency was increased to once per 10 minutes on June 30 , 1997 to have a more accurate monitoring of the temperature variations, which started on June 12, 1997. This will be discussed in greater detail later in this section.

Figures 5-2 and 5-3 show the history of the heating at TT1-14 and TT2-14. These two RTDs are $5 \mathrm{~cm}$ above and below the heater horizon, respectively. All of the sharp decreases in temperature, which occurred before 2500 hour, are related to power outages. The straight-line segment at about 3200 hour was caused by a temporary malfunction of the data acquisition

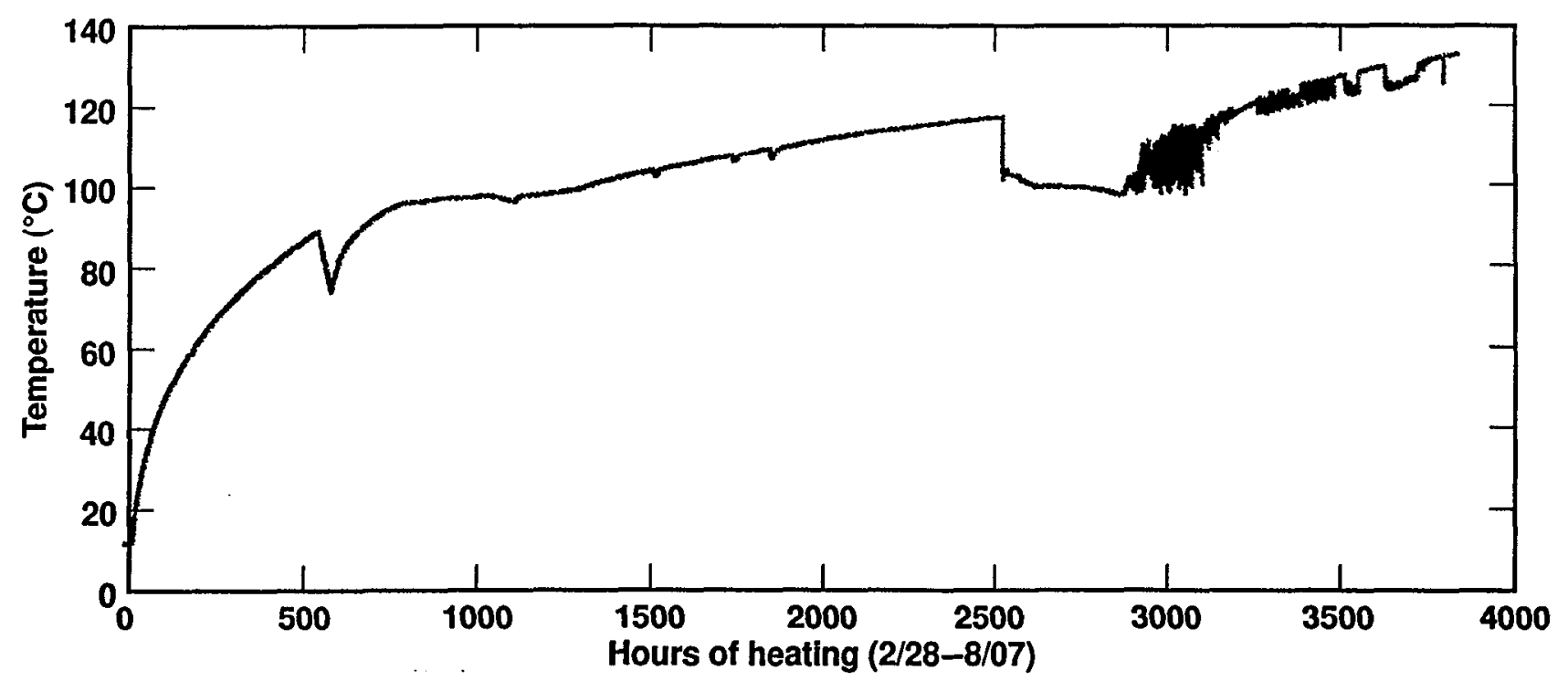

Figure 5-2. Temperature at TT1-14 as a function of time. 
system. Temperature variations after 2500 hour, as shown in Figs. 5-2 and 5-3, will be discussed later. Figures 5-4 and 5-5 show weekly snapshots of the temperatures measured at every RTD along TT1 and TT2, respectively. Again, the RTD numbers 1 through 30 in both TT1 and TT2 are from the bottom to the top of the block. The flat temperature profile involving several RTDs in both TT1 and TT2, when the temperature was about the boiling point of water, may be related to boiling of water in the rock. This topic will be discussed further later.

Figures 5-6 to 5-12 show weekly snapshots of the temperature profiles along the seven horizontal RTD holes NT1, NT2, NT3, NT4, WT1, WT2, and WT3, respectively. Again, for the NT series, the RTD number 1 is near the south side of the block; RTD number 14 is near the north side of the block. For the WT series, the RTD number 1 is near the east side of the block, and the RTD number 14 is near the west side of the block. Generally speaking, the horizontal temperature profiles are fairly flat.

All of the temperature data are input to EarthVision to construct a 3D contour of the temperature field within the block at certain instances. Figure 5-13 shows one example of the $3 \mathrm{D}$ contour of the temperatures in the block at about 10 am on August 7, 1997. This figure shows the temperature contour in a vertical cross section along TT1. With the 3D temperature field contour, temperatures within any cross section in the block can be illustrated.

As shown in Figure 5-2, the temperature in the block began to show abnormal behavior shortly after 2500 hour, which was on June 12, 1997. The following figures show the duration and spatial distribution of the temperature variations. Excel, which is the software used to plot the temperature data, has a limit of 4000 data points in each series. Therefore, the temperaturetime plots are divided into several figures. Figure 5-14 shows the temperatures at TT1-8 to TT1-13 as a function of time from June 12 to July 23 , 1997. Figure 5-15 shows the temperatures at TT114 to TT1-19 as a function of time from June 12 to July 23, 1997. As shown in these two figures the event at 2525 hour, in which the temperatures seemed to converge toward the boiling point of water, affected all of the RTDs included in those figures. But the amplitude of the temperature variation was most significant for TT1-13 to TT1-19. The cause of this event is still under investigation. One of the possible explanations is that some mechanisms, such as fracturing, released the pressure in the superheated pore

(Continued on page 53)

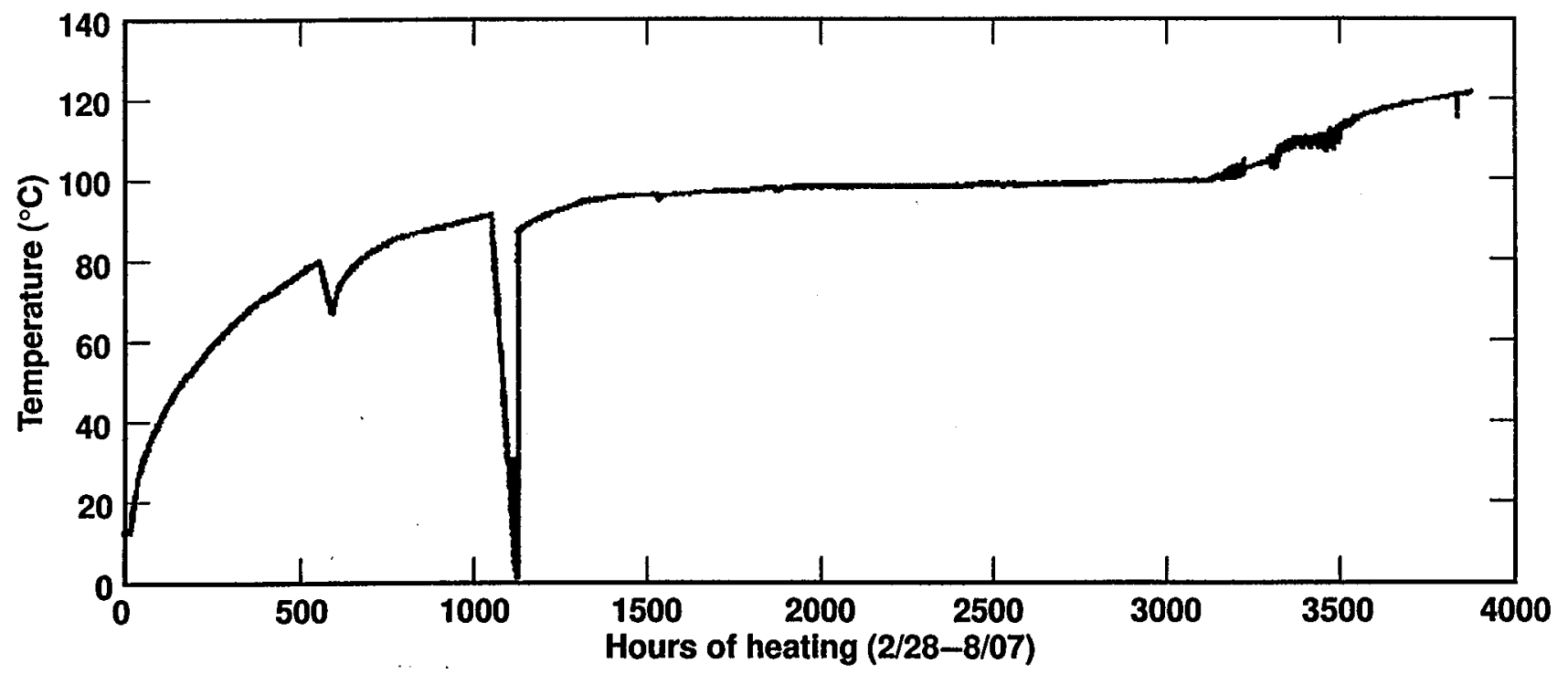

Figure 5-3. Temperature at TT2-14 as a function of time. 

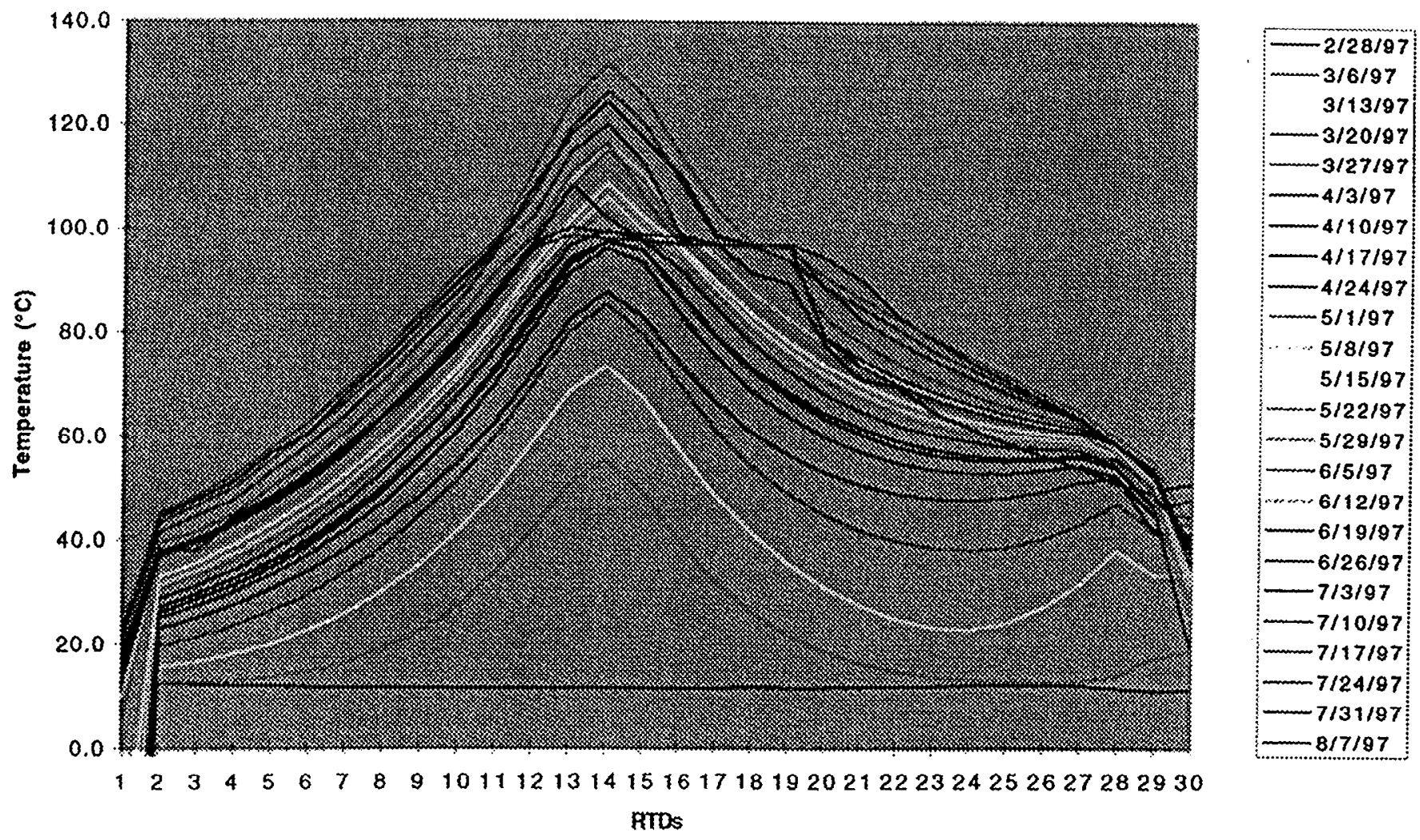

Figure 5-4. Weekly snapshots of temperature in TT1.

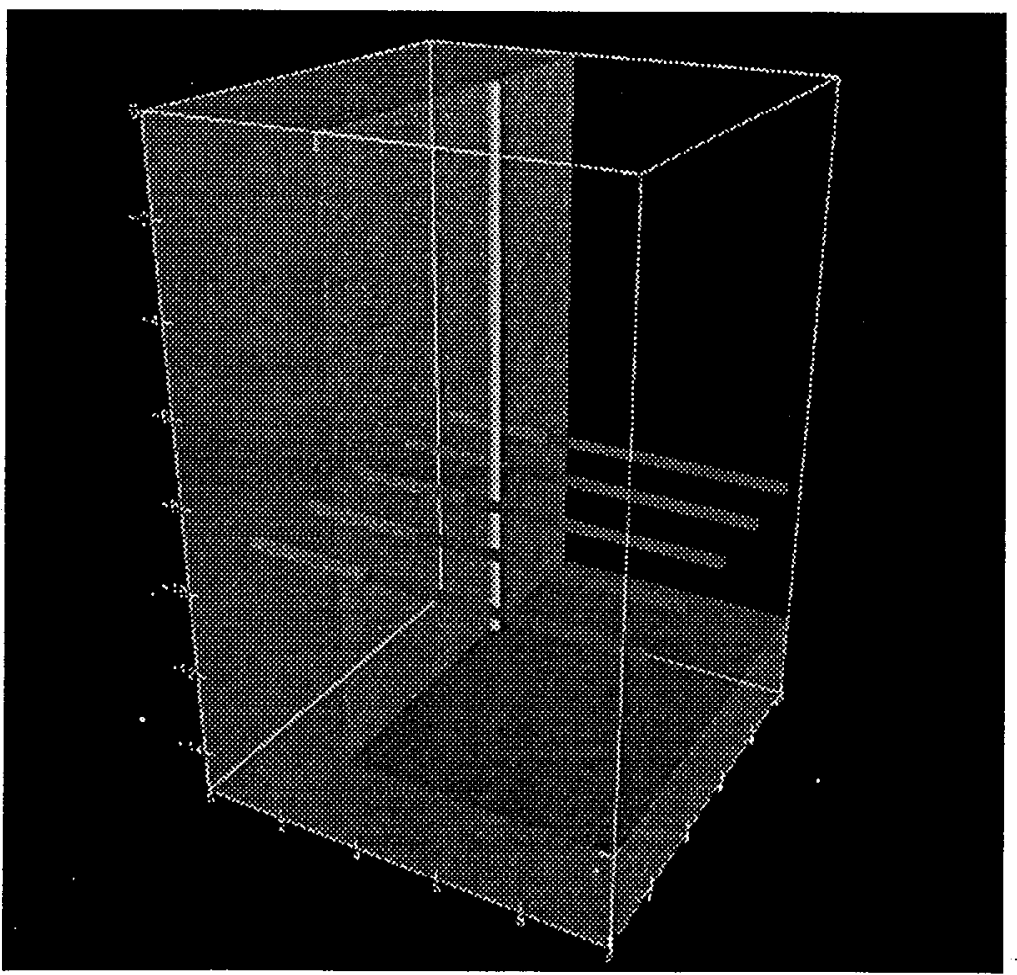

Location of borehole TT1 (and five heater boreholes) 

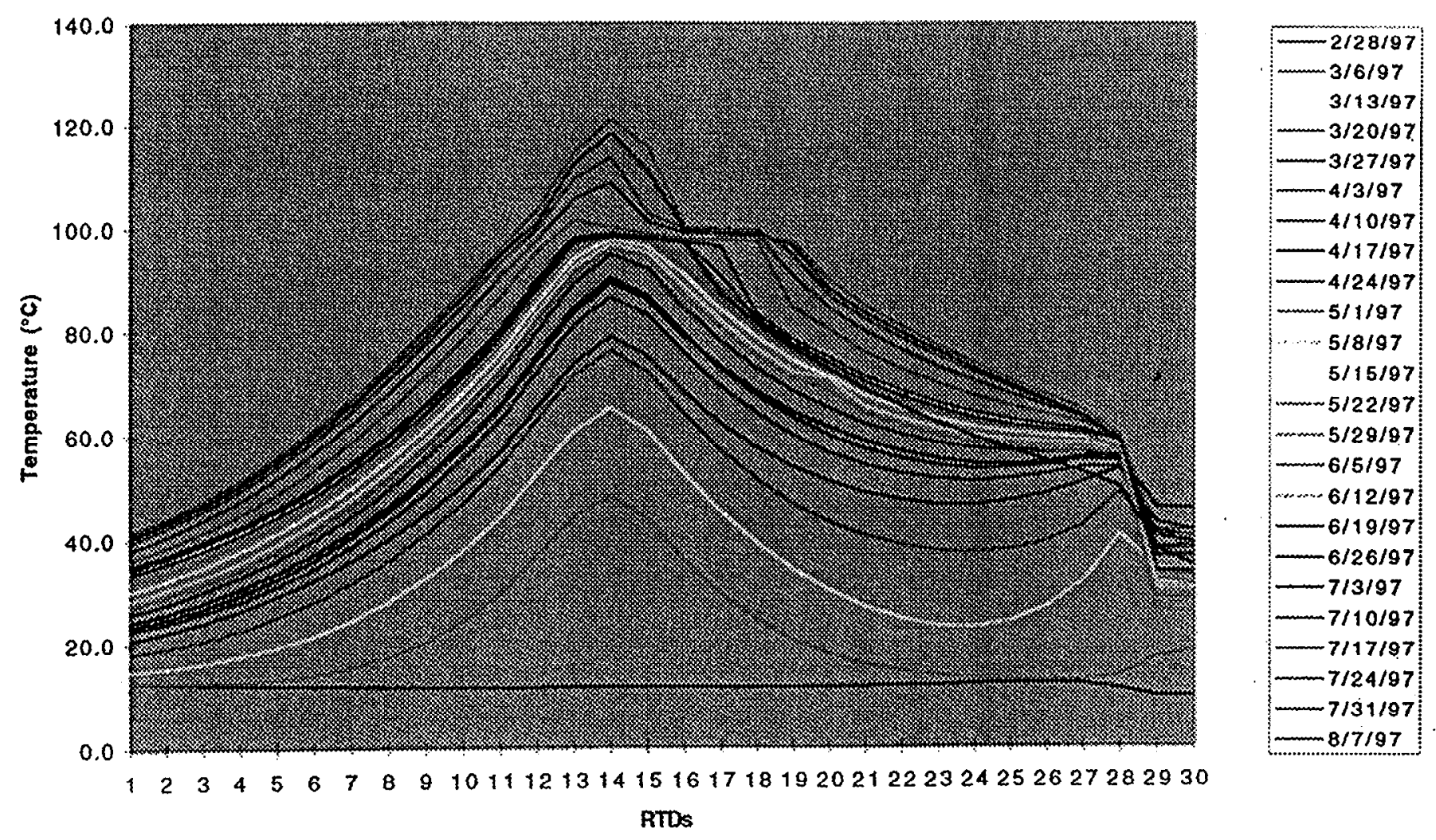

RTDS

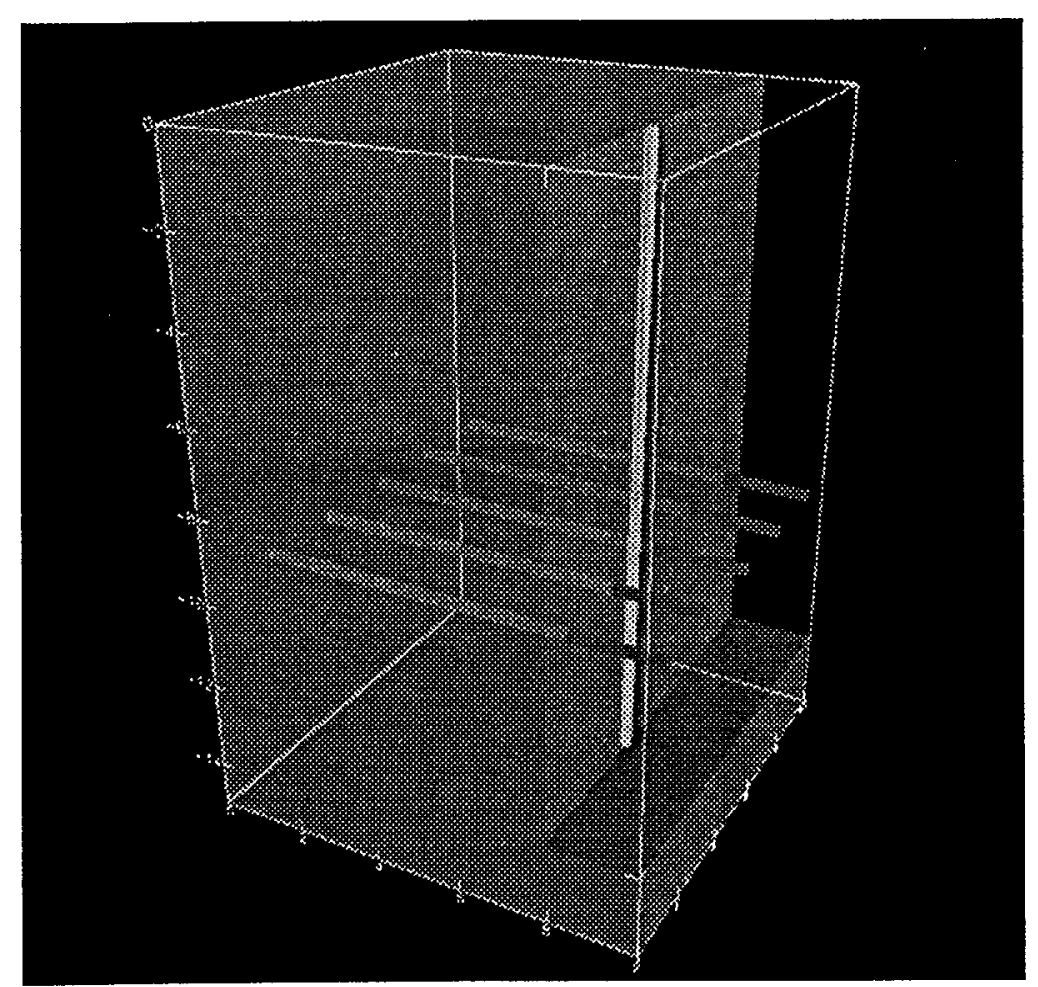

Figure 5-5.

Weekly snapshots of temperature in TT2.

Location of borehole $\mathrm{TT2}$ (and five heater boreholes) 

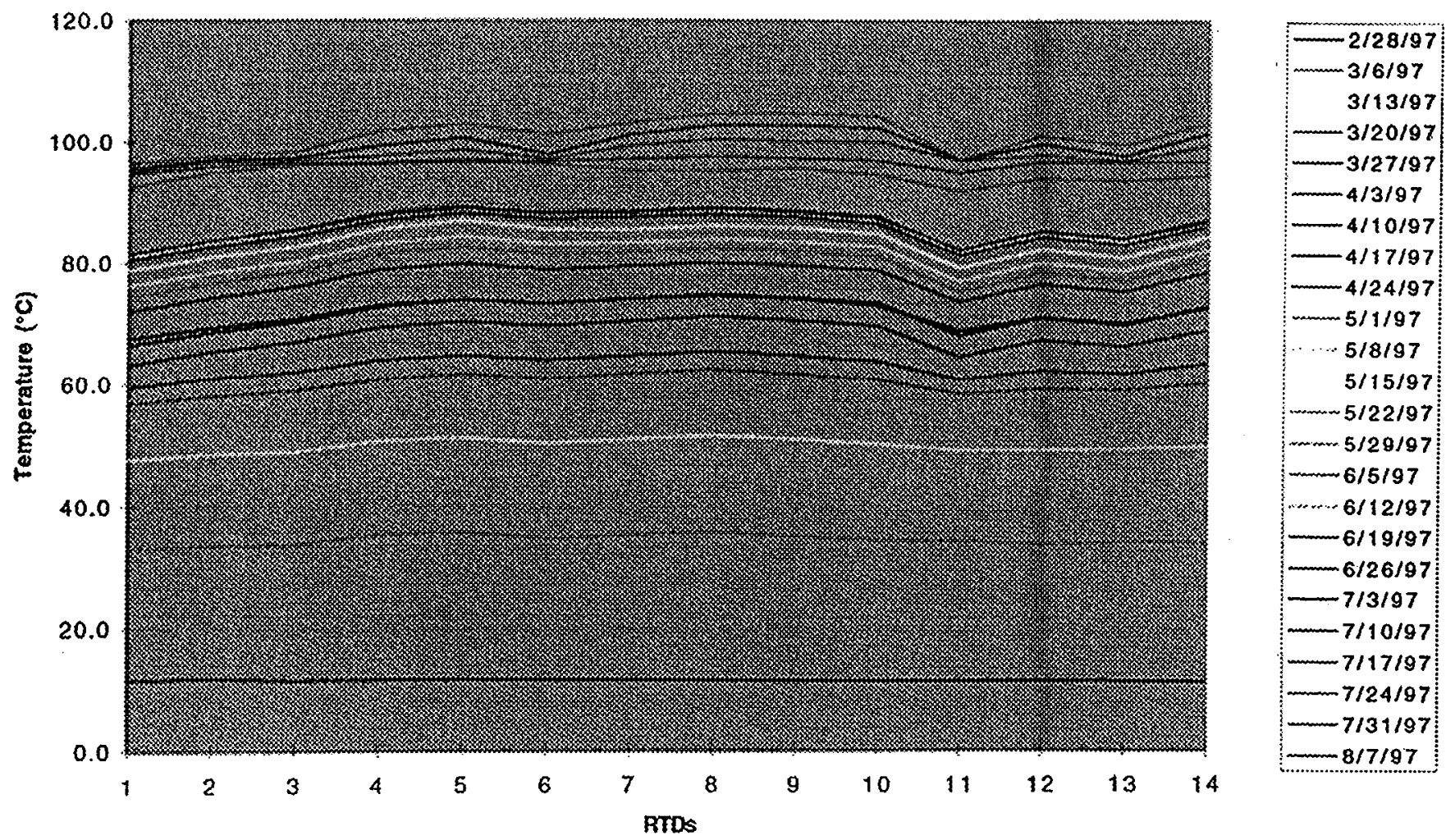

Figure 5-6.

Weekly snapshots of temperature in NT1.

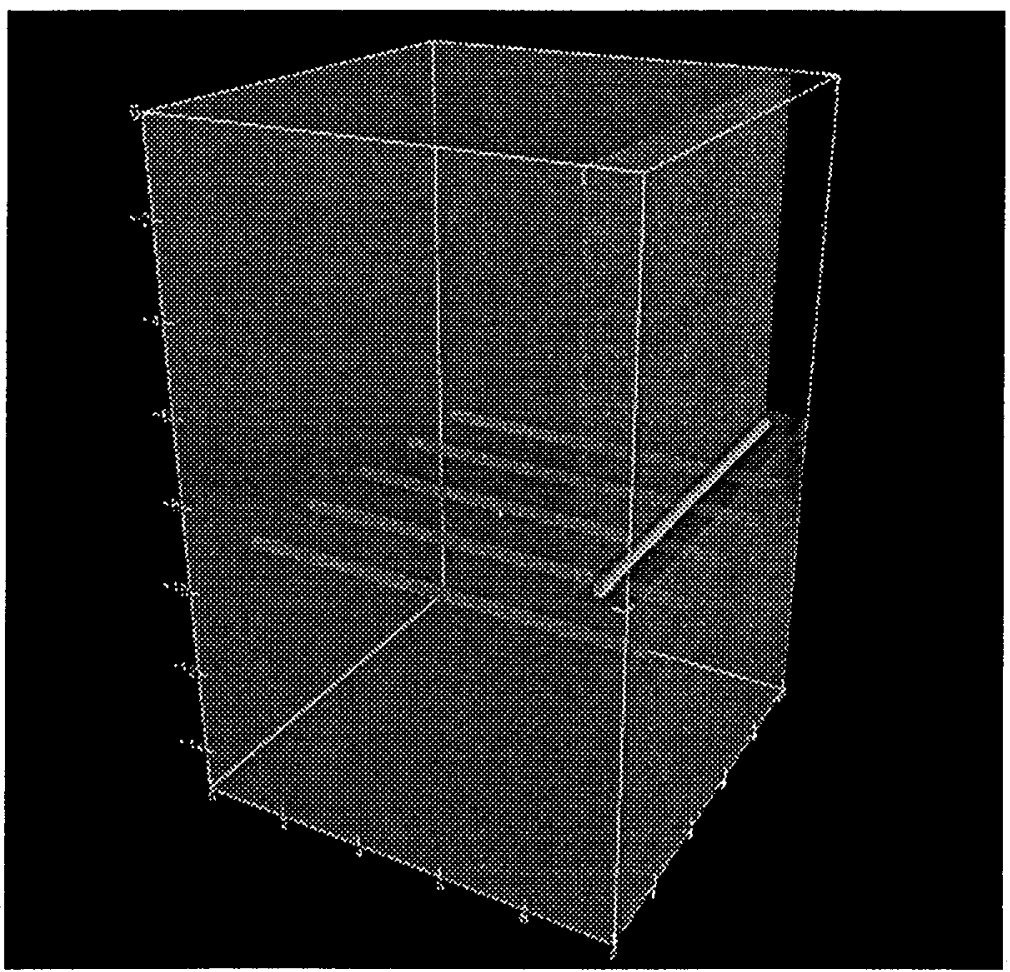

Location of borehole NT1 (and five heater boreholes) 

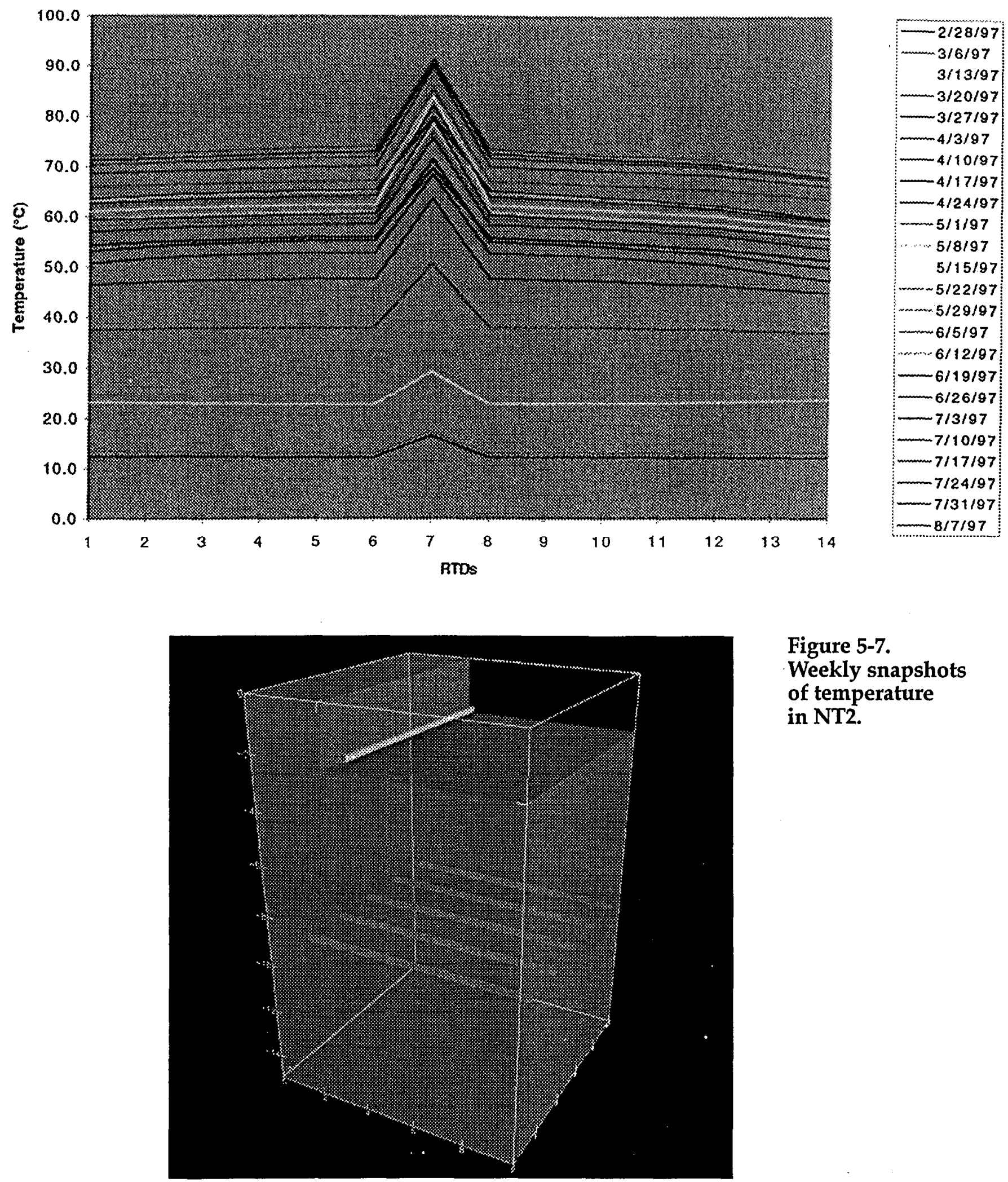

Figure 5-7.

Weekly snapshots of temperature in NT2.

Location of borehole NT2 (and five heater boreholes) 


\subsection{Results}
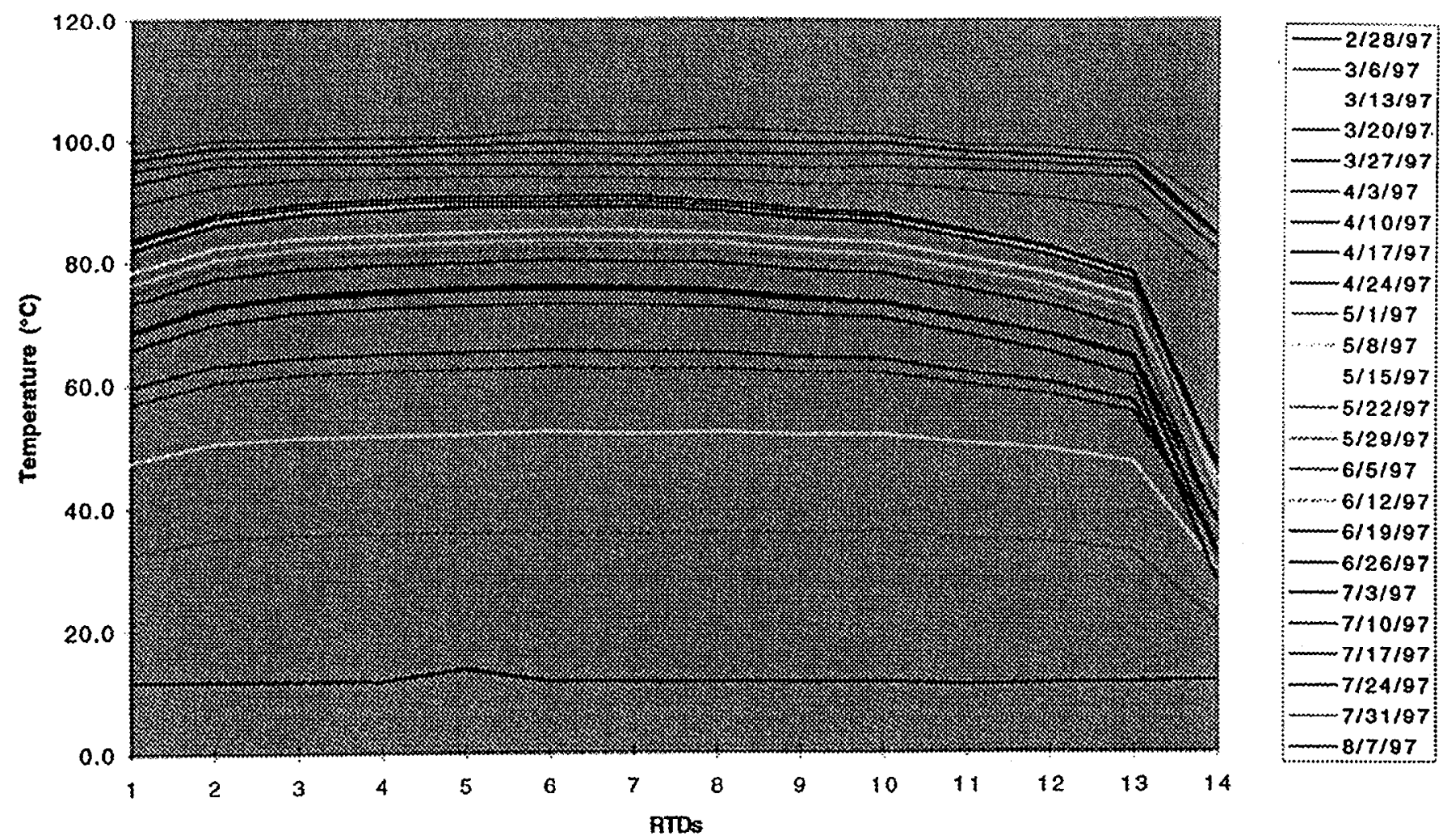

Figure 5-8.

Weekly snapshots of temperature in NT3.

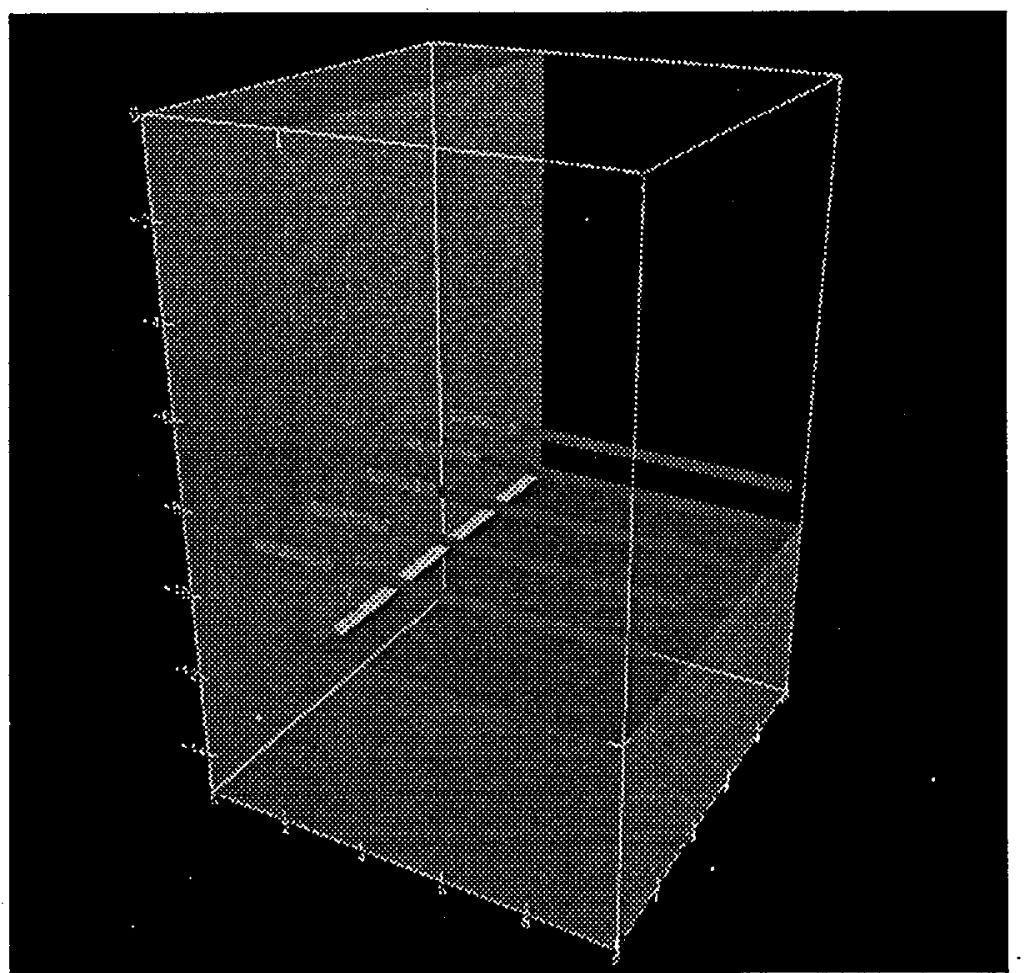

Location of borehole NT3 (and five heater boreholes) 

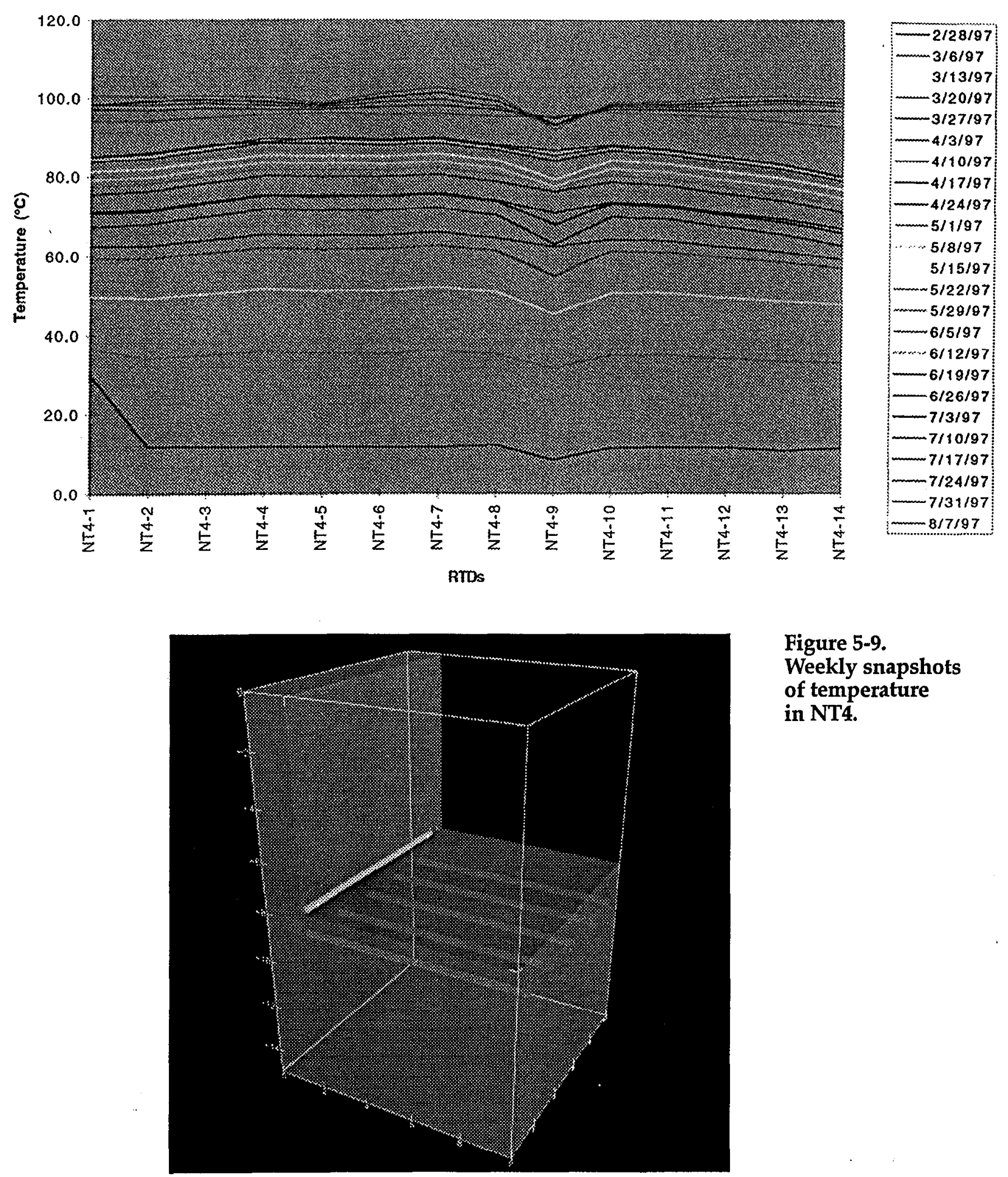

Figure 5-9. Weekly snapshots of temperature in NT4.

Location of borehole NT4 (and five heater boreholes) 


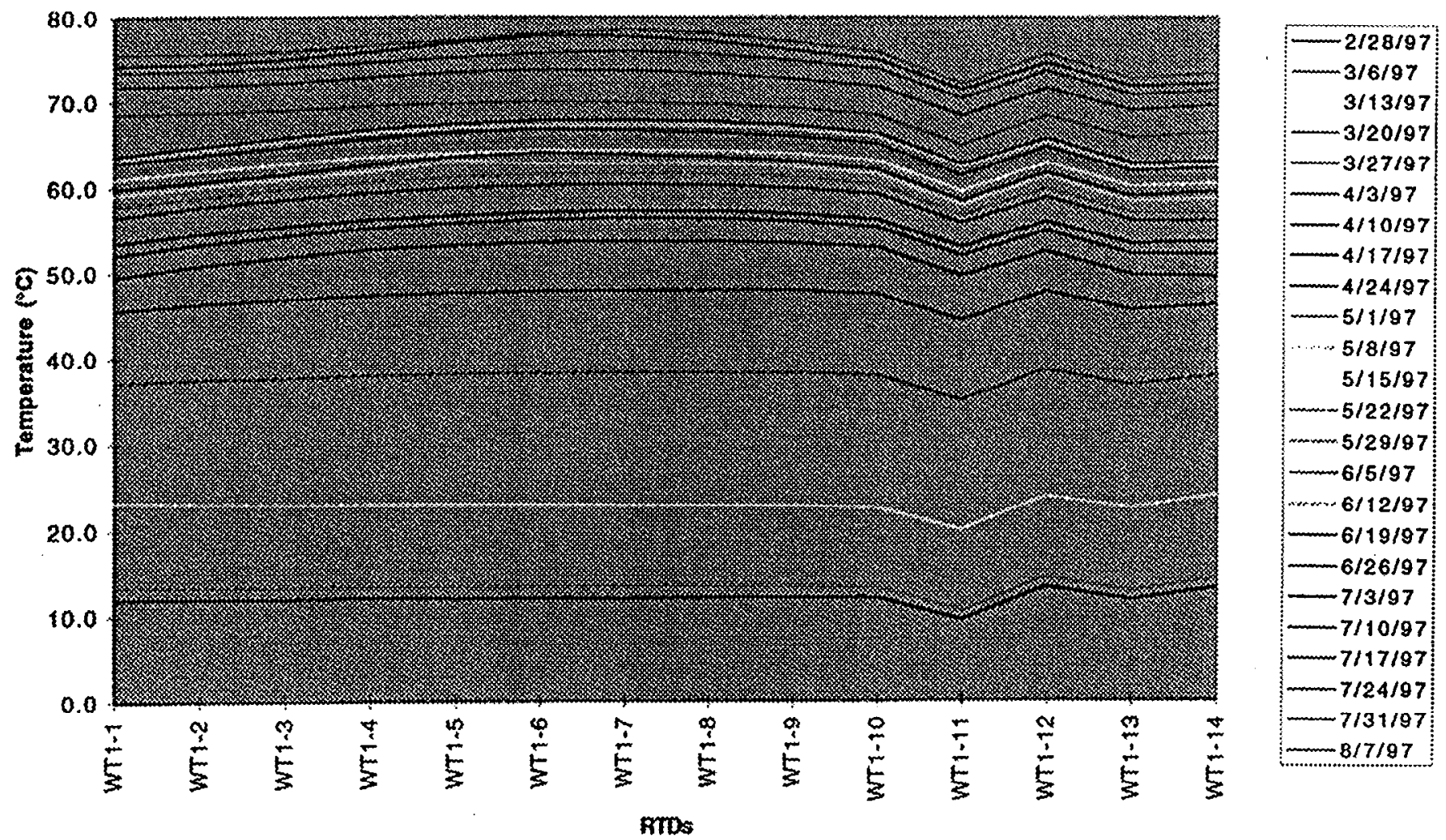

Figure 5-10.

Weekly snapshots of temperature in WT1.

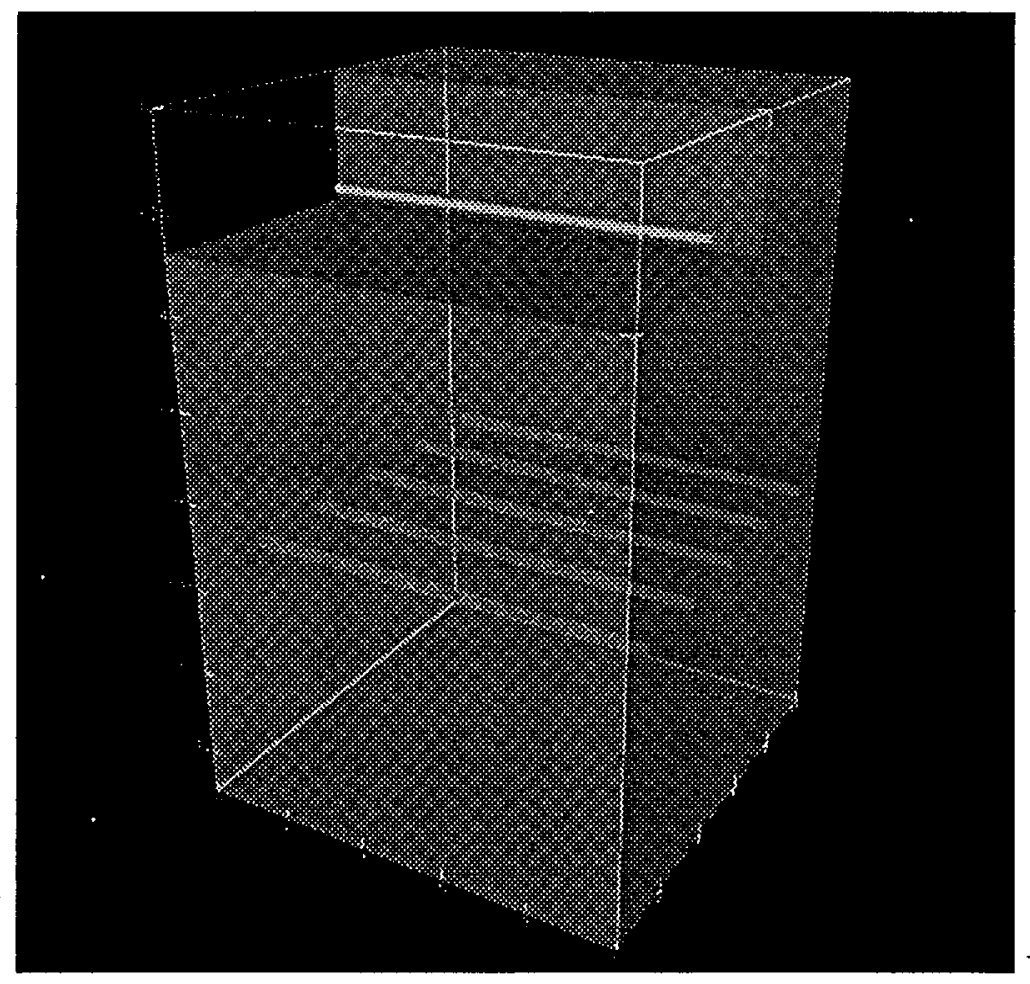

Location of borehole WT1 (and five heater boreholes) 

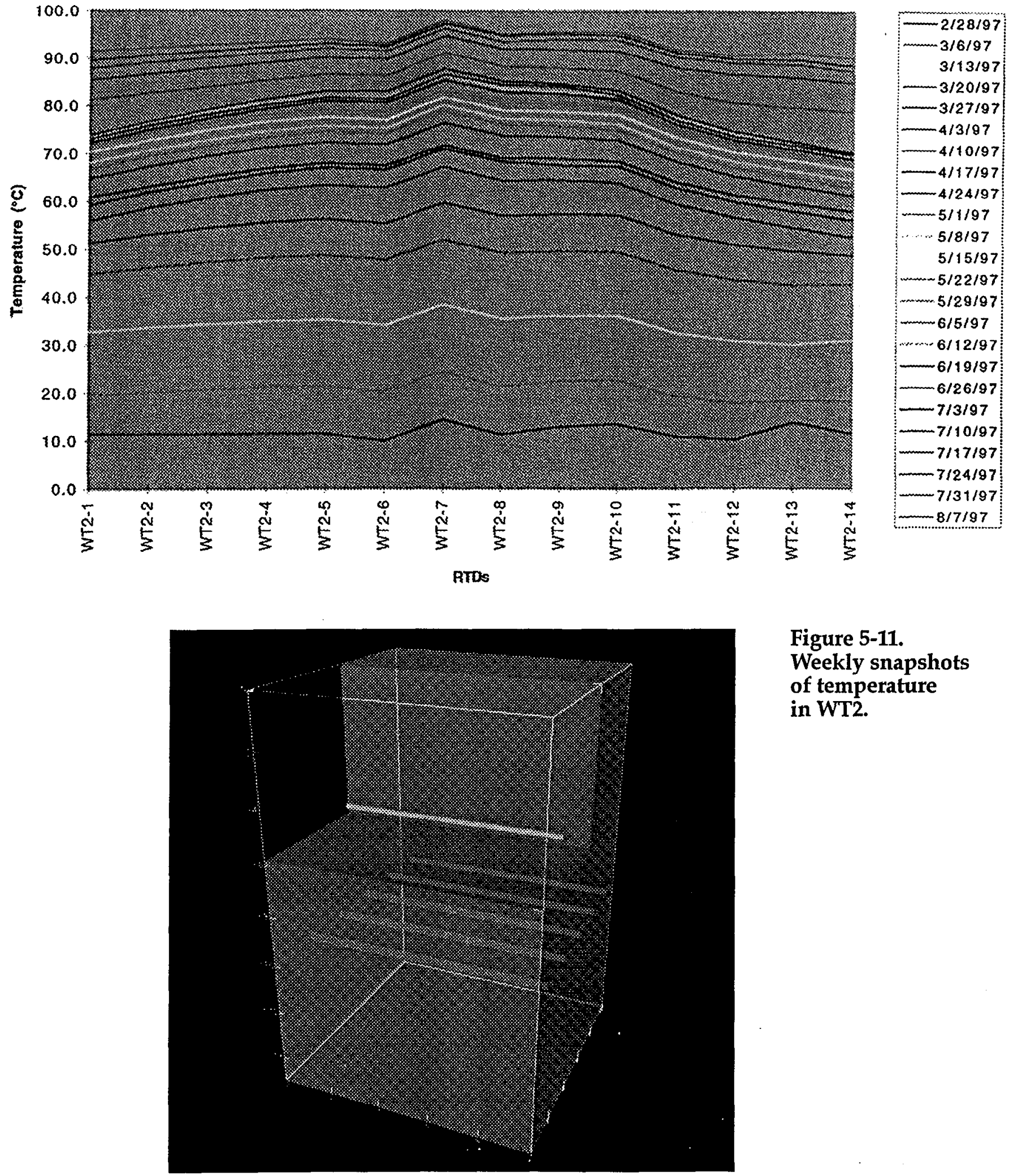

Figure 5-11.

Weekly snapshots of temperature in WT2.

Location of borehole WT2 (and five heater boreholes) 


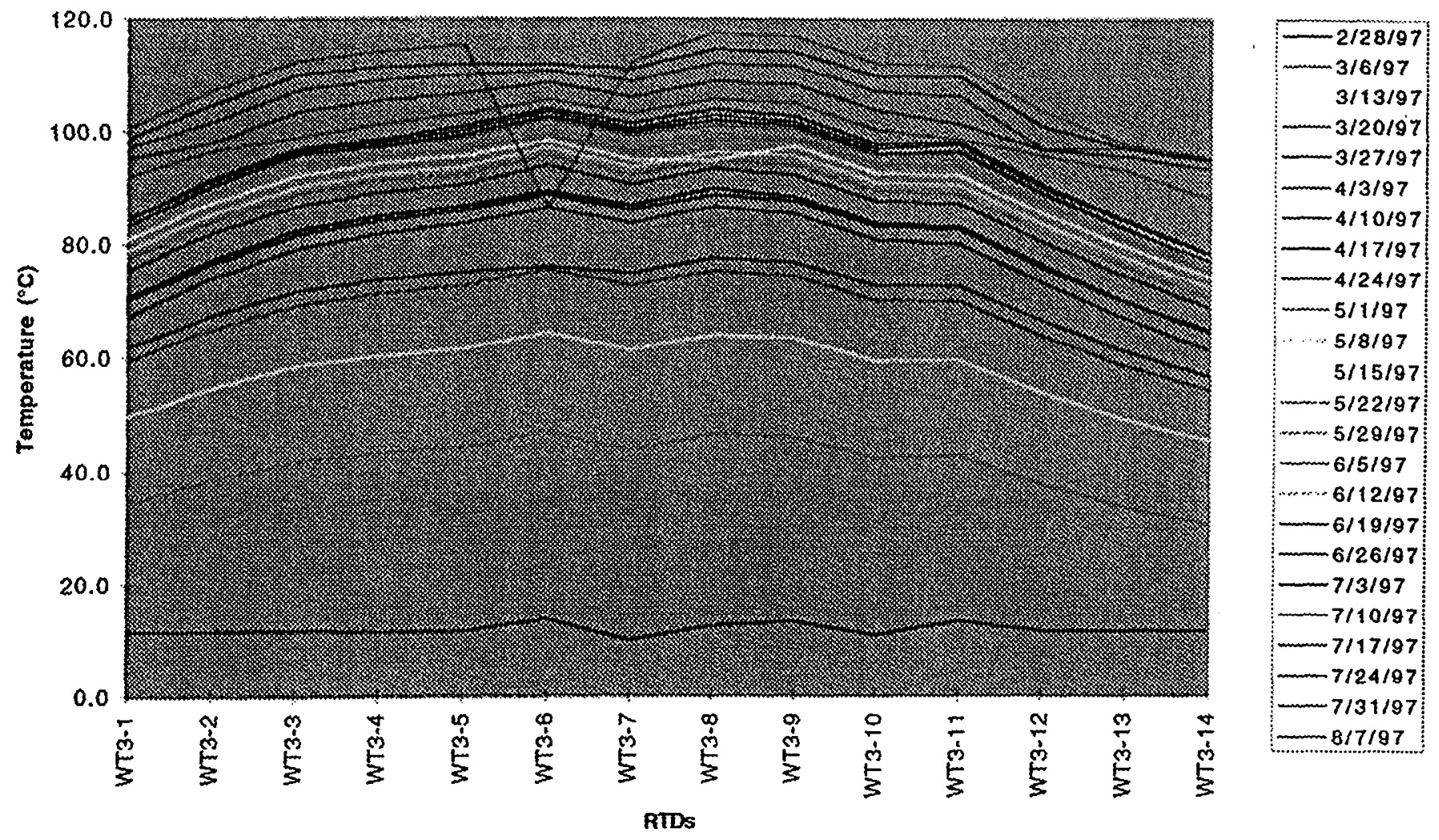

Figure 5-12.

Weekly snapshots of temperature in WT3.

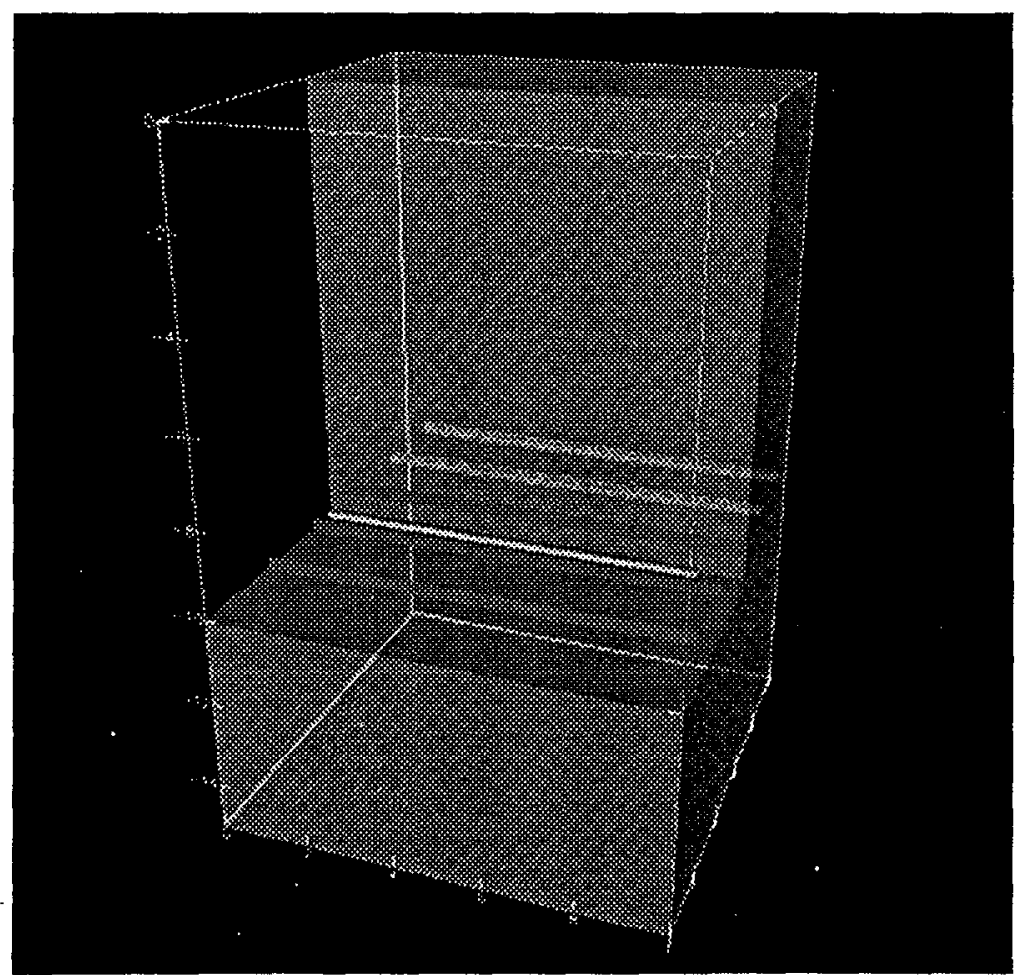

Location of borehole WT3 (and five heater boreholes) 
water and allowed hot water to flow quickly along the borehole toward the RTDs below.

The temperatures at TT1-13 and TT1-14 began to rise and fluctuate at about 2880 hour. At 2930 hour, the data acquisition rate was increased to once every 10 minutes to have a better sampling of the high-frequency fluctuation in the temperature. The temperature fluctuation did not occur at RTDs below TT1-13, nor at RTDs above TT1-22. It did not occur at RTDs TT1-17 and 18 either.

Figures 5-16 and 5-17 show the temperatures at some of the RTDs in hole TT2 during the same period as that in Figures 5-14 and 5-15. The event at 2525 hour seemed also to affect those RTDs in TT2, with a much smaller amplitude than that in
TT1. Then the high-frequency fluctuation in the temperature occurred at TT2-13 and.-14 at a later time than that at TT1-13 and -14. TT2-13 and TT2-14 were the only two RTDs in this hole showing the temperature fluctuation before July 23, 1997. So far, as shown in Figures 5-18 to 5-21, up to August 7, 1997 most of the RTDs registered stable temperatures except TT1-17 and TT1-19 in hole TT1, and TT2-19 in hole TT2.

The causes of the high-frequency temperature fluctuations at some of the RTDs are still under investigation. We had switched wires of one of the RTDs with that of one of the standard resistors at the junction box of the signal cables to verify that the fluctuation in temperature was not

(Continued on page 58)

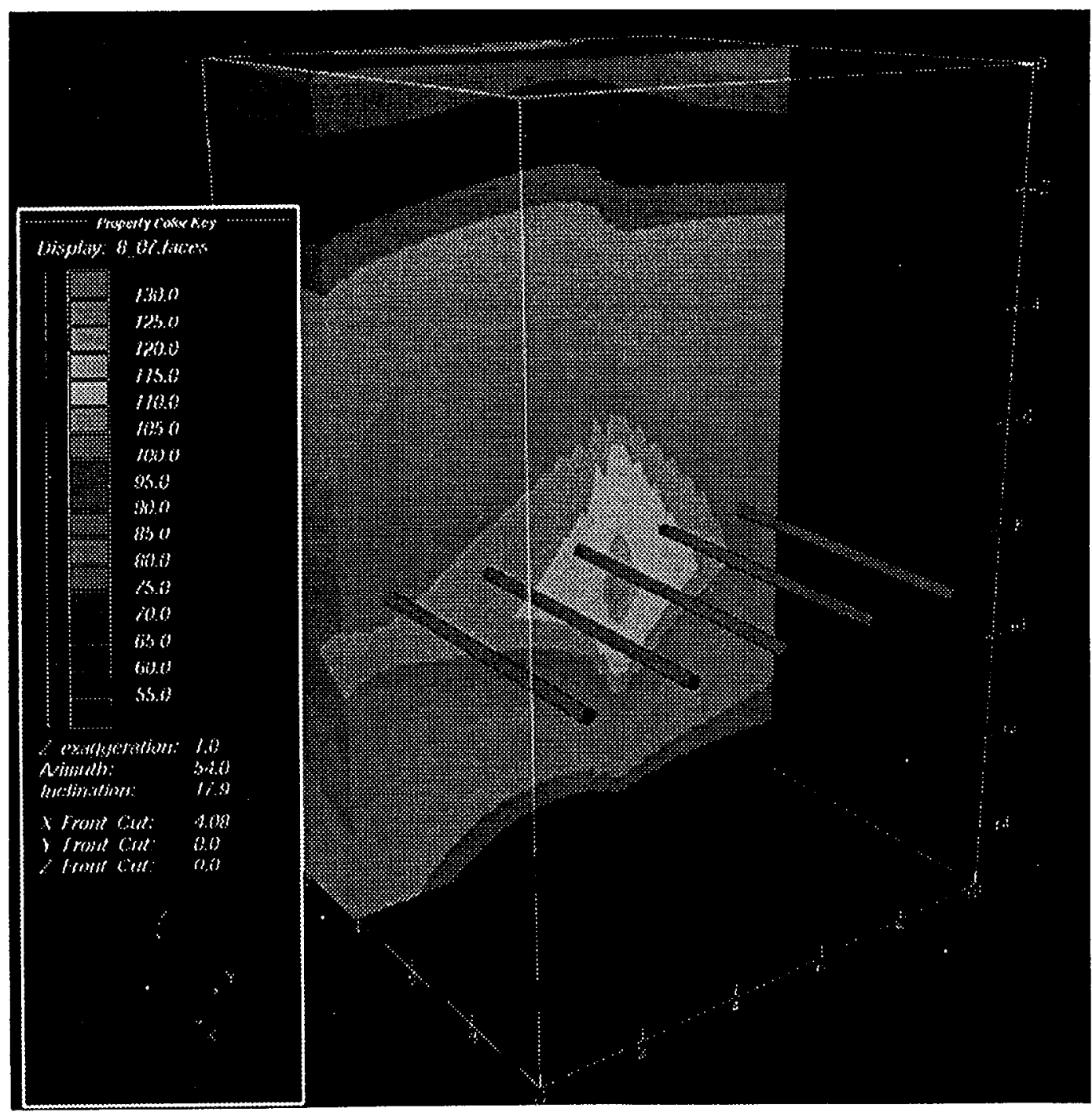

Figure 5-13.

Temperature contours in a vertical cross section along TT1 on $8 / 7 / 97$. 


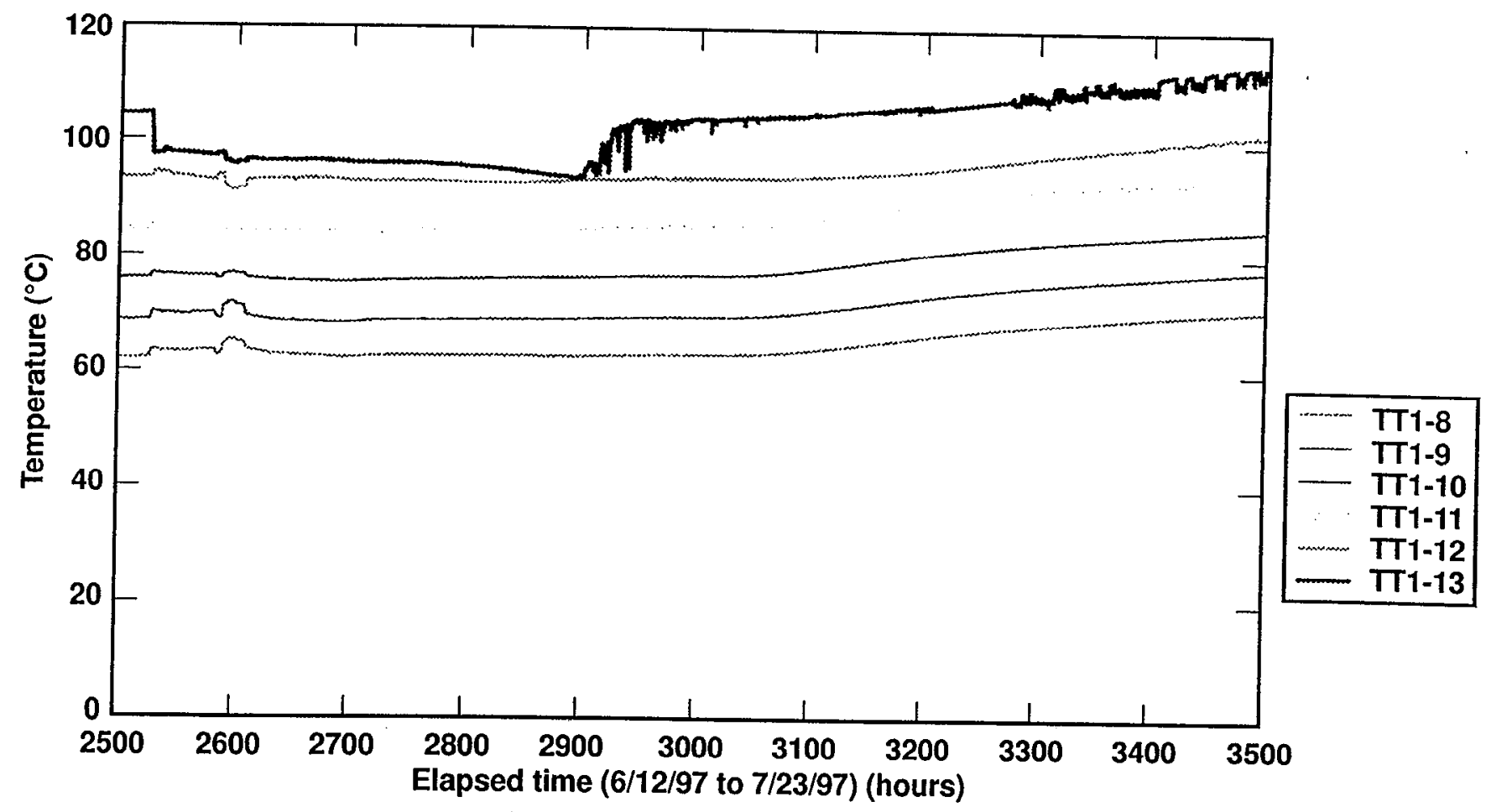

Figure 5-14. Temperatures at TT1-8 to -13 as a function of heating time.

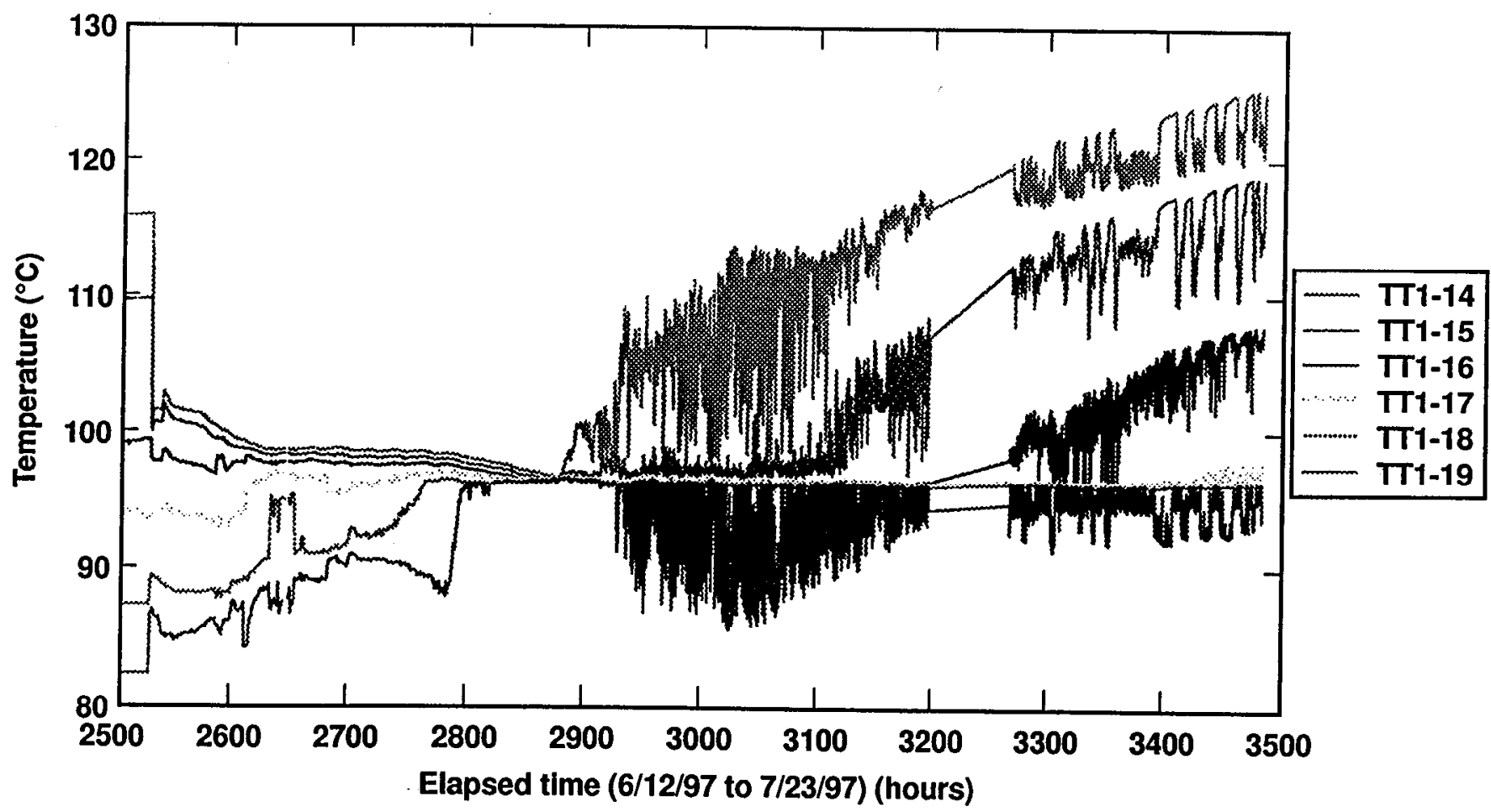

Figure 5-15. Temperatures at TT1-14 to -19 as a function of heating time. 


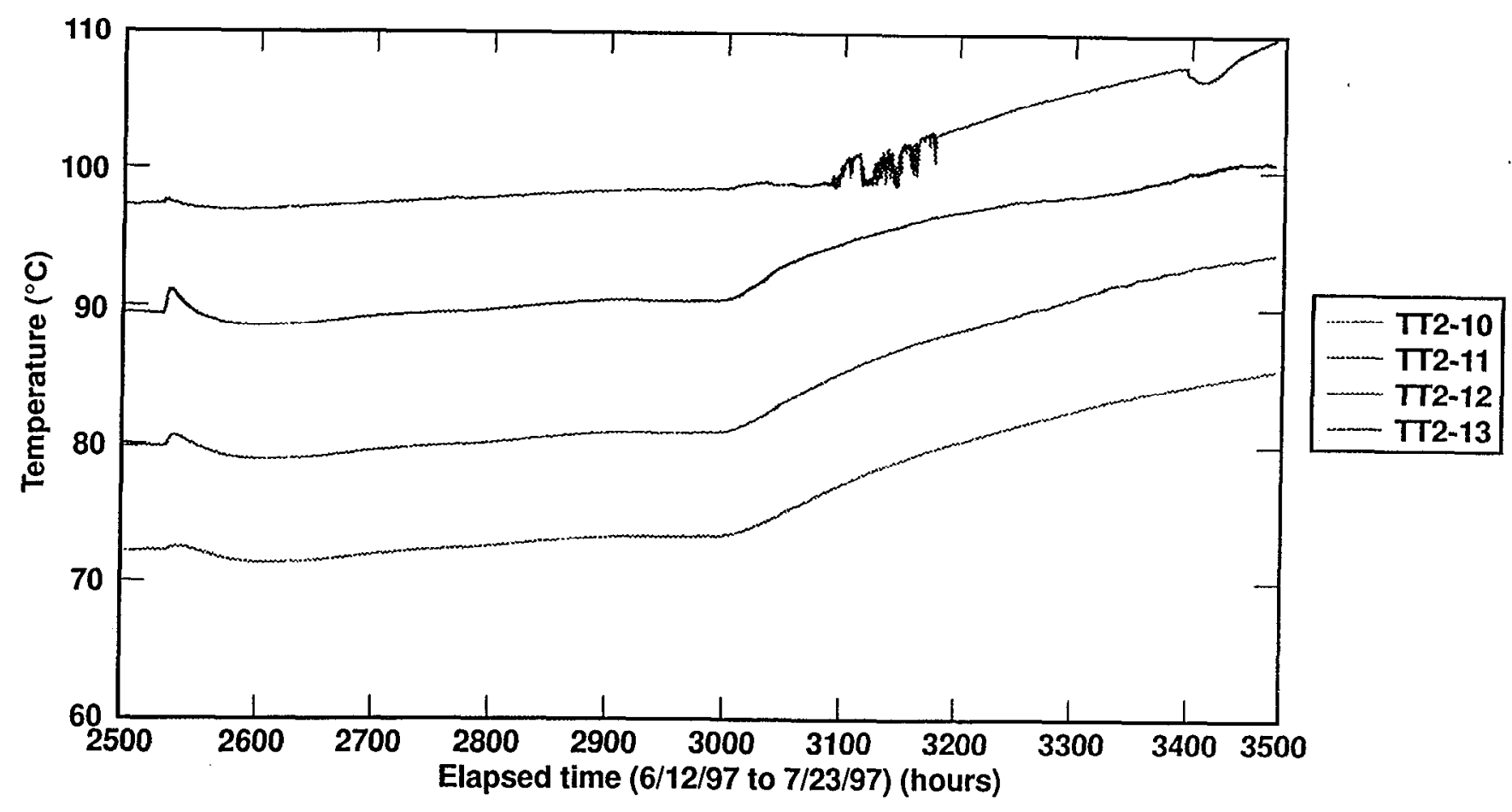

Figure 5-16. Temperatures at TT2-10 to -13 as a function of heating time.

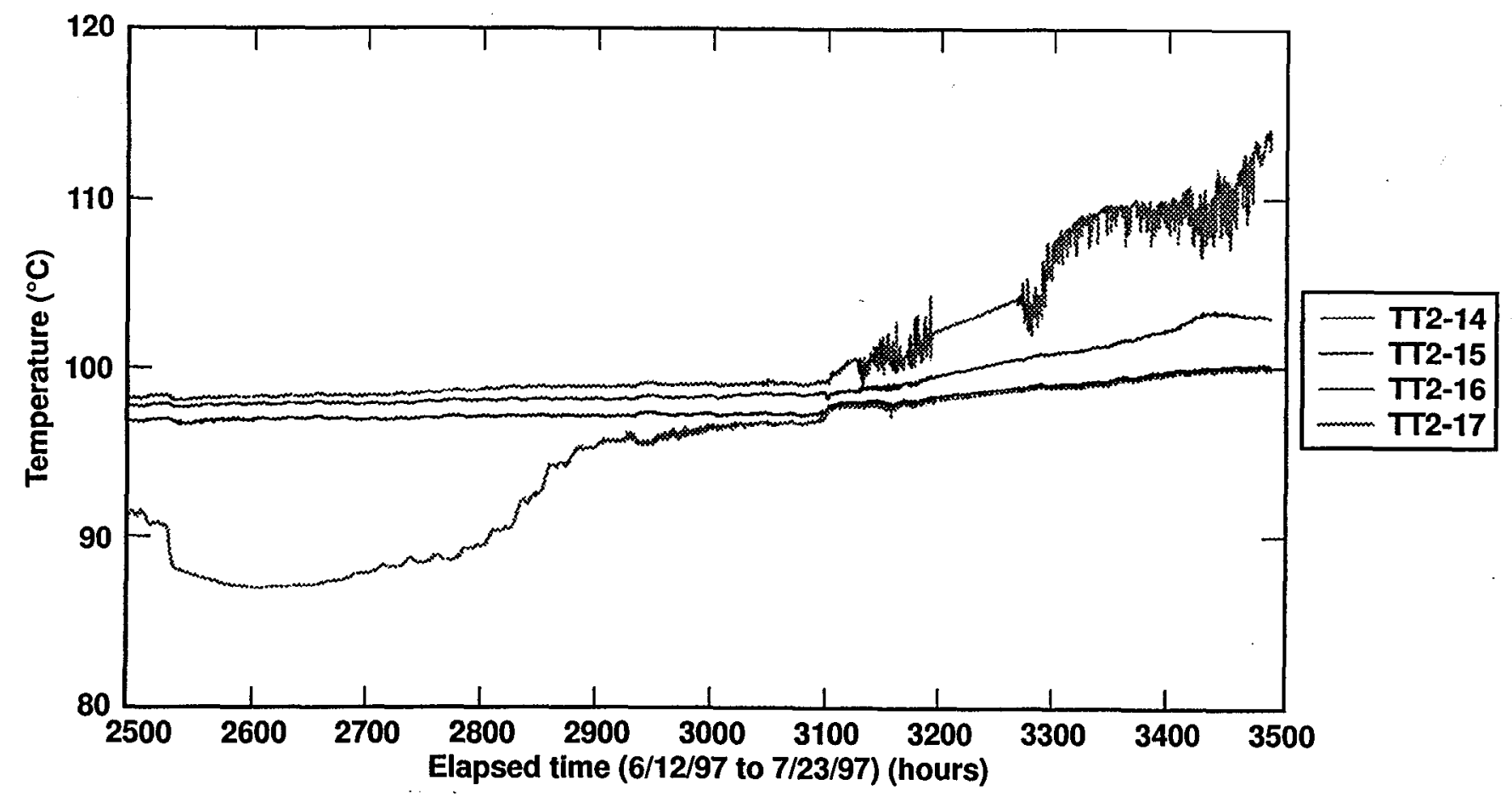

Figure 5-17. Temperatures at TT2-15 to -17 as a function of heating time. 


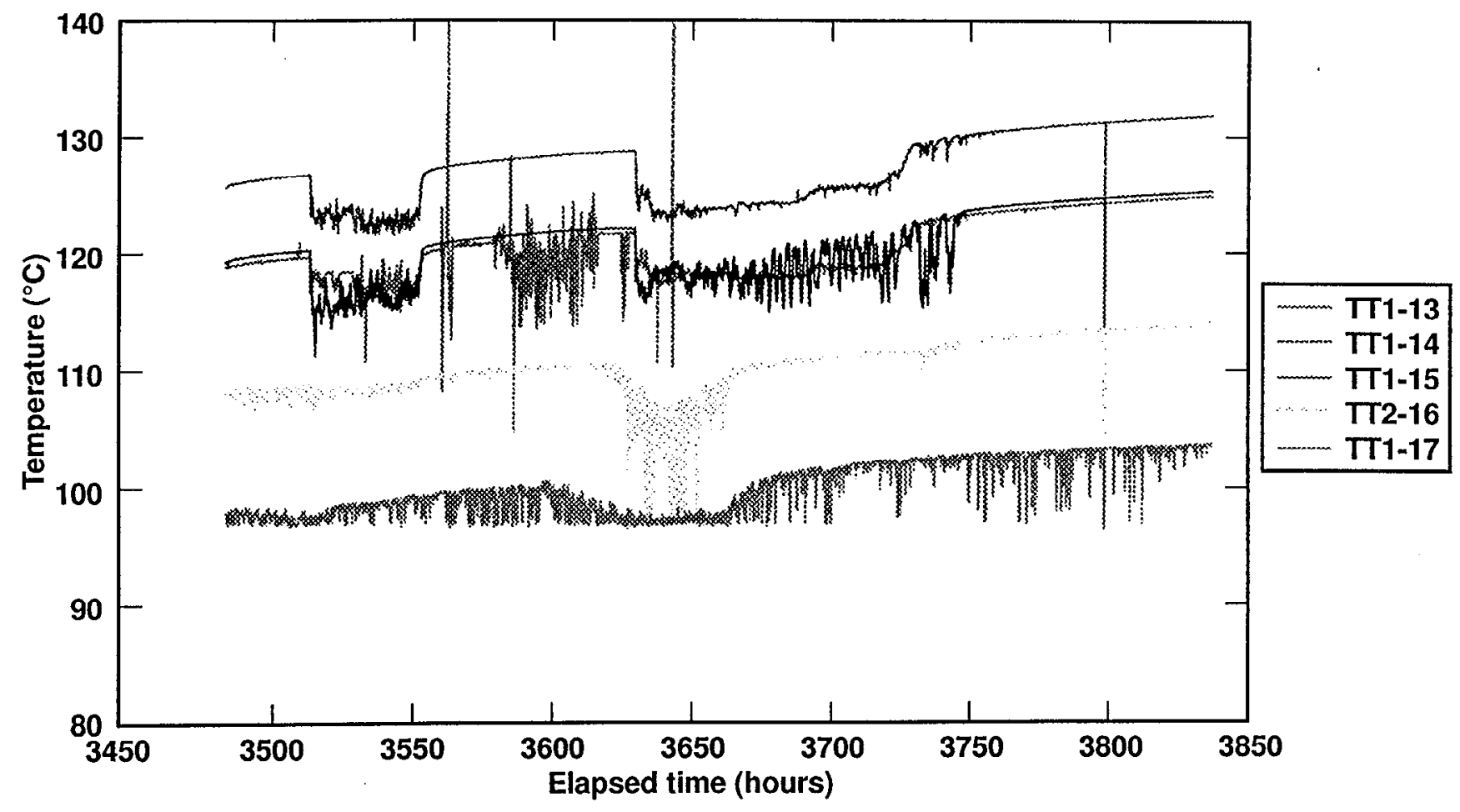

Figure 5-18. Temperatures at TT1-13 to -17 as a function of heating time.

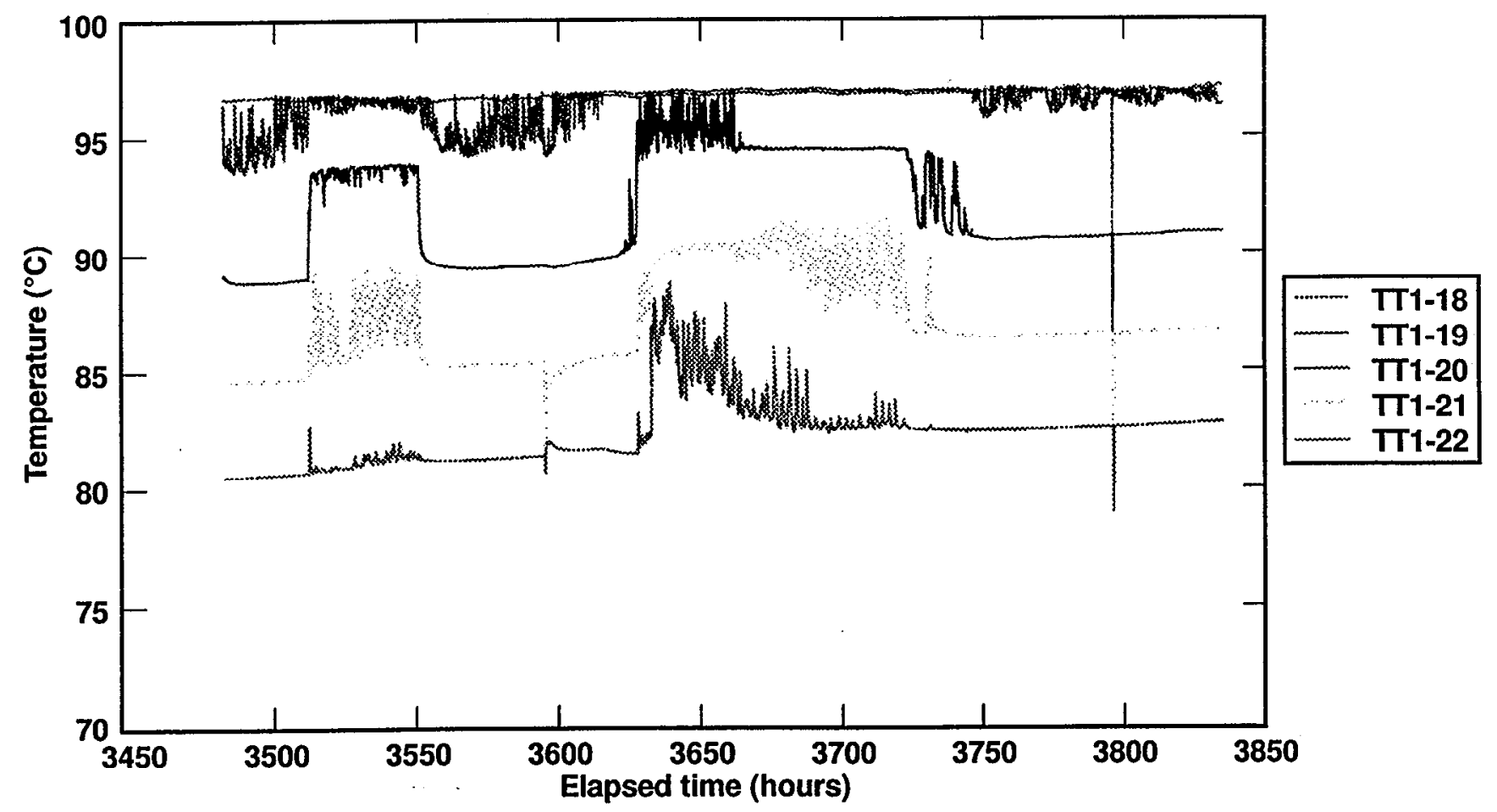

Figure 5-19. Temperatures at TT1-18 to -22 as a function of heating time. 


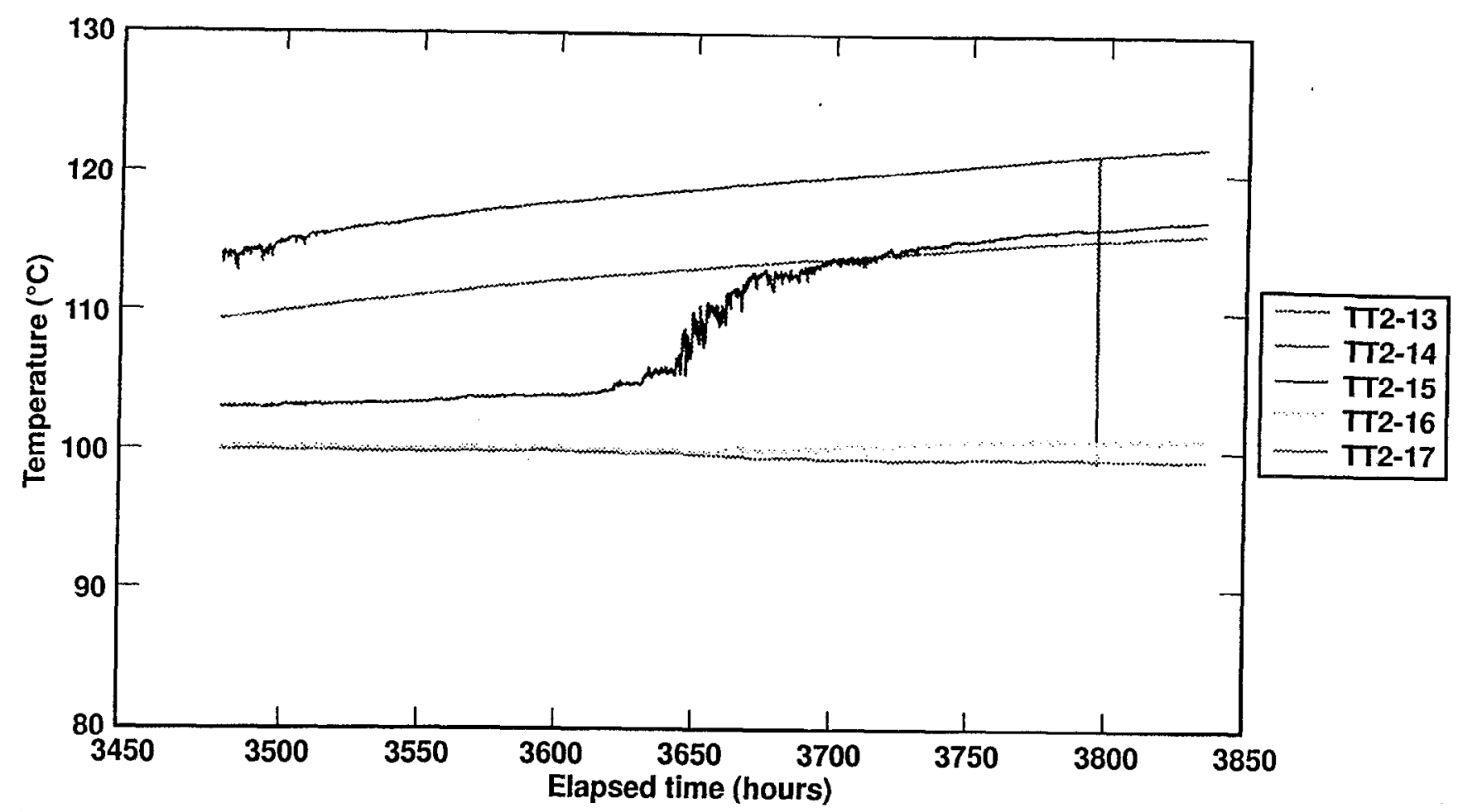

Figure 5-20. Temperatures at TT2-13 to -17 as a function of heating time.

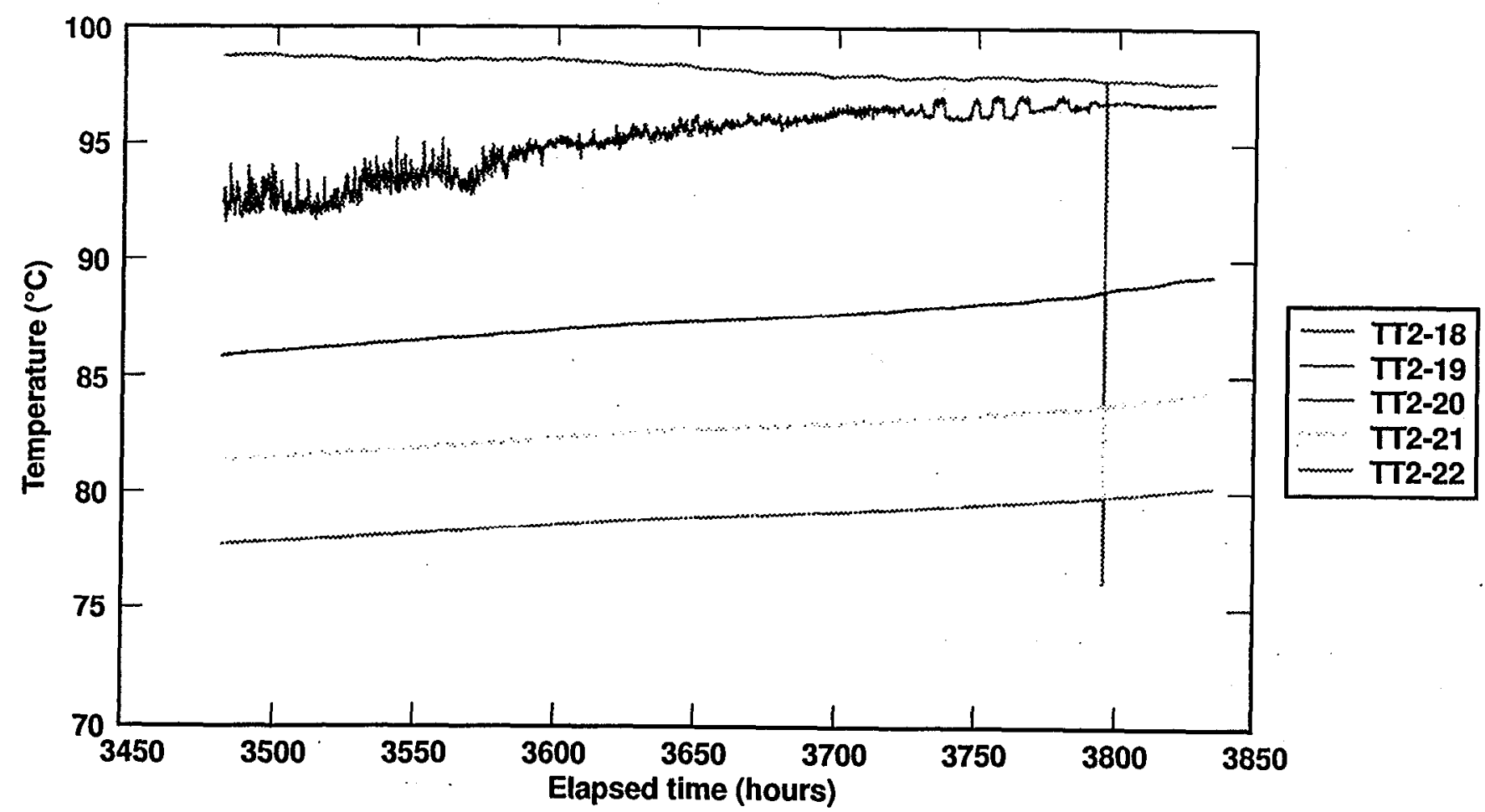

Figure 5-21. Temperatures at TT2-18 to -22 as a function of heating time. 
caused by the data acquisition system. One of the possible causes of the fluctuation in temperature is the refluxing of the condensed pore water either in the block or within the vertical boreholes. We will replace one of the removable RTDs with a thermocouple to see if the same behaviors in the temperature will be recorded by the thermocouple. In the final analyses of the measured data, the temperatures from all of the RTDs will be compared to search for correlation among the temperatures measured at various locations within the block. In addition, the correlation between the temperature measurements and other parameters, such as the displacements, will be evaluated.

\subsection{Electrical Resistance Tomography}

This sections describes electrical resistance tomography (ERT) surveys made during the LBT to map the changes in moisture content caused by temperature changes. Of particular interest is the formation and movement of condensate within the fractured rock mass. ERT is a geophysical imaging technique that can be used to map subsurface resistivity. Rock-mass heating creates temperature and liquid saturation changes, which result in electrical resistivity changes that are readily measured. The ERT measurements consist of a series of voltage and current measurements from buried electrodes using an automated data acquisition system. The data are then processed to produce electrical resistivity tomographs using state-of-the-art data inversion algorithms. We use these measurements to calculate tomographs that show the spatial distribution of the subsurface resistivities.

Here, we describe briefly some of the important features of the 2D algorithm used for ERT. For additional details, refer to Morelli and LaBrecque (1996). The algorithm solves both the forward and inverse problems. The forward problem is solved using a finite element technique in $2 \mathrm{D}$. The inverse problem implements a regularized solution that minimizes an objective function. The objective of the inverse routine is to minimize the misfit between the forward modeling data and the field data, and a stabilizing functional of the parameters. The stabilizing funclional is the solution's roughness. This means that the inverse procedure tries to find the smoothest resistivity model that fits the field data to a prescribed tolerance.

Resistivity values assigned in this way to the finite element mesh constitute the ERT image. Although the mesh is of a large region around the electrode arrays, only the region inside the ERT electrode array is shown in the results because the region outside the array is poorly constrained by the data.

To calculate the changes in the rock's electrical resistivity, we compared a data set obtained after heating started, and a corresponding data set obtained prior to heating. It is possible to consider subtracting pixel-by-pixel images from two different conditions. However, this approach could not be used because the resistivity structure was three-dimensional. The finite element forward solver cannot generate a model that will fit the data, so the code chooses a solution with a poor fit. Our experience is that these effects can be reduced by inverting the quantity

$$
\frac{R_{\mathrm{a}}}{R_{\mathrm{b}}} \times R_{\mathrm{h}}
$$

where $R_{\mathrm{a}}$ is the measured transfer resistance after heating started, $R_{\mathrm{b}}$ is the transfer resistance before heating, and $R_{\mathrm{h}}$ is the calculated transfer resistance for a model of uniform resistivity. This approach tends to reduce the effects of anomalies that do not match the $2 \mathrm{D}$ assumptions of the resistivity model because the 3D effects tend to cancel in the ratio since they are contained in both terms $R_{\mathrm{a}}$ and $R_{\mathrm{b}}$.

The electrodes used for the ERT surveys are located as follows (Fig. 5-22). Four vertical electrode arrays are located along the north, south, west, and east faces of the block near each face's centerline. A fifth vertical array is located inside the block, near the middle. Two horizontal electrodes arrays are located approximately $1.4 \mathrm{~m}$ above and below the heater plane.

To date, eight ERT surveys have been conducted, two before and six after heating began. Resistivity change tomographs have been calculated using these data. The resistivity 
change tomographs are shown in Figs. 5-23 to 5-26. The vertical tomographs (Figs. 5-23 and 5-24) indicate that resistivity decreases were observed along the heater plane two weeks (March 11, 1997) after heating started. The resistivity of the rock near the heater has decreased relative to the baseline. Vertical, roughly linear anomalies indicating resistivity increases can also be observed. As time progressed, the resistivity decreases have been propagating above and below the heater plane. Note that the resistivity decreases are stronger above the heater plane than below. The last three surveys show that the resistivity near the heater plane is increasing relatively quickly.

Horizontal tomographs above and below the heater show interesting differences in the behavior of the resistivity changes. The plane above the heater shows primarily resistivity decrease anomalies. These anomalies tend to be rounded in shape, and the contrast within the plane is relatively small. In contrast, the horizontal plane below the heater shows anomalies that are linear in shape; the contrasts within the plane are stronger than those observed above the heater. We suggest that the observed differences are caused by differences in condensate behavior. Above the heater, condensate tends to accumulate and imbibe into the rock matrix. Below the heater, condensate tends to drain and does not have as much time to imbibe.

The resistivity change tomographs are sensitive to changes in both saturation and temperature. In future reports, a first-order correction will be applied to the resistivity tomographs to remove the effects of temperature and allow calculation estimates of saturation. A more complete interpretation of the ERT results will then be possible.

\subsection{Moisture Content Determined by Neutron Logging}

The moisture content in the large block is determined by two different methods: neutron logging and electrical resistivity tomography (ERT). The results of the ERT are discussed in the previous section. The moisture content
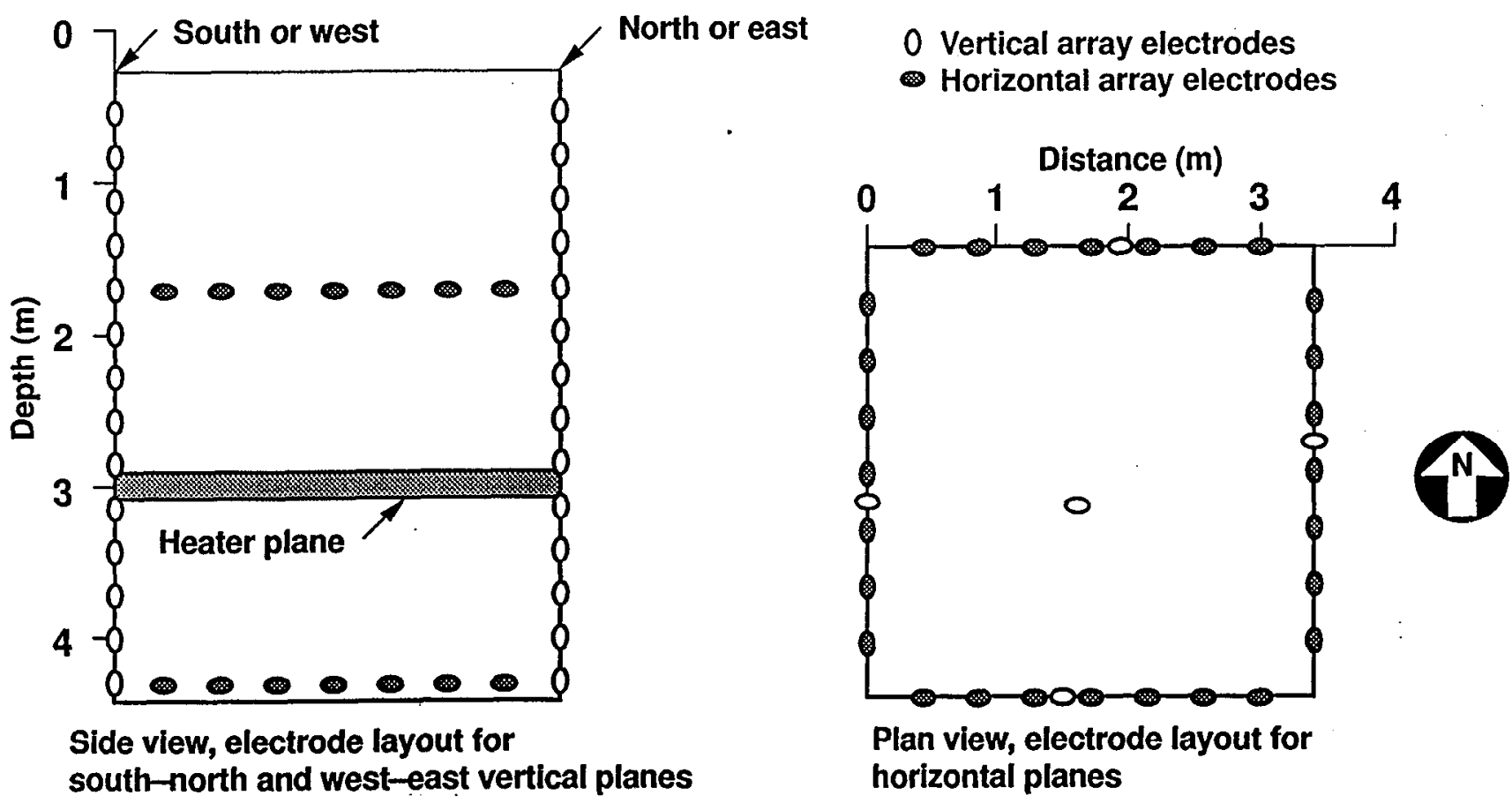

Figure 5-22. ERT electrode arrays at the LBT. The layout relative to the walls of the block is shown. 
Figure 5-23.

Resistivity changes observed along a vertical plane parallel to the north-south direction. Near the heater, resistivity decreases are observed during the first three months of heating. Later tomographs show the resistivity near the heater is increasing.

Figure 5-24.

Resistivity changes observed along a vertical plane parallel to the east-west direction. Near the heater, resistivity decreases are observed during the first three months of heating. Later tomographs show the resistivity near the heater is increasing.

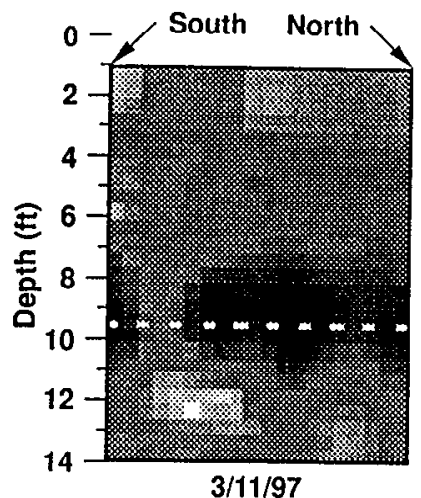

$3 / 11 / 97$

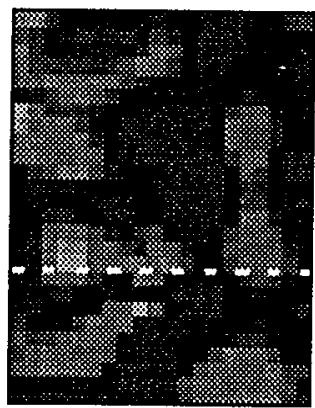

$5 / 22 / 97$

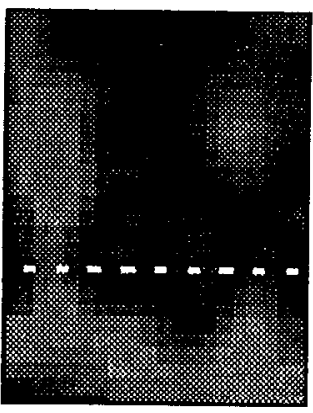

$3 / 26 / 97$

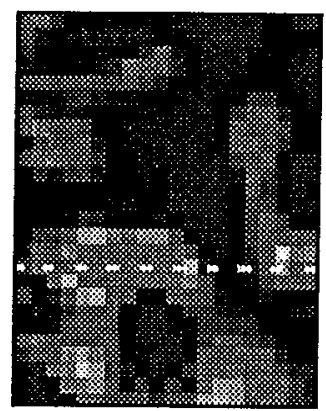

$6 / 25 / 97$

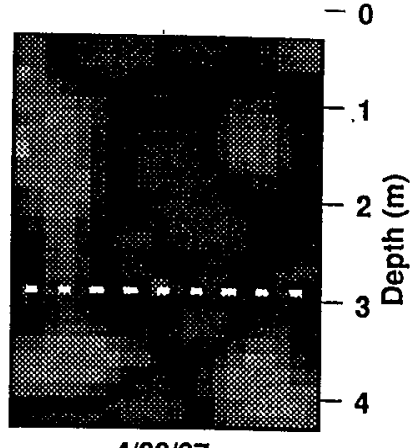

$4 / 22 / 97$

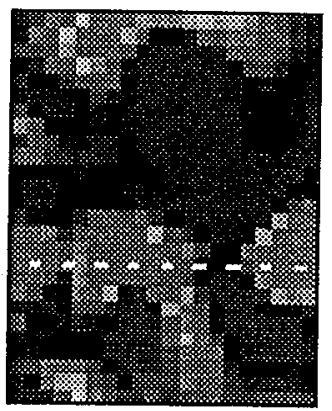

7/23/97

Resistivity ratio

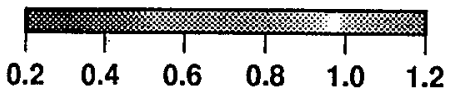

White dashed line shows location of the heater plane

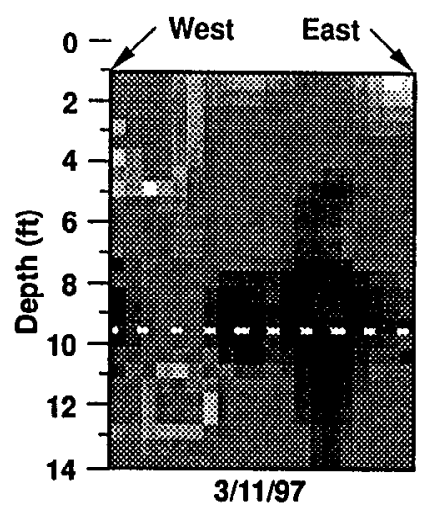

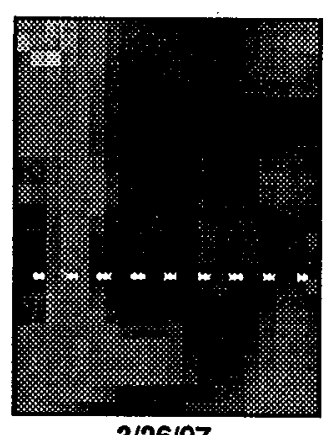

$3 / 26 / 97$

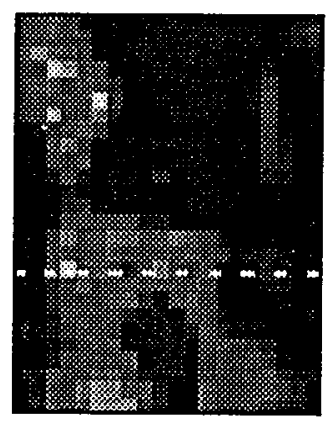

$6 / 25 / 97$
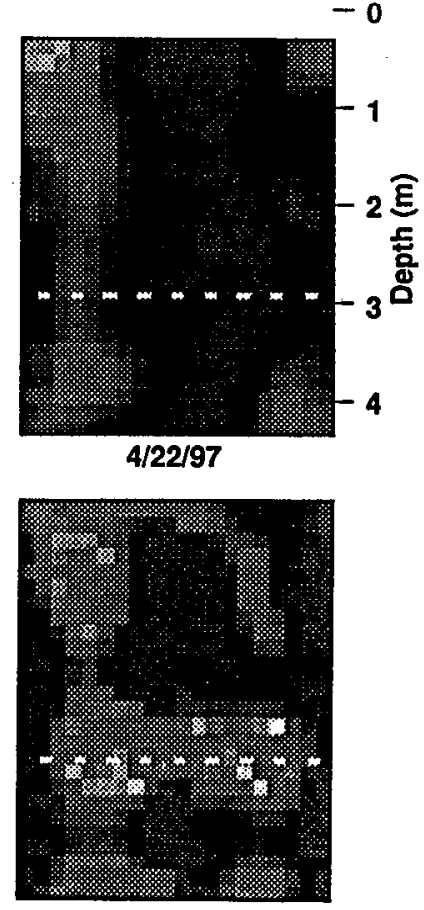

$7 / 23 / 97$

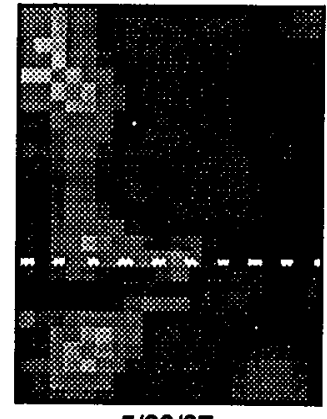

$5 / 22 / 97$ 
Horizontal plane $1.52 \mathrm{~m}$ below top of block,

$1.37 \mathrm{~m}$ above heater plane

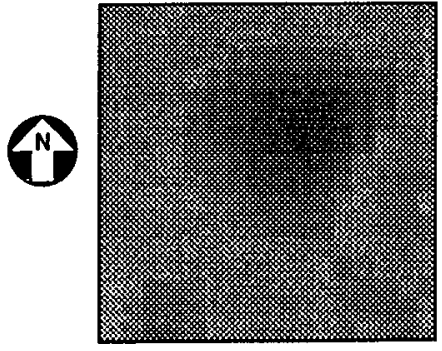

$3 / 11 / 97$

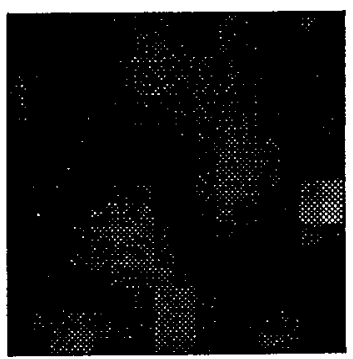

$5 / 22 / 97$
$3 / 26 / 97$

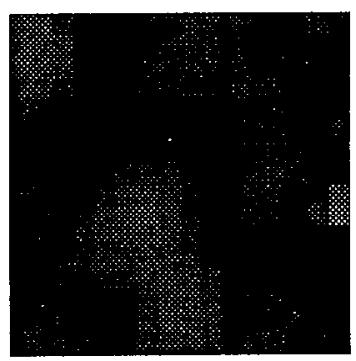

$6 / 25 / 97$

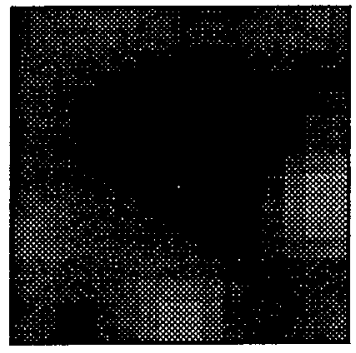

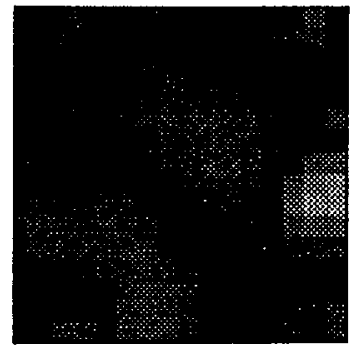

$4 / 22 / 97$

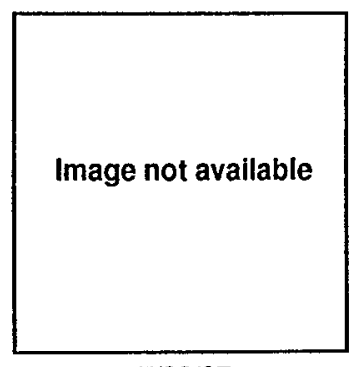

$7 / 23 / 97$
Resistivity ratio

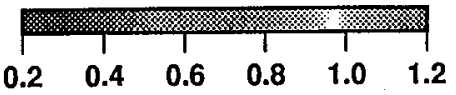

Horizontal plane $4.27 \mathrm{~m}$ below top of block, $1.37 \mathrm{~m}$ above heater plane

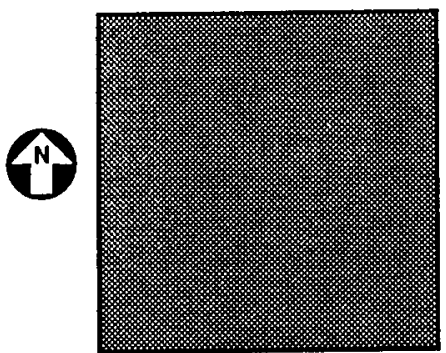

$3 / 11 / 97$

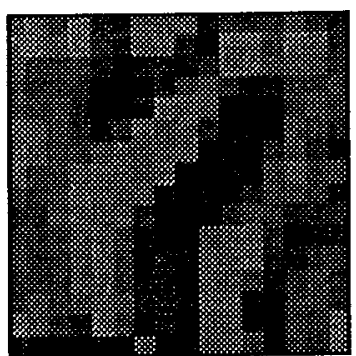

$5 / 22 / 97$

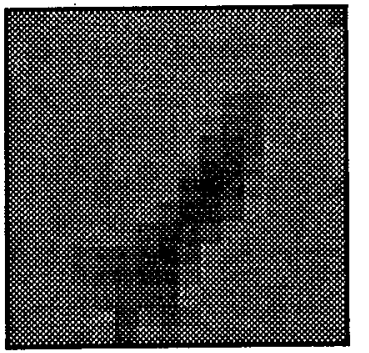

$3 / 26 / 97$

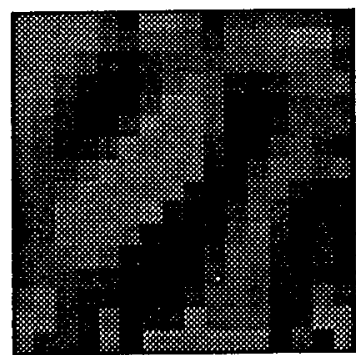

$6 / 25 / 97$

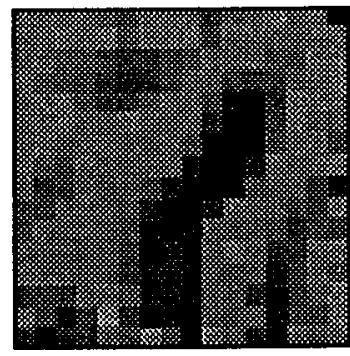

$4 / 22 / 97$

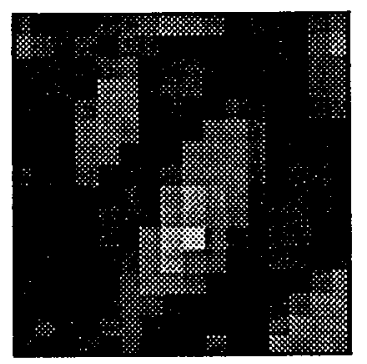

$7 / 23 / 97$
Resistivity ratio

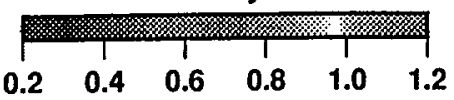

Figure 5-25.

Resistivity changes

observed along a horizontal plane located above the heater plane. At this location, the rock's resistivity has decreased relative to the baseline.
Figure 5-26.

Resistivity changes observed along a horizontal plane located below the heater plane. At this location, the rock's resistivity has decreased relative to the baseline. The resistivity anomalies form lineaments trending to the northeast. 
determined by neutron logging for up to 103 days of heating are presented here. The neutron tool has being repaired; therefore, no logging has been conducted since June, 1997. The neutron logging results are available in spread sheets in the data base at LLNL. Only a portion of the neutron logging results are presented in graphic form in this report. A complete presentation, including the spread sheets and discussion of the neutron logging results, will be included in the final report on the LBT. Discussion of the neutron logging results is divided into two categories: the background moisture content, and the in-heat neutron logging.

\subsubsection{Background Moisture Content}

The background moisture content in the block was determined at three different periods: before the boundary of the block was cut (pre-cut) in December of 1993, after the boundary of the block was cut (post-cut) in March of 1994, and after the completion of the installation of instruments (pre-heat) in February of 1997. Both the pre-cut and post-cut moisture content were determined in the five vertical neutron holes without the Teflon liner and cement grout. The pre-heat moisture content in February of 1997 was determined in both the five vertical and the ten horizontal neutron holes with both the Teflon liner and the cement grout in place. The determination of the pre-cut moisture content was to evaluate the initial moisture content in the rock mass to see if it was enough for conducting a thermal-hydrological test. The post-cut moisture content was determined to evaluate how cutting the boundary of the block with water affected the moisture content of the block. The neutron tool was calibrated in a $3.81-\mathrm{cm}$-diameter hole without the Teflon liner and cement grout for the pre-cut and post-cut measurements. The background moisture saturation levels were determined to be about 60 to $80 \%$, for a laboratory determined porosity of about $11 \%$. Sawing of the block boundary using water was found to have no significant effect on the moisture content of the block (Lin et al., 1995).

The pre-heat moisture content was determined to establish the baseline so that the effect of heating the block on its moisture content could be studied. The pre-heat neutron logging was conducted twice on February 25, 1997 in the fifteen neutron holes (five vertical holes and ten horizontal holes) after the installation of instruments was completed, and the heaters were ready to be energized. At that time, the neutron holes were sealed with a piece of Teflon liner and cement grout in the annular space between the liner and the borehole wall. The neutron tool was calibrated in a $3.81-\mathrm{cm}-$ diameter hole with the Teflon liner/grout assembly exactly the same as that in the neutron holes of the LBT. It was determined that the Teflon liner/grout assembly may have changed the moisture content by no more than 4 to $6 \%$ of the determined value. This is not surprising because the neutron holes in the LBT are designed in such a way that the thickness of the annular cement grout is minimal, only about $0.3 \mathrm{~cm}$.

Figures 5-27 to 5-31 show the pre-heat baseline fraction volume water content in the five vertical holes TN1 to TN5, respectively. Generally, the initial moisture content in those holes increased with depth and ranged between 0.08 and 0.1. A region at about $0.5-\mathrm{m}$ depth in TN1 to TN3 had a fraction volume water content greater than 0.1 , which may be caused by a horizontal fracture intersecting those holes. There is a region at about 4-m depth in TN5 where the initial moisture content was greater than 0.14 . With more core

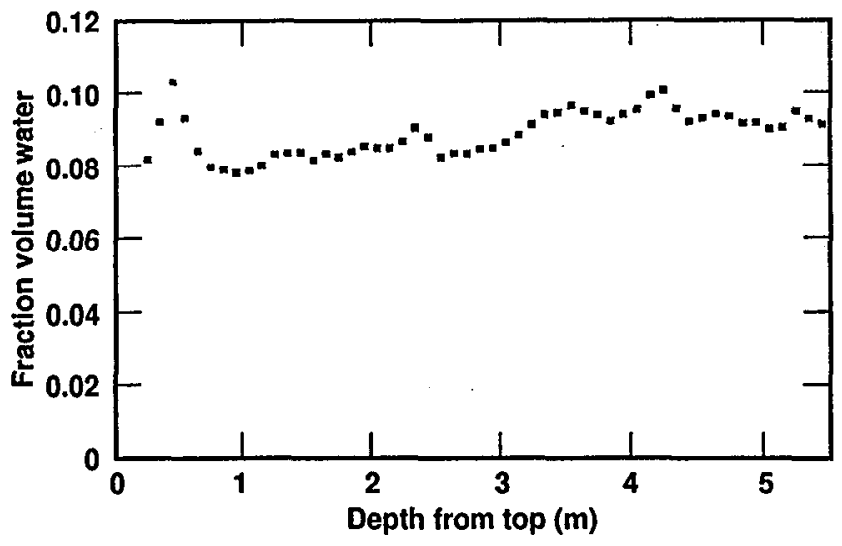

Figure 5-27. Initial fraction volume water content in TN1 as a function of depth from top of the block. 
samples available than those reported in Lin, et al, (1995), the average porosity of the core samples of the large block was determined to be $10.4 \pm 1.3 \%$. The fraction volume water contents shown in Figs. 5-27 to 5-31 correspond to a range of saturation levels between 77 and $96 \%$.

As mentioned earlier, the purpose of conducting the pre-heat neutron logging was to provide the baseline data for studying the effect of heat on the moisture content in the block. The neutron counts of the pre-heat logging were

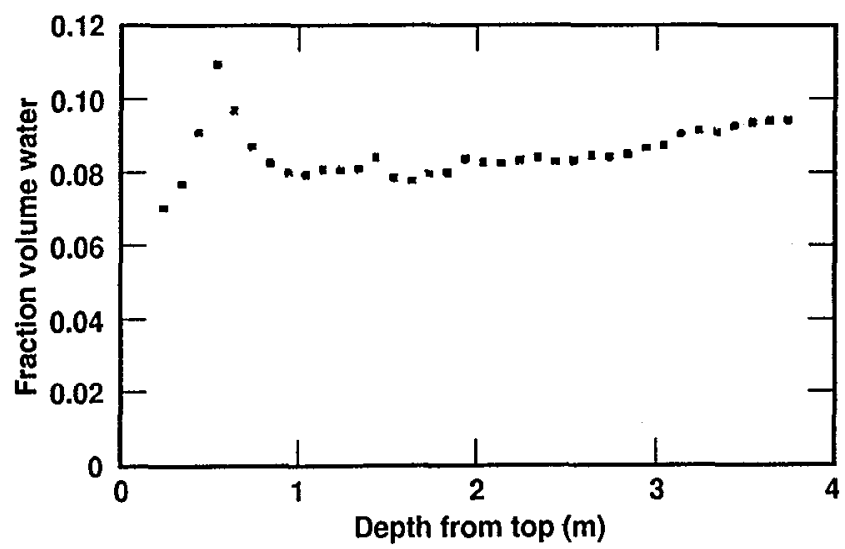

Figure 5-28. Initial fraction volume water content in TN2 as a function of depth from top of the block.

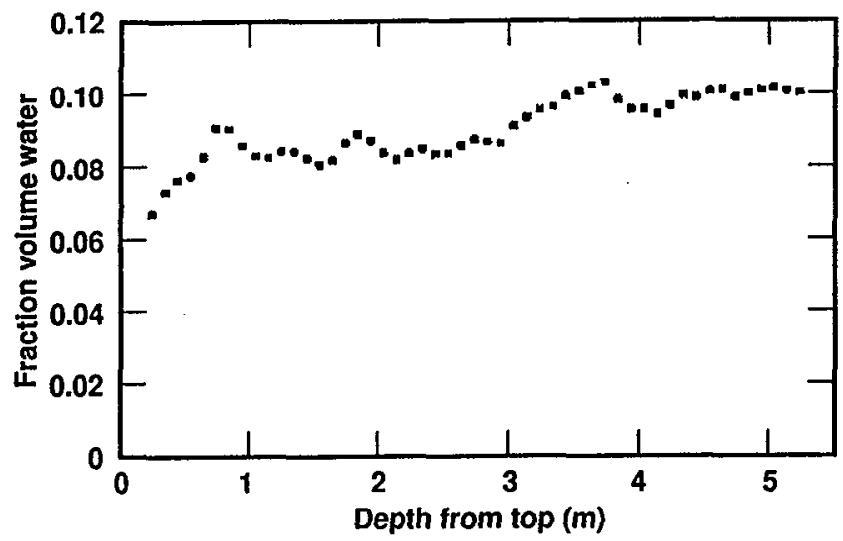

Figure 5-30. Initial fraction volume water content in TN4 as a function of depth from top of the block. subtracted from the in-heat neutron counts, and calibration data were used to convert the difference in the neutron counts into the difference in volume water content. The variation in the water saturation level can be determined by dividing the difference fraction volume water content by the porosity of the rock mass. However, for this report, the difference fraction volume water content, instead of water saturation, during the heating phase of the LBT is presented.

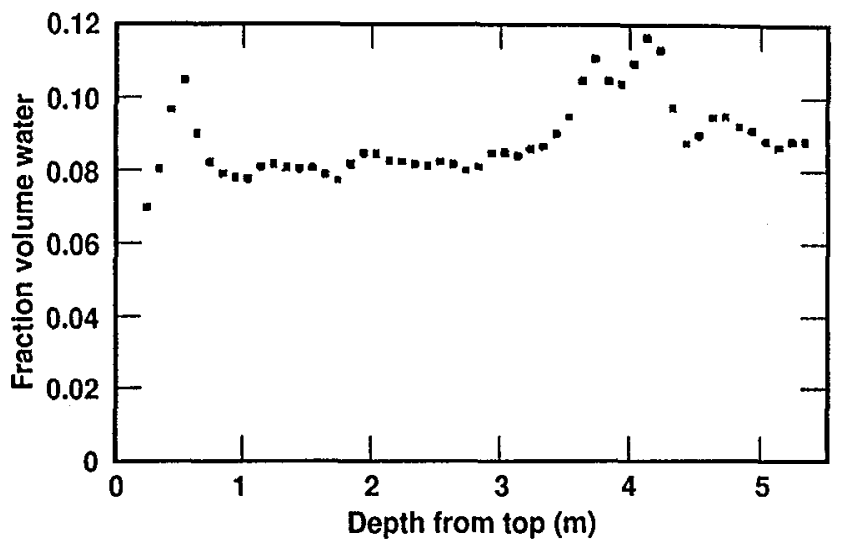

Figure 5-29. Initial fraction volume water content in TN3 as a function of depth from top of the block.

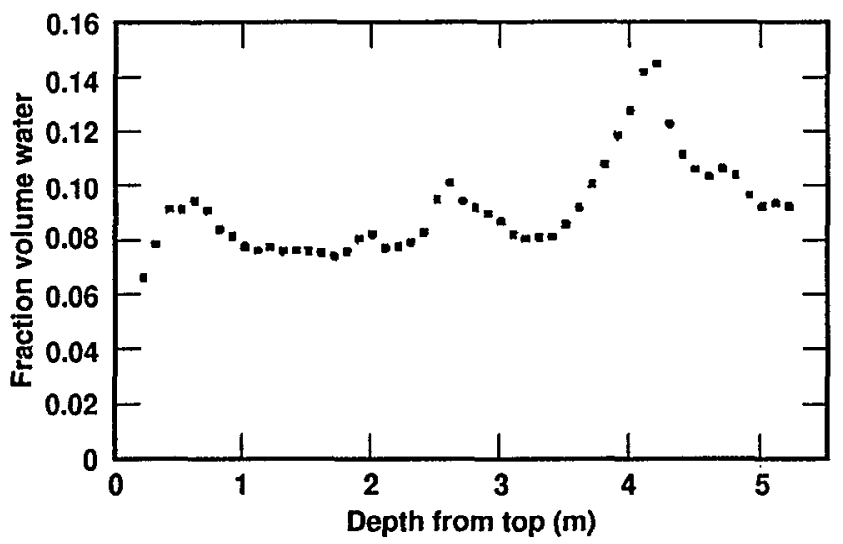

Figure 5-31. Initial fraction volume water content in TN5 as a function of depth from top of the block. 


\subsubsection{Heating Phase Moisture Content}

To date during the heating phase of the LBT, seven neutron loggings have been conducted in the fifteen neutron holes. The fifteen neutron holes include five vertical holes (TN1 to TN5), six horizontal holes from the north side (NN1 to NN6), and four horizontal holes from the west side (WN1 to WN4). The location of these neutron holes is given in Section 4 of this report. During each of the neutron loggings, neutron counts were obtained in each hole at intervals of $10 \mathrm{~cm}$. The raw neutron counts, the location of measurements in each hole, and the converted difference fraction volume water content are all included in the spread sheets in the data base at LLNL. In this report, only the difference fraction volume water content in the five vertical holes are presented because they clearly show a drying zone near the heater horizon. The neutron logging results in the ten horizontal holes show very little variation in the water content along each hole. This is expected, because the LBT is designed so that the movement of moisture due to heating is one-dimensional.

Figures 5-32 through 5-36 show the fraction volume water content in TN1 to TN5 as a function of depth from the top of the block, respectively, for up to 103 days of heating (June 11, 1997). Because the pre-heat baseline data have been subtracted from the in-heat results, zero fraction volume water content in these figures means no change in the moisture; a positive fraction volume water means increase in the moisture content; and a negative fraction volume water means drying. A horizontal line is drawn at the zero fraction volume water in these figures to assist the depiction of drying and wetting conditions. The heater horizontal in the LBT is at about $2.75 \mathrm{~m}$ from the top. It is clear that a drying zone has developed at the heater horizon in every one of the five vertical neutron holes. However, the amplitude of drying, the thickness of the drying zone, and the timing of the development of the drying zone varied among the five holes. This is probably due to heterogeneity in the block. Four of the five holes show

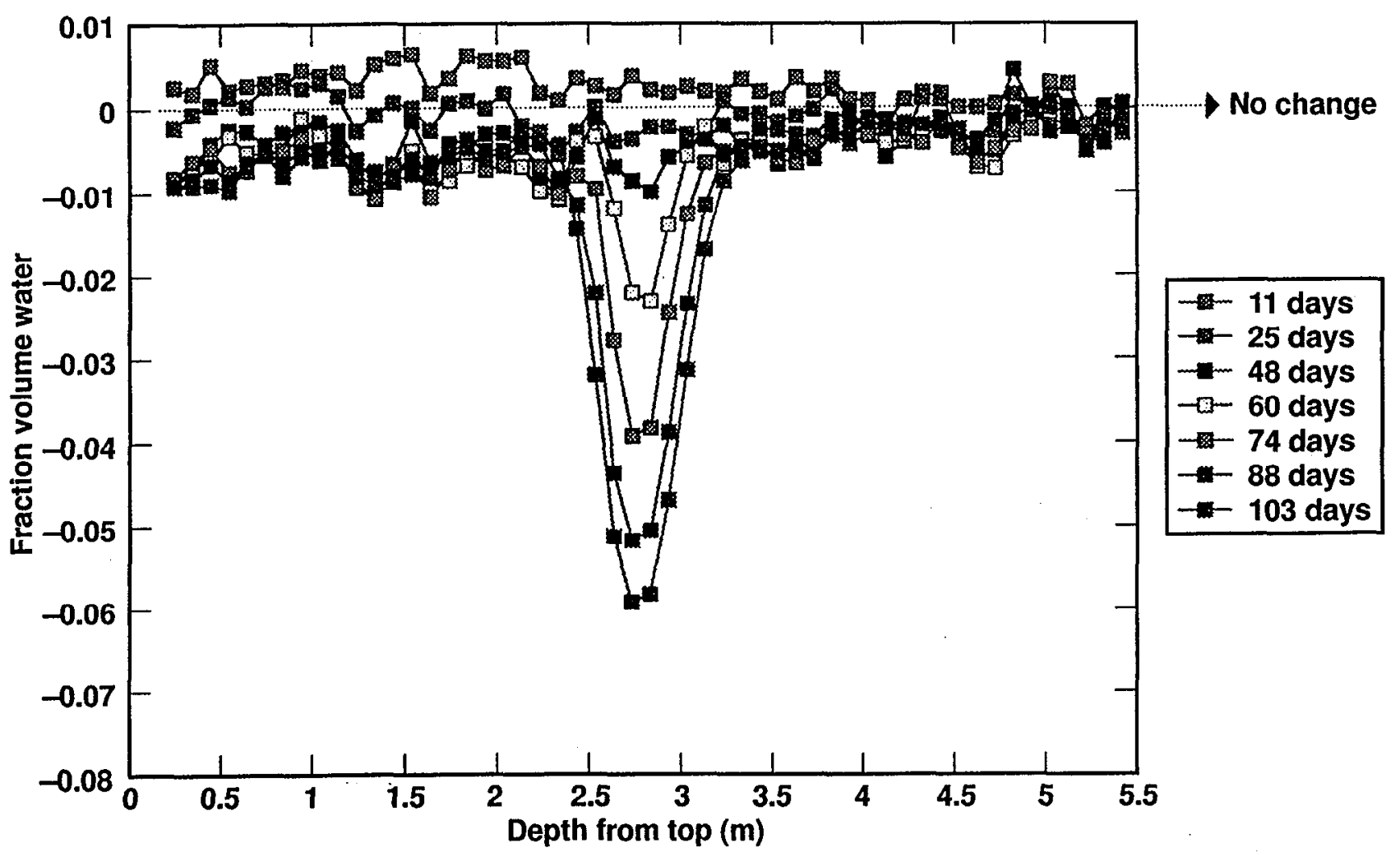

Figure 5-32. Difference fraction volume water content in TN1 as a function of depth from top of the block. 


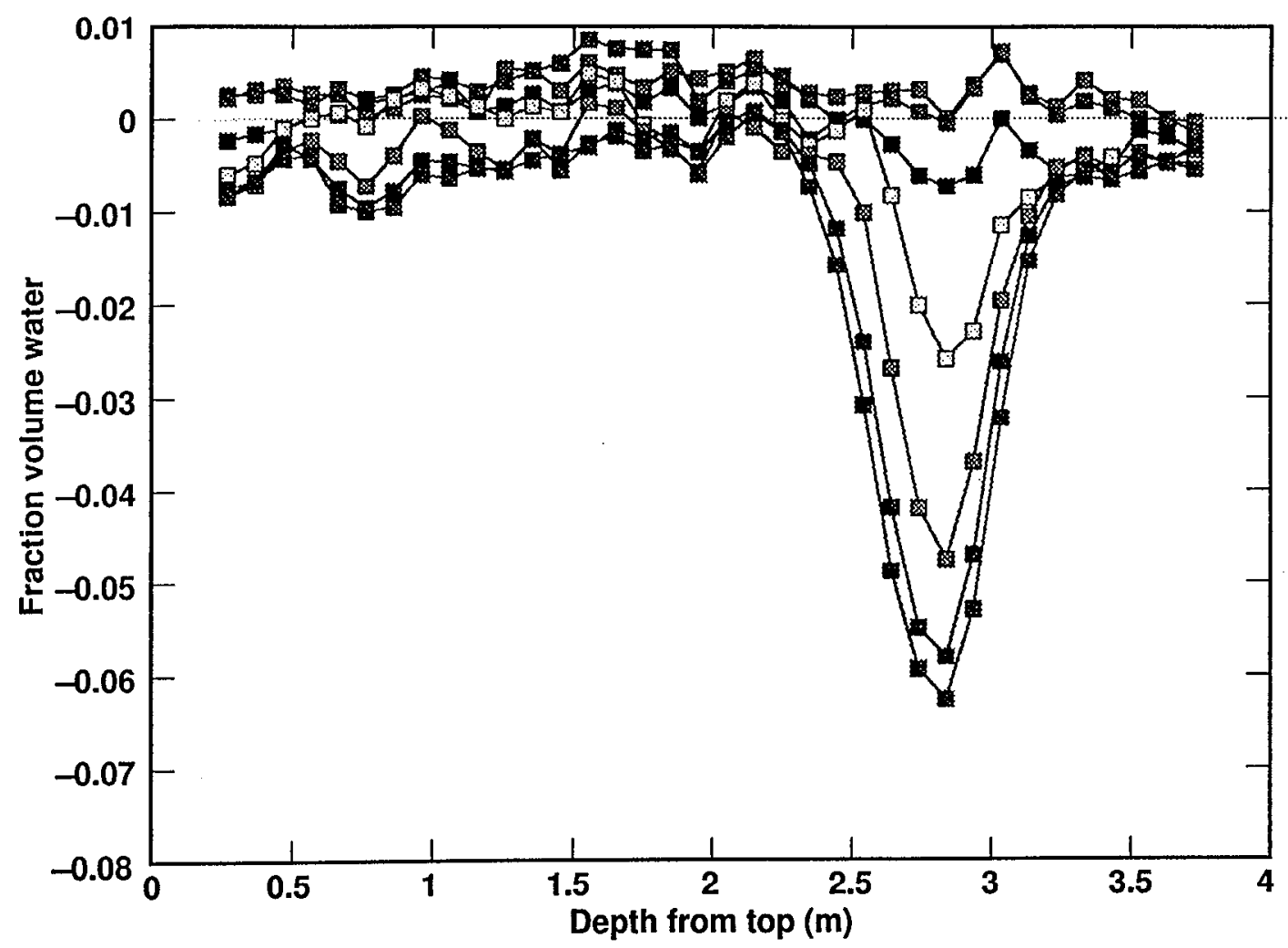

$\rightarrow$ No change

Figure 5-33.

Difference fraction volume water content in TN2 as a function of depth from top of the block.

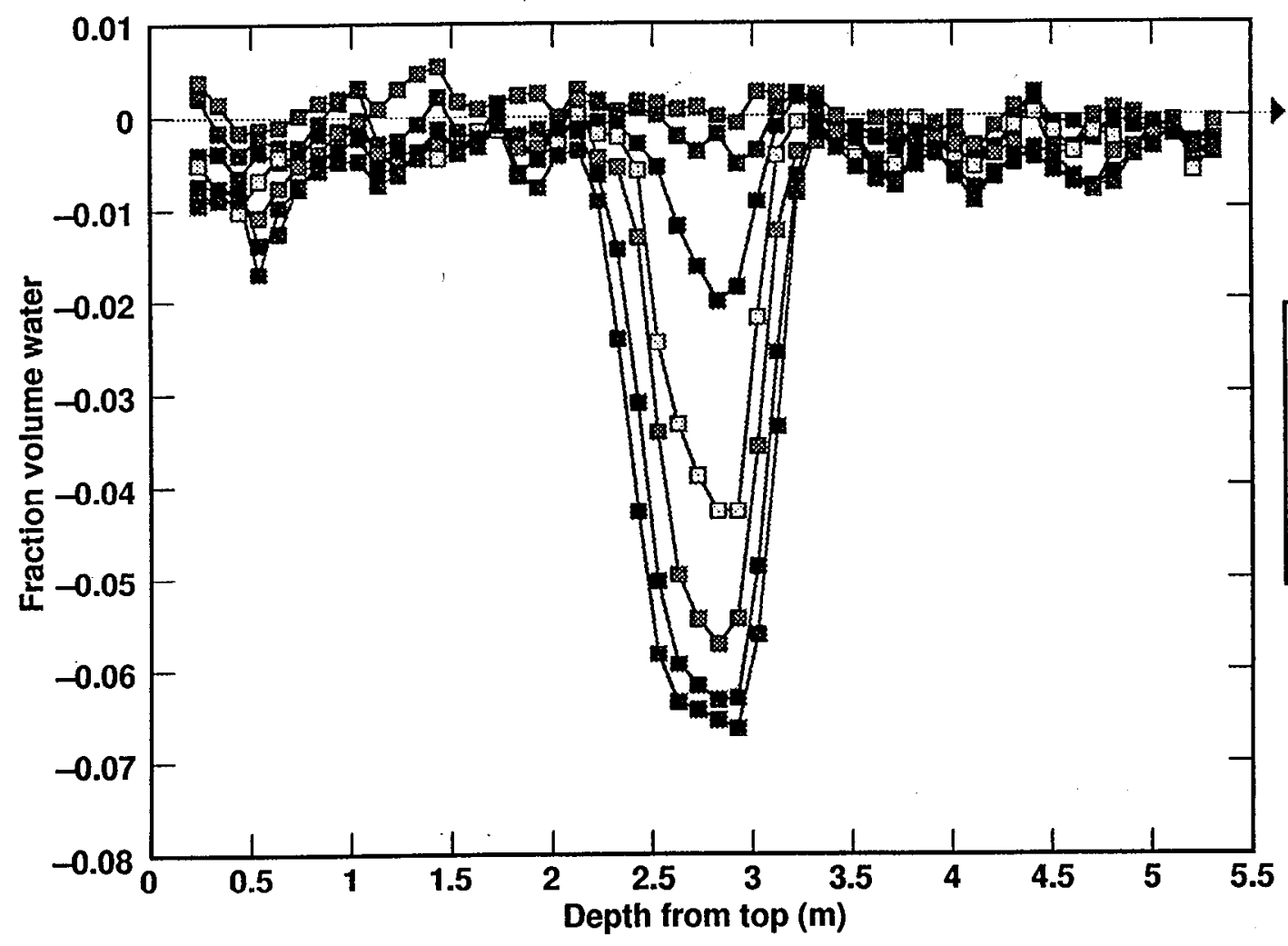

No change

\begin{tabular}{|l}
-11 days \\
-25 days \\
--48 days \\
-60 days \\
-74 days \\
--88 days \\
--103 days
\end{tabular}

Figure 5-34.

Difference fraction volume water content in TN3 as a function of depth from top of the block. 
that the drying zone began to develop after 48 days of heating. TN4, on the other hand, did not show much drying until 74 days of heating. The amplitude of drying ranged from about 0.05 in TN4 to 0.075 in TN5. Assuming a porosity of $10.4 \%$, this range of negative fraction volume water corresponds to a decrease in water saturation level ranging from 48 to $72 \%$. If the initial water saturation level in the block was 77 to $96 \%$ (see the discussion above) then the saturation level in the drying zone after 103 days of heating was 5 to $48 \%$. The thickness of the drying zone also varies, with TN2 and TN3 as the thickest, TN1 and TN5 in the middle, and TN4 as the thinnest.

The neutron logging results will be analyzed in greater detail when the heating phase of the test is completed. The neutron logging results will also be compared with other measurements in an integrated interpretation and analysis of the test results.

\subsection{Geomechanics}

Preliminary analysis of the large block deformation has been conducted using data from the six multiple-point borehole extensometer (MPBX) systems and approximately 20 fracture monitors. Results from both the MPBX systems (Fig. 5-37) and the fracture monitors (Fig. 5-38) show that, within a few hours of heater startup, the block started expanding.

The MPBX data (Fig. 5-37) show that most of the expansion has occurred in the upper onethird of the block and in the horizontal plane. In this region, horizontal strain of 0.0006 was observed through March 18. This is somewhat

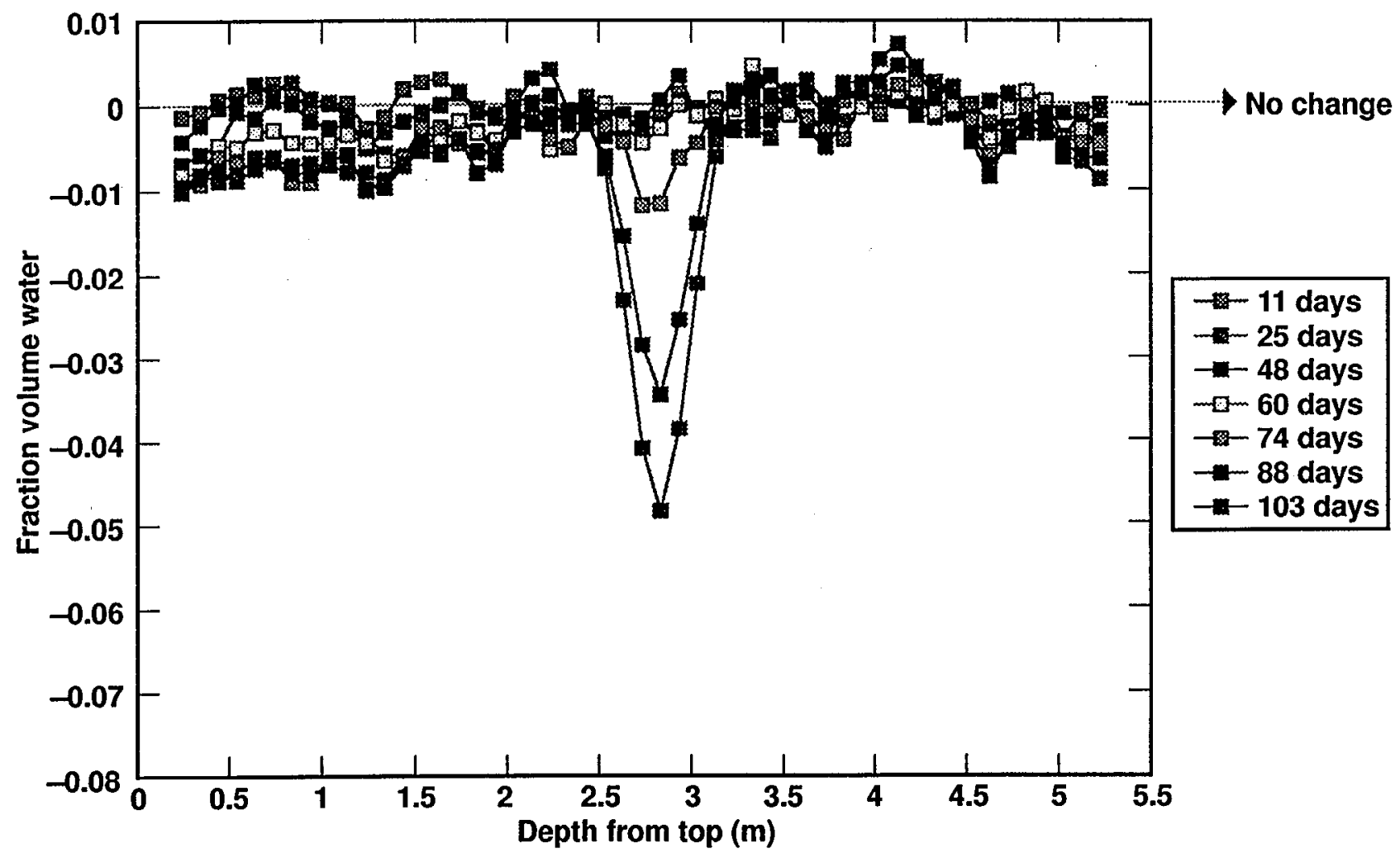

Figure 5-35. Difference fraction volume water content in TN4 as a function of depth from top of the block. 
greater than the valuc of 0.0001 that is predicted in a thermal-mechanical simulation of the test (Blair et al., 1996). Moreover, MPBX data from boreholes in this region show that most of the deformation occurs in discrete, vertically oriented zones. This is may be caused by opening of vertical fractures in this upper region.

The central one third of the block, although hotter than the upper third, shows less horizontal expansion. However, the observed strain of 0.0004 is in good agreement with the value of 0.0006 predicted for this zone after this period of heating. Finally, deformation in the lower third of the block is small, with total horizontal strain estimated as 0.0002 . This is consistent with the predicted thermal expansion. Data for one of the horizontal holes also indicate that deformation is occurring in a discrete, vertically oriented zone.
Data also indicate that strain in the vertical direction is less than that observed in the horizontal direction, and that the region of the block above the heaters is moving upward as a unit.

In summary, thermal expansion of the block was evident a few hours after the start of heating. This is verified by data recorded on the fracture. monitors and MPBX systems. MPBX data indicate that during the first month of heating, the upper third of the block is expanding in the horizontal direction more than was estimated using continuum assumptions, and much of the deformation is taking place in discrete zones. This is consistent with opening of vertical fractures. In the middle third and lower third of the block, expansions are more consistent with predicted values. In the vertical direction, the upper twothirds of the block are extending as a unit.

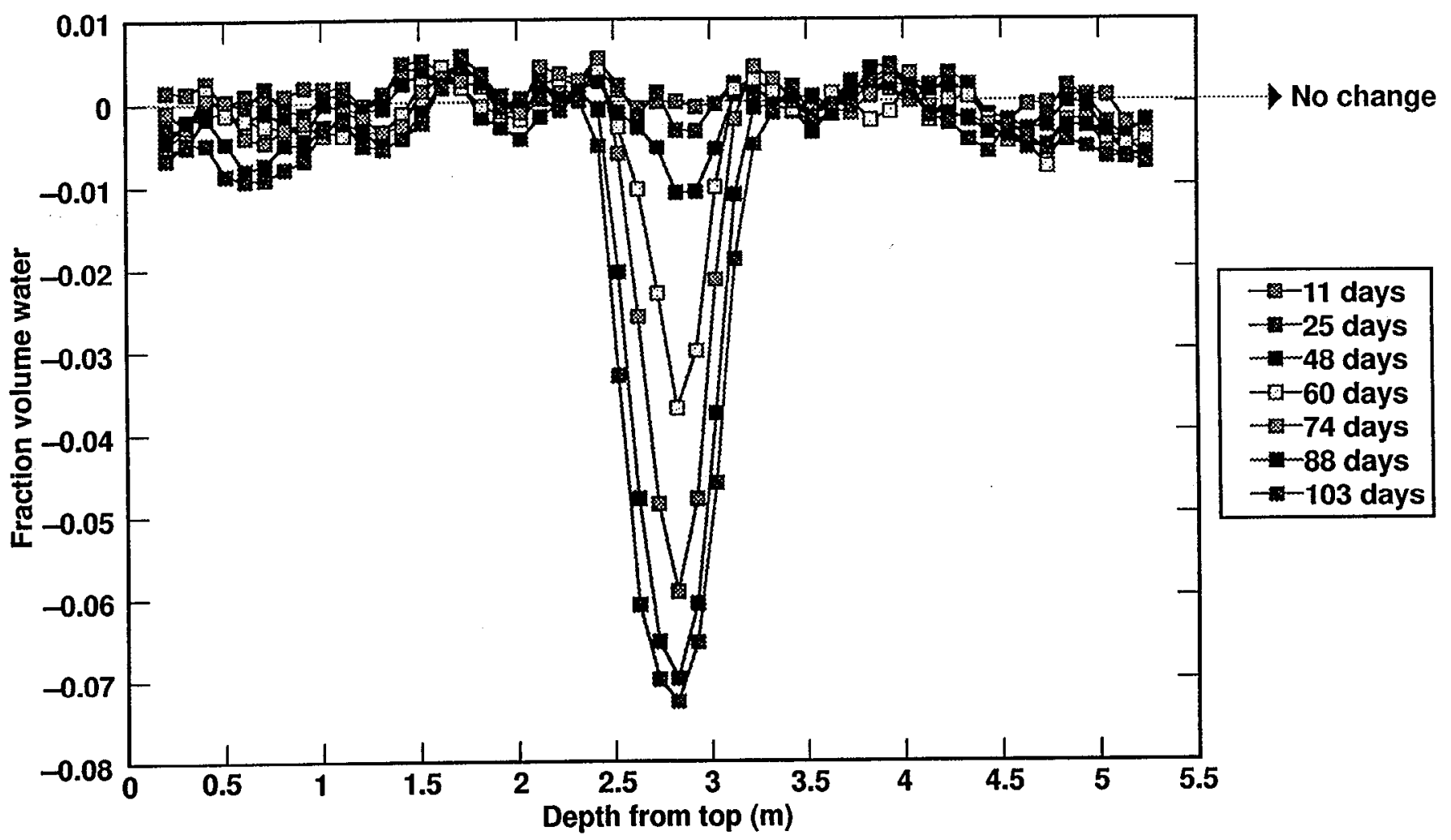

Figure 5-36. Difference fraction volume water content in TN5 as a function of depth from top of the block. 
(a) NM-1

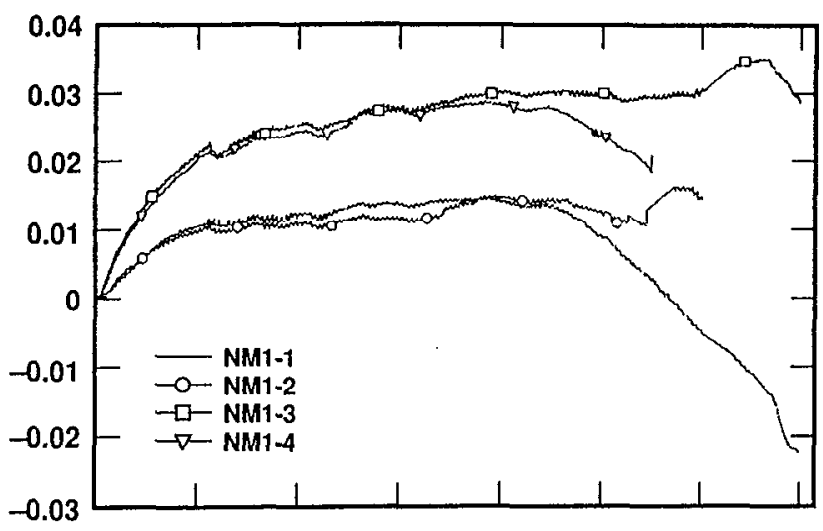

(c) WM-2

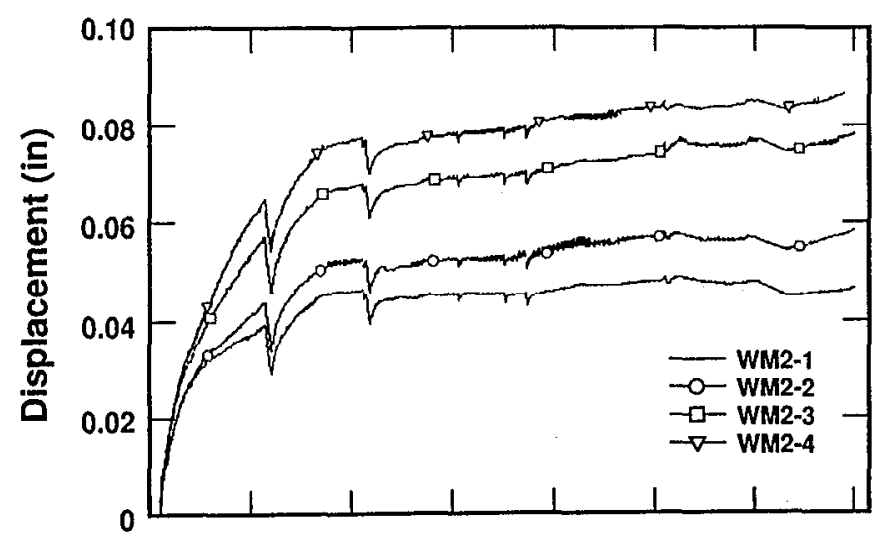

(e) WM-1

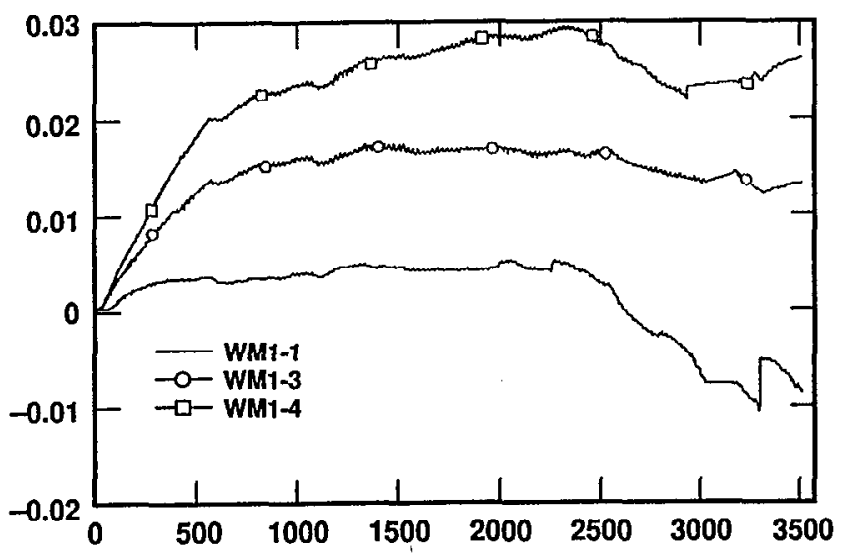

(b) NM-3

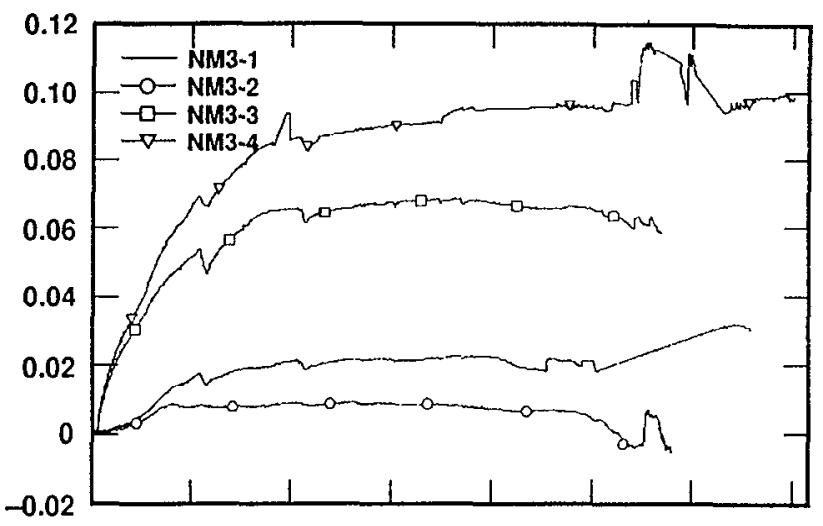

(d) NM-2

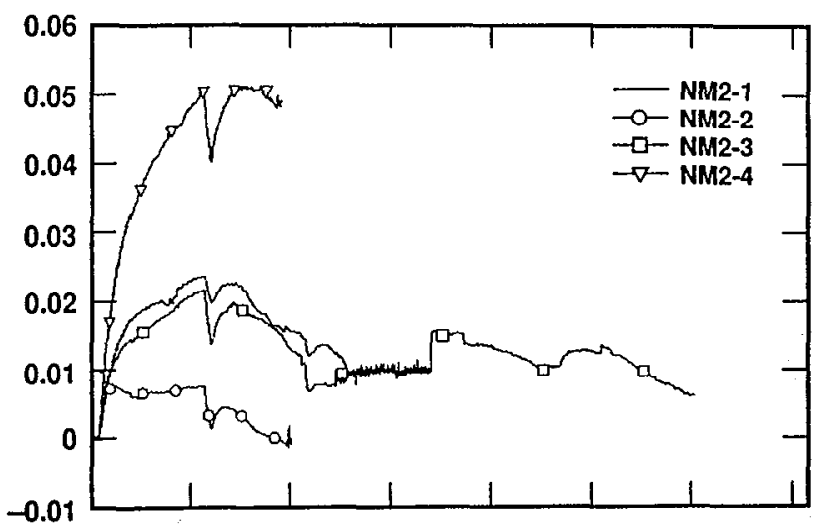

(f) TM-1

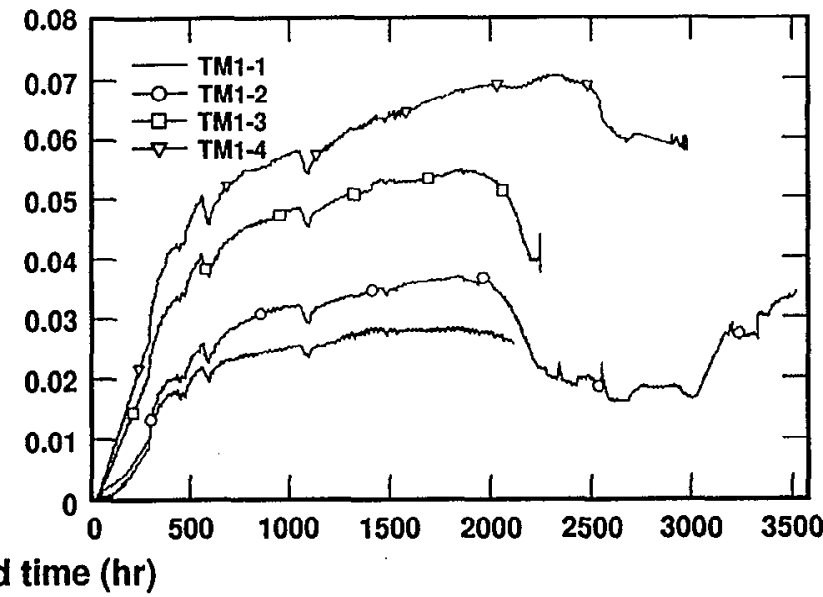

Start time: Feb 27, 1997 at $1251 \mathrm{hrs}$

End time: July 23, 1997 at 1630 hrs

Figure 5-37. Displacement (in.) versus elapsed time for (a) NM-1, (b), NM-2, (c) NM-3, (d) WM-1, (e) WM-2, and (f) TM-1. 


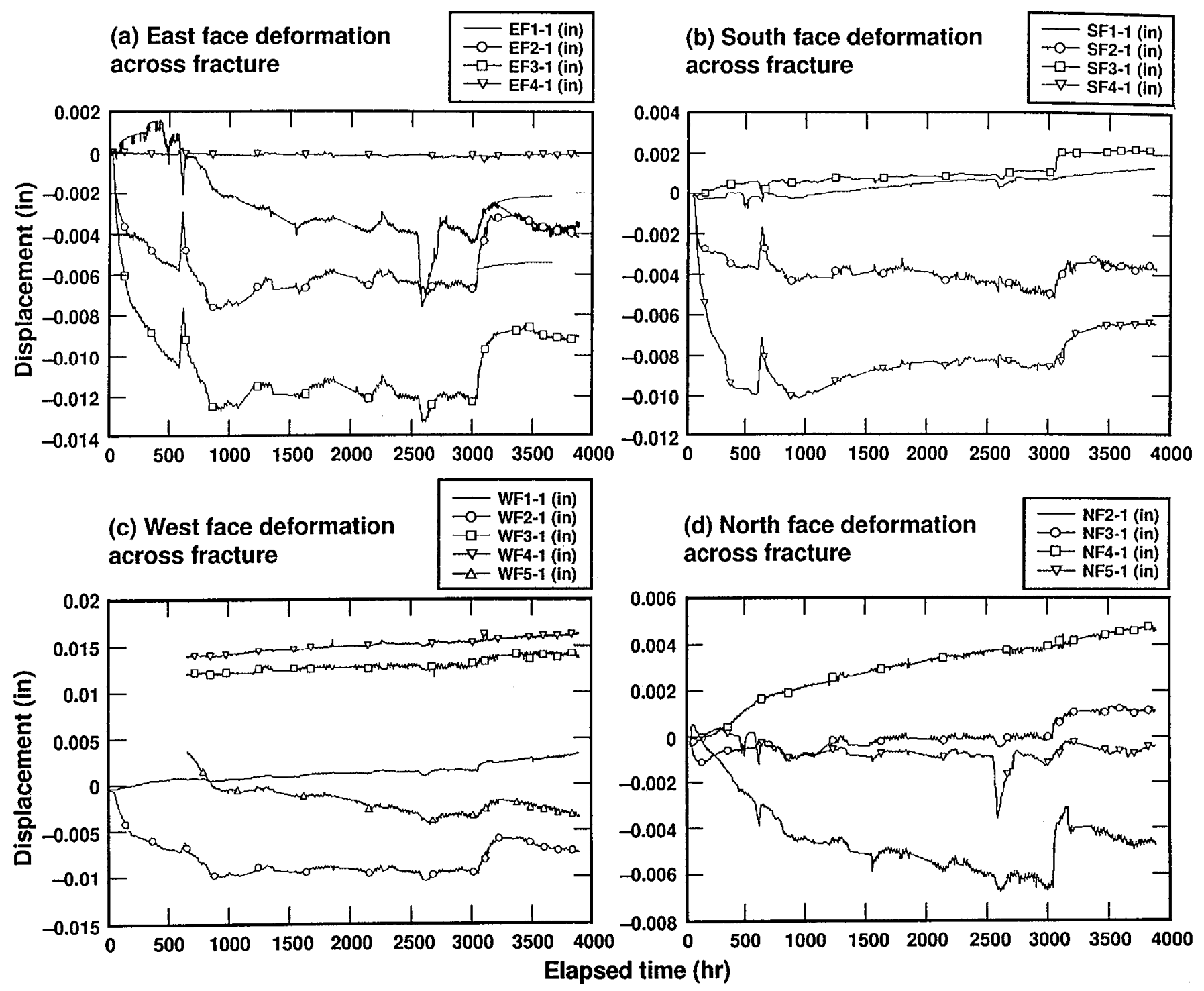

Start time: Feb 27, 1997 at 1604 hrs

End time: Aug 07, 1997 at 1031 hrs

Figure 5-38. Displacement (in.) versus elapsed time for the (a) east, (b) south, (c) west, and (d) north face of the large block. 


\subsection{Future Work}

As stated in the Purpose of this Report (Section 1), the data included in this status report have received only cursory evaluations and analyses consistent with determining whether the data are real as opposed to an artifact of glitches in the DAS. The analyses will be performed during FY98 and will include both heating and cooling cycles.
At the time that the future report is prepared, this status report will serve as one of the bases for preparing that document. $\Lambda$ s such, the work reported here will be included. If, as a result of the detailed analyses, it is determined that any of the data or preliminary conclusions are in error, that will be noted and documented in the subsequent report.

This plan for the future work has been reflected in the current budget planning and includes the following specific activities and deliverables:

\begin{tabular}{lll} 
Activity/deliverable & Description & Due date \\
\hline SP90173 & Conduct the Heating Phase & $1 / 5 / 98$ \\
SP90185 & Conduct the Cooling Phase & $6 / 30 / 98$ \\
SP09175 & Analyze Heating Phase & $9 / 30 / 98$ \\
SP90190 & Analyze Cooling Phase & $9 / 30 / 98$ \\
SP902M4 & Level 3-Report on heating and cooling & $9 / 30 / 98$ \\
SP90195 & Disassembly and sampling & $1 / 6 / 2000$ \\
SP90200 & Testing/analyses of samples & $5 / 1 / 2000$ \\
SP9904M3 & Final Report & $5 / 1 / 2000$
\end{tabular}

\section{Acknowledgments}

The authors would like to recognize the very significant effort of R. Kirvel who spent many long hours assisting in the editing and assembly of this report. We also want to express appreciation to S. Fletcher, T. Carey, and P. Harding for their very helpful assistance with preparing the figures for this report. 


\section{References}

Blair, S. C. and P. A. Berge (1996). "Uniaxial Compression Behavior of Small Blocks of Welded Tuff," Proc. 1996 Intl. High Level Radioactive Waste Management Conf., April 29-May 3, 1996, Las Vegas, NV, published by American Nuclear Society and American Society of Civil Engineers, pp. 409-411.

Blair, S. C., P. A. Berge, and H. F. Wang (1996), Geomechanical Analysis of the Large Block Test, Lawrence Livermore National Laboratory, Livermore, CA, UCRL-ID-122898.

Bodvarsson, G. S. and T. M. Bandurraga (1996), Development and Calibration of the ThreeDimensional Site-Scale Unsaturated Zone Model of Yucca Mountain, Nevada, Lawrence Berkeley National Laboratory, Earth Sciences Division, Berkeley, CA.

Buscheck, T. A., and J. J. Nitao (1995), Thermal-Hydrological Analysis of Large-Scale Thermal Tests in the Exploratory Studies Facility at Yucca Mountain, Lawrence Livermore National Laboratory, Livermore, CA, UCRLID-121791.

Buscheck, T. A., D. G. Wilder, and J. J. Nitao (1993), "Large-Scale In Situ Heater Tests for Hydrothermal Characterization at Yucca Mountain", in High Level Radioactive Waste Management, Proceedings of the Fourth Annual International Conference, Las Vegas, Nevada, April 26-30, 1993, American Nuclear Society, La Grange Park, IL; also Lawrence Livermore National Laboratory, UCRL-JC-112445. (NNA.930217.0046)

Buscheck, T. A., R. J. Shaffer, K. H. Lee, and J. J. Nitao (1997), Analysis of Thermal-Hydrological Behavior during the Heating Phase of the Single Heater Test at Yucca Mountain, Lawrence Livermore National Laboratory, Livermore, CA, SP9266M4.

Danko, G. and P. F. Mousset-Jones, (1991), "A Probe Method for Measuring In Situ
Thermophysical Properties," in Proc. 2nd International High Level Radioactive Waste Management Conference, Las Vegas, NV, April 28-May 3, 1991, American Nuclear Society, La Grange Park, IL, pp. 555-563.

DOE (U.S. Department of Energy) (1995), Yucca Mountain Project Reference Information Base, YMP/CC-0002, Version 4.002, Yucca Mountain Site Characterization Project Office, Las Vegas, NV, YMP/CC-0002.

(NNA.910129.0066)

DOE (U.S. Department of Energy) (1988), Site Characterization Plan, Yucca Mountain Site, Nevada Research and Development Area, Nevada, Office of Civilian Radioactive Waste Management, Washington, DC, DOE/RW0199. (HQO.881201.0002)

Kim, K. and W. M. McCage (1984), "Geomechanics Characterization of the Candidate Nuclear Waste Repository Site in Basalt," Proceedings in the 25th U.S. Symposium on Rock Mechanics, pp. 874-882.

(NNA.891212.0018)

Klavetter, E. A., and R. R. Peters (1986), Estimation of Hydrologic Properties of an Unsaturated, Fractured Rock Mass, Sandia National Laboratories, Albuquerque, NM, SAND842642. (NNA.870317.0738)

Konikow, L. F. and J. D. Bredehoeft (1992), "Ground-Water Models Cannot Be Validated," Advances in Water Resources 15, pp. 75-83.

Lee, K. (1995a), Progress Report on Pre-Test Calculations for the Large Block Test, Lawrence Livermore National Laboratory, Livermore, CA, UCRL-ID-118699. MOL.19950406.0143.

Lee, K. (1995b), Second Progress Report on Pre-Test Calculations for the Large Block Test, Lawrence Livermore National Laboratory, Livermore, CA, UCRL-ID-122300. MOL.19960417.0218. 
Lin, W. (1994a), Activity Plan, AP-LBT-01, Rev. 0, for Large Block Tests of Coupled

Thermal-Hydrological-Chemical Processes (YMP WBS Element 1.2.3.12.4), Lawrence Livermore National Laboratory, Livermore, CA. MOL.19940908.0093.

Lin, W. (1994b), Large Block Tests of Coupled Thermal-Mechanical-Hydrological-Chemical Processes, Lawrence Livermore National Laboratory, Livermore, CA, Activity Plan APLBT-01, Rev 0 for YMP WBS Element 1.2.3.12.

Lin, W., D. Wilder, J. Blink, P. Berge, S. Blair, V. Brugman, R. Carlson, K. Lee, M. Owens, R. Pletcher, N. Rector, J. Roberts, D. Ruddle, S. Sommer, T. Ueng, and J. Wagoner (1995), "The Large Block Test, A Progress Report," Proc. Sixth Annual Internat. Conf. High Level Radioactive Waste Management, Las Vegas, NV, April 30-May 5, 1995, American Nuclear Society, Inc., La Grange Park, IL 60525, pp. 46-47.

Lin, W., D. G. Wilder, J. A. Blink, S. C. Blair, T. A. Buscheck, W. E. Glassley, K. Lee, M. W. Owens, and J. J. Roberts (1995), "A Heated Large Block Test for High Level Nuclear Waste Management," Proc. Second Internat. Conf. on the Mechanics of Jointed and Faulted Rock, Vienna, Austria, April, 1995.

Meike, A. and J. Horn (1997), Installation of Labeled Microbe Samples into Large Block, Lawrence Livermore National Laboratory, Livermore, CA, letter report (SPLG1BM4).

Morelli, G. and D. LaBrecque (1996), "Robust Scheme for ERT Inverse Modeling," Proc. Symp. Appl. Geophysics to Engineering and Environmental Problems, Keystone, CO, April 28-May 1, 1996; sponsored by the
Environmental and Engineering Geophysical Society.

Terzaghi, R. (1965), "Sources of Error in Joint Surveys," Geotech. 15, 287-304.

Wang, J. S. Y. and C. F. Ahlers (1996), Pre-Test Analysis of the Large Block Test-Air Flow and Gas Tracer Transport for Thermal-Hydrological Evolution, Lawrence Berkeley Laboratory, Berkeley, CA, SP9012M5.

Wilder, D. G. (1993), Preliminary Near-Field Environment Report, Volume I: Technical Bases for EBS Design, Lawrence Livermore National Laboratory, Livermore, CA, UCRL-LR-107476, Vol. 1.

Wilder, D. G. (1996), Near-Field and Altered-Zone Environment Report, Volume II, Lawrence Livermore National Laboratory, Livermore, CA, UCRL-LR-124998, Vol II.

Wilder, D. G. (1997), Near-Field and Altered-Zone Environment Report: Volume I, Technical Bases for EBS Design, Lawrence Livermore National Laboratory, Livermore, CA, UCRL-LR-124998, Vol. I.

Yow, J. L. Jr. and D. G. Wilder (1993), “Planning Exploratory Drilling: The Effect of Blind Zones and Level of Logging Effort," Proc. 24th U.S. Symp. Rock Mechanics, College Station, TX, pp. 807-812.

Zimmerman, R. M., and M. K. Blanford (1986), "Expected Thermal and Hydrothermal Environments for Waste Emplacement Holes Based on G-Tunnel Heater Experiments," in 27th U.S. Symposium on Rock Mechanics, H. Hartman, Ed., (Society of Mining Engineers, Inc., Littleton, CO), pp. 874-882.

(NNA.891212.0018) 